The influence of texture on phase transformation in metastable austenitic stainless steel

\author{
P. Hilkhuijsen
}


This research was carried out under project number M63.1.09324 in the framework of the Research Program of the Materials innovation institute (M2i) in the Netherlands (www.m2i.nl).

The influence of texture on phase transformation in metastable austenitic stainless steel

P. Hilkhuijsen

PhD thesis, University of Twente, Enschede, The Netherlands August 2013

ISBN 978-90-365-0125-5

Keywords: Transformation, Austenite, Martensite, Texture, Strain Path 1st and only printing August 2013

Printed by Ipskamp Drukkers B.V., Enschede, Nederland 


\title{
THE INFLUENCE OF TEXTURE ON PHASE TRANSFORMATION IN METASTABLE AUSTENITIC STAINLESS STEEL
}

\author{
PROEFSCHRIFT
}

ter verkrijging van

de graad van doctor aan de Universiteit Twente, op gezag van de rector magnificus, prof. dr. H. Brinksma, volgens besluit van het College voor Promoties in het openbaar te verdedigen op vrijdag 30 Augustus 2013 om 16:45 uur

door

Peter Hilkhuijsen

geboren op 24 Juni 1983

te IJsselstein, Nederland 
Dit proefschrift is goedgekeurd door de promotor

Prof. dr. ir. A. H. van den Boogaard

en de assistent promotor

Dr. ir. H. J. M. Geijselaers 


\section{Samenvatting}

Metastabiel austenitisch roestvast staal wordt in veel producten gebruikt, van scheerapparaten en gootstenen tot toepassingen in de levensmiddelenindustrie. Deze grote verscheidenheid in de toepasbaarheid van austenitisch roestvast staal is mogelijk door de vele positieve eigenschappen die het staal bezit. Het is niet alleen mooi om te zien, maar het is ook roestvast, slijtvast, makkelijk schoon te maken en biedt een moeilijke hechtingsondergrond voor bacteriën.

Naast de voordelen van het gebruik van roestvast staal in producten, biedt het ook voordelen tijdens het produceren van deze producten: dit type materiaal is niet alleen gemakkelijk te vervormen, maar heeft ook een hoge sterkte, hetgeen over het algemeen tegengestelde eigenschappen zijn. Het staal bezit beide eigenschappen doordat er een fase-transformatie kan plaatsvinden tijdens het vervormen van het staal. De austeniet fase, die goed vervormbaar is, kan transformeren naar de martensiet fase, die een stuk harder is maar minder goed vervormbaar is dan het austeniet. De transformatie gaat gepaard met een transformatie rek, hetgeen bijdraagt aan de goede vervormbaarheid van dit type staal.

Hoewel het materiaal veel voordelen heeft, heeft het ook nadelen, zoals het complexe materiaalgedrag en het modelleren hiervan. Vaak worden er modellen van een productieproces gebruikt om deze te ontwerpen of aan te passen zodat er het proces kan worden geoptimaliseerd naar, onder andere, gewenste mechanische eigenschappen, dimensies en kosten. De nauwkeurigheid van deze modellen hangt onder andere af van hoe goed het materiaalmodel het gedrag van het te vervormen staal beschrijft. In het geval van austenitische stalen is het maken van nauwkeurig materiaal model niet eenvoudig. Hoewel er wel enkele modellen zijn die bruikbaar zijn in simulaties en die in staat zijn om proportionele experimenten goed te beschrijven, zijn deze niet in staat om het materiaal gedrag tijdens een deformatieproces op elke plek in het materiaal nauwkeurig te beschrijven. 
Enkele voorbeelden van invloeden op het transformatiegedrag die niet in de huidige modellen zijn meegenomen, zijn bijvoorbeeld het effect van voorkeursoriëntaties van de austeniet kristallen - textuur- op de transformatie wanneer er in verschillende richtingen wordt getrokken of wanneer er achter elkaar verschillende rekpaden worden opgelegd aan een materiaal -een niet-monotoon rekpad-. Dit soort invloeden zal niet snel uit standaardexperimenten volgen waarop de meestemateriaal modellen zijn gebaseerd, maar heeft zeker een invloed tijdens het deformatieproces. In dit onderzoek zijn deze invloeden onderzocht en de resultaten verkregen uit dit onderzoek kunnen worden gebruikt bij het ontwikkelen van nieuwe, nauwkeurigere materiaalmodellen.

Het materiaalgedrag van twee verschillende austenitische stalen, een met een sterke textuur en een zonder, is onderzocht tijdens het deformeren in verschillende richtingen. Beide stalen transformeerden tijdens en na het deformeren, maar terwijl het getextureerde staal een afhankelijkheid tussen de deformatierichting en de transformatie vertoonde, deed het ongetextureerde staal dit niet. Het bestuderen van de austeniet textuur na deformatie liet zien dat de oriëntatie van een austenietkristal ten opzichte van de aangelegde spanning een grote invloed heeft op het moment dat transformatie optreedt in het kristal. Enkele modellen zijn gepresenteerd die deze relatie goed kunnen voorspellen.

De invloed van een niet-monotoon rekpad is bestudeerd door verschillende rekpaden achter elkaar op te leggen een proefstuk. Vooral een omkering van het rekpad is bestudeerd in dit onderzoek. Hierbij werd ontdekt dat, naast het klassieke Bauschinger effect - de verlaging van de vloeispanning na de rekpad verandering-, het transformatie gedrag van het staal, en dus ook het materiaal gedrag, sterk veranderdt. Vergelijkbare effecten zijn geobserveerd tijdens andere niet monotone rekpaden.

Dit onderzoek laat zien dat de huidige materiaalmodellen, die het gedrag van metastabiele austenitische stalen beschrijven, nog sterk verbeterd kunnen worden. Met de kennis opgedaan in dit onderzoek is het mogelijk om een nieuwe stap te zetten in het ontwikkelen van modellen die nauwkeurig een 3-dimensionaal deformatieproces beschrijven. 


\section{Summary}

Metastable austenitic stainless steels are used in many applications, from shavers and kitchen sinks to various applications in the food industry. The diversity in applications of this type of steels is possible due to the many positive properties of the steel. It is not only esthetically pleasing, it also has a good corrosive and wear resistance, it is easy to clean and it does not support biofilm growth as well as other steels.

Besides the benefits of using austenitic stainless steels in products, also some benefits can be found during the production of the products: these types of steel are easily deformable, but also have a high strength. These contradicting properties can both be found in the steel because of a phase change occurring during deformation. The austenitic phase, which is soft and easily deformable, can transform into the martensite phase, which is harder and less deformable compared to the austenite. Accompanying the transformation is a transformation strain, witch improves the deformability of the steel even further.

A downside of the steel is the complex material behavior and the complicated modeling of this behavior. Models of production processes are often used to determine the optimal process conditions to obtain the desired dimensions, mechanical properties and the lowest cost price of a product. The accuracy of these models depends greatly on the accuracy of the material model describing the deformation process of the steel. The development of an accurate model describing the deformation of a metastable austenitic stainless steel is not easily done. While several models exist which can describe various, relatively straight forward proportional experiments performed on austenitic steels, none can describe the correct behavior of the steel at more complex strain paths, which commonly occur during the production of a product.

Two examples of areas in which the current models need to be improved are the relation between the transformation behavior of the steel, preferred orientations of the austenite grains -texture- and the strain direction as well 
as the influence of a changing strain path -non-proportional strain- on the transformation. These effects cannot be observed during standard experiments used to determine the parameters for the currently existing material models, but do occur during the deformation process of a product. In this research these effects on transformation of austenitic stainless steels were investigated. The results from this research can be used to develop new, more accurate material models.

The material behavior during the deformation in various directions of two metastable austenitic stainless steels, one with and one without a crystallographic texture, were investigated. Both steels show transformation during deformation, but while transformation in the textured material dependeds on the deformation direction, in the untextured steel it does not. Investigating the austenitic texture after deformation and transformation shows that the orientation of an austenite grain with respect to the stress has a strong influence on the transformation properties of the grain. Several models are presented which can predict this behavior.

The influence of a non-monotonic strain path on the transformation is studied by applying various subsequent strain paths on a steel specimen. In this research, most attention has been paid on a strain path containing a strain reversal. It is shown that, besides the classical Bauschinger effect -the decrease in flow stress after a load reversal-, also the transformation behavior, and thus the material behavior, changes significantly after the strain reversal. The similar effect has been observed during non-proportional strain paths.

This research shows that the current material models describing the material behavior of metastable austenitic stainless steels during deformation, can be improved. Based on the knowledge obtained during this research, it is possible to develop new models capable of describing the material behavior during 3dimensional deformation processes more accurately. 


\section{Contents}

Samenvatting v v

Summary vii

1 Introduction 1

1.1 About this thesis . . . . . . . . . . . . . . . 2

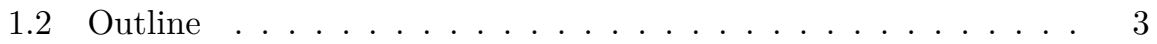

2 Crystalline texture $\quad \mathbf{5}$

2.1 Description of crystal orientations . . . . . . . . . . 6

2.2 Measurement of Textures . . . . . . . . . . . . . . . . . . 9

2.3 The Orientation Distribution Function . . . . . . . . . . . . 12

2.4 Discretization of the ODF . . . . . . . . . . . 15

2.5 Summary . . . . . . . . . . . . . . . 16

3 Martensitic transformations 19

3.1 Martensitic transformations . . . . . . . . . . . . . . . . 19

3.1 .1 The $M_{s}$ temperature . . . . . . . . . . . . 21

3.2 Crystallography of martensitic transformations . . . . . . . . 22

3.3 Stress-induced transformation . . . . . . . . . . . . . . . . . 23

3.3.1 Stepwise transformation . . . . . . . . . . . 25

3.4 Material behavior . . . . . . . . . . . . . . . 26

3.4.1 Determination of the critical driving force . . . . . . . . 26

3.4.2 TRansformation Induced Plasticity (TRIP) . . . . . . . 28

3.4.3 Temperature \& transformation during deformation . . . . 28

3.5 Transformation \& austenitic texture . . . . . . . . . . . . . . 29

3.5.1 Driving Force in Generalized Spherical Harmonics . . . . 30 
3.6 Summary . . . . . . . . . . . . . . . . . . . 34

4 Influence of texture on transformation $\quad 35$

4.1 Material . . . . . . . . . . . . . 36

4.2 Experiments . . . . . . . . . . . . . . . . . 37

4.2.1 Steel 1 (Untextured) . . . . . . . . . . . . . 38

4.2 .2 Steel 2 (Textured) . . . . . . . . . . . . . . . . . . 40

4.3 Austenitic textures . . . . . . . . . . . . . . . . . . . . . . . . . . . . 42

4.3.1 Steel 1 (Untextured) . . . . . . . . . . . . . . 42

4.3.2 Steel 2 (Textured) . . . . . . . . . . . . . . . . . 43

4.4 Texture Based Stress Induced Transformation model . . . . . . . 44

4.5 Discussion . . . . . . . . . . . . . . . . . . 45

4.5.1 Texture evolution . . . . . . . . . . . . . 45

4.5.2 Driving Force Distribution . . . . . . . . . . . . . . . . 47

4.5.3 TBSIT Model . . . . . . . . . . . . . . . . . 49

4.6 Summary . . . . . . . . . . . . . . . . . . 50

5 Influence of texture evolution on transformation 51

5.1 Extended macro-mechanical transformation model . . . . . . . . 52

5.1 .1 General Overview . . . . . . . . . . . . . 53

5.1 .2 Discretization . . . . . . . . . . . . . 57

5.1 .3 Homogenization ................. . . . 57

5.1 .4 Stress-induced transformation . . . . . . . . . . . . . 58

5.1 .5 Transformation . . . . . . . . . . . . 59

5.1.6 Crystal Rotations . . . . . . . . . . . . . 61

5.2 Simulations . . . . . . . . . . . . . . . 63

5.2 .1 Individual Grain Behavior . . . . . . . . . . . . . . . . 64

5.2 .2 Simulated Texture Evolution . . . . . . . . . . . . . 65

5.2 .3 Full Model Calculations . . . . . . . . . . . . . . . . . 68

5.2 .4 Influence of step size . . . . . . . . . . . . . . . 71

5.3 Experiments . . . . . . . . . . . . . . . . 72

5.3.1 Texture evolution due to Transformation only . . . . . . 73

5.3.2 Texture evolution due to Deformation only . . . . . . . 76

5.3.3 Texture evolution due to Transformation and Deformation 76

5.4 Discussion . . . . . . . . . . . . . . . 78

5.4 .1 Austenitic texture . . . . . . . . . . . . . 78

5.4 .2 Transformation behavior . . . . . . . . . . . 79

5.4 .3 Material behavior ... . . . . . . . . . . . . . 80

5.5 Summary . . . . . . . . . . . . . . . . . 82 
6 Transformation \& Non-Monotonic Deformation 83

6.1 Experimental Setup . . . . . . . . . . . . . . . 84

6.2 Experimental Results . . . . . . . . . . . . . . . . . 85

6.2.1 Proportional Experiments . . . . . . . . . . . . 85

6.2.2 Strain reversal experiments . . . . . . . . . . . . 87

6.2.3 Non-Proportional Experiments . . . . . . . . . . . . . . 89

6.3 Strain Reversal Simulations . . . . . . . . . . . . . . . . . 92

6.3 .1 TBSIT . . . . . . . . . . . . . . . . . 92

6.3.2 Advanced Model . . . . . . . . . . . . . . . . . . 92

6.4 Discussion . . . . . . . . . . . . . . . . . . . . . . 93

6.5 Summary . . . . . . . . . . . . . . . . 97

7 Conclusions \& Recommendations $\quad 99$

Appendix A Crystallography of martensitic transformations 105

A.1 Multiplicity of solution . . . . . . . . . . . . 111

Appendices

Bibliography

113 


\section{Chapter 1}

\section{Introduction}

Austenitic stainless steels are applied when a combination of corrosion resistance and good mechanical properties is desired. When these materials are plastically deformed a phase transformation of the metastable Face Centered Cubic (FCC) austenite to the stable Body Centered Cubic (BCC) martensite may occur $[1,2]$. The transformation causes a strong hardening of the material while the ductility remains good.

In industrial forming processes the constitutive behavior of the processed materials needs to be accurately known to ensure proper product dimensions and mechanical, corrosion and other properties. Since the phase transformation of the material has a considerable influence on the mechanical behavior and the desired properties of the final product, an accurate description of the phase transformations that may occur during forming is essential.

A large number of macroscopic models has been suggested in the past that explain details of the phase transformation during loading. None of them has been shown to be generic enough to capture all deformation modes encountered in modern forming processes. If a reliable and accurate phase transformation model is available, the forming production process can be optimized with respect to the robustness of the process and the desired properties of the product.

The existing models describing the transformation from austenite to martensite can be roughly divided in two categories. The first postulates that martensite nucleates on shear band intersections and that therefore the kinetics only depends on plastic strain in the austenite [3, 4]. The second considers the stress as the driving force behind transformation, as described by Tamura [5]. Although based on different mechanisms, both approaches yield models which 
are capable of describing the transformation behavior of metastable austenitic stainless steels during proportional experiments.

Although the macroscopic models can describe proportional strain paths well, the influence of the strain direction and non-monotonic deformation is not incorporated in these models, while incorporating these strains in a model is important when an accurate description of a three-dimensional forming process is required.

\section{$1.1 \quad$ About this thesis}

The main objective of this thesis is to provide a deeper understanding of the transformation behavior in metastable austenitic stainless steels during strain paths commonly occurring during the forming of products. This understanding helps during evaluation of forming processes of austenitic stainless steels and provides knowledge for further development of constitutive models usable in Finite Element Analysis (FEA). Models based on the stress-induced transformation theory show good performance describing proportional strain paths. Part of this thesis is devoted to verification of the stress-induced transformation theory and its potential to describe the transformation behavior at various additional strain paths.

In this thesis, two different strain path effects found in forming processes, but currently not present in most models describing the transformation during deformation, are considered.

First, applying a strain in different directions. While the parameters for use in the stress-induced transformation model are obtained from experiments during which the axis of tension is in a specific direction, during a forming process the same strain might be applied in different directions. It is already well known that materials can show an anisotropic material behavior, which becomes evident by the earring behavior of steels during deep drawing. A major part of this thesis discusses the dependency of the transformation on the strain direction and the role the austenitic texture plays in the material behavior.

Second, applying non-proportional strain paths. While during most experiments a proportional strain path is applied, during the forming of a product a material point can be subjected to several strain path changes. This can happen during a single step of a forming process, where the strain gradually changes from one state to another, or by applying a different strain in different stages of a multistage forming process. In this thesis experiments are discussed representing the latter case. It is known that some steels show a decrease of the yield 
stress when the strain path is reversed. However, these types of experiments were not conducted using metastable austenitic stainless steels, in which the transformation has a large influence on the material behavior.

\subsection{Outline}

The work presented in this thesis is based on the stress-induced transformation theory. The theory implies that the orientation of a grain has an influence on the transformation behavior of the grain. Depending on the crystallographic texture in the austenite phase, this may result in a dependency of the transformation on the strain direction when deforming an austenitic stainless steel. Chapter 2 will provide the reader with some basic knowledge on the description of orientations and the measurement and presentation of crystallographic textures.

Chapter 3 will discuss the austenite to martensite transformation as well as the influence of the orientation of a grain on the transformation and how this is presented in a similar way as the crystallographic texture.

Textured and non-textured austenitic stainless steels were used for experiments. Chapter 4 shows the transformation behavior of the two steels during deformation in different strain and stress directions and under different stress states. The stress-induced transformation theory is verified in this chapter by comparing the austenitic texture evolution with the predicted evolution based on the theory. A model capable of describing the relation between texture, stress direction and transformation is presented in this chapter as well. The model shows qualitatively accurate results. To improve the model, several additional mechanisms must be incorporated in the model.

A new model is developed to predict more accurately the influence of the texture and the strain direction on the transformation behavior. Besides a more accurate transformation mechanism, close attention has been paid to the evolution of the austenitic texture during deformation. A description of the model, as well as several simulations and experiments to validate the model, are presented and discussed in Chapter 5 .

The final chapter, Chapter 6 , discusses the influence of several non-monotonic strain paths on the transformation behavior on the austenitic stainless steels. The steels show an unexpected material behavior during these experiments, which cannot be explained even by the more accurate model of Chapter 5 . 


\section{Chapter 2}

\section{Crystalline texture}

Most engineering materials are polycrystalline, consisting of many, often small grains. In the grains, the atoms are arranged in a specific pattern repeated throughout the grain, called the crystalline structure. The patterns are located on each point of a lattice, an array of points repeating periodically in three dimensions, and can be represented by a unit cell: a small volume containing atoms in the pattern of the crystalline structure, such as the Simple Cubic, Face Centered Cubic (FCC) and Body Centered Cubic (BCC) unit cells, see Figure 2.1. The pattern of the crystalline structure inside a grain is usually only distorted by lattice defects such as vacancies, dislocations and stacking faults. Between grains, the lattice orientation can differ. The distribution of these orientations in a polycrystalline aggregate is called the crystallographic texture, referred to in this thesis as the texture. In a non-textured polycrystalline material all orientations of the lattice are equally present, while in a textured material some orientations are preferred over others.

The texture can have an influence on the material properties, such as chemical reactivity and magnetic susceptibility, but it is best known for causing anisotropy in mechanical properties. This e.g. results in the formation of ears found in cups produced by deep drawing $[6,7]$. In this thesis the influence of the austenitic texture on the transformation of the austenite FCC phase to the martensite BCC phase will be discussed.

A short overview of crystalline textures is given in this chapter. In Section 2.1 several methods of describing directions and orientations used in crystallography are described. Section 2.2 deals with the determination of textures using X-Ray Diffraction (XRD) techniques and the representation of textures in pole figures. 


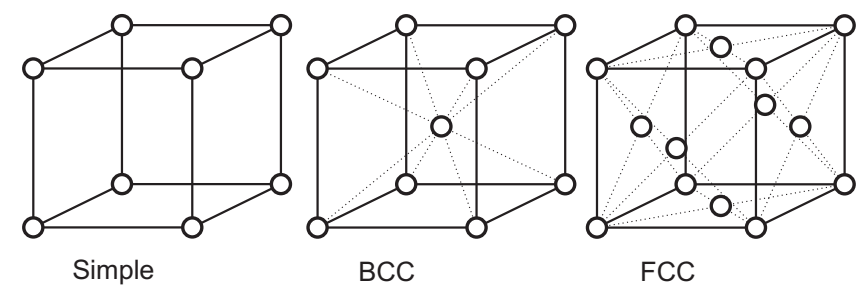

Figure 2.1: The Simple, Body Centered and Face Centered Cubic unit cells.

To obtain the fraction of grains for each orientation, an Orientation Distribution Function can be calculated from the measured texture. A short description of this calculation is given in Section 2.3. The final Section 2.4 discusses some methods to obtain a discrete description of a texture based on the ODF for use in numerical models.

\subsection{Description of crystal orientations}

In crystallography, several methods for the description of an orientation of the lattice are used. The two methods used in this thesis are based on Miller indices and Euler angles.

Miller indices can be used to describe both directions and planes in a unit cell. A unit cell is constructed out of three base vectors $\boldsymbol{a}, \boldsymbol{b}$ and $\boldsymbol{c}$, see Figure 2.2. All derivations in this work are for a cubic lattice, in which case the three base vectors are all equal in length and perpendicular to each other. A direction vector $\boldsymbol{d}$ can be described by a linear combination of these 3 vectors as

$$
\boldsymbol{d}=u \boldsymbol{a}+v \boldsymbol{b}+w \boldsymbol{c}
$$

with $u, v$ and $w$ integer values. For shortness, this can be noted by only writing $[u v w]$, where negative values are denoted by a bar above the index: $\ulcorner$. Square brackets $[u v w]$ denote a single direction, and in the case of a cubic lattice $\langle u v w\rangle$ designates all directions which are equivalent due to symmetry of the lattice.

A plane is described by

$$
h \frac{x}{a}+k \frac{y}{b}+l \frac{z}{c}=1,
$$

where $x y z$ are the coordinates of any point on the plane and $a, b$ and $c$ the lengths of the unit cell base vectors, respectively. Since in a cubic lattice the 


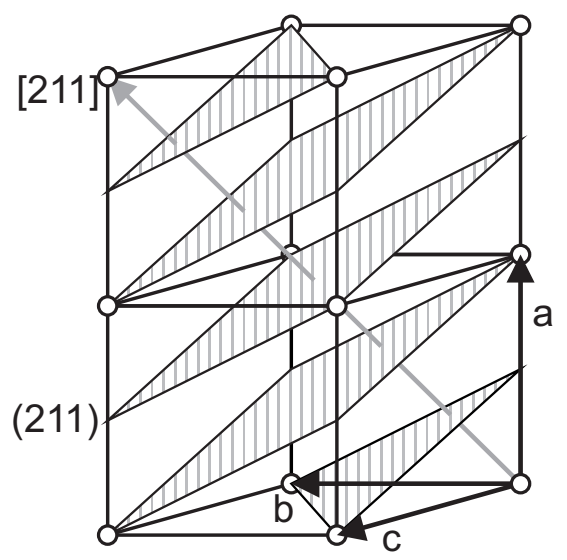

Figure 2.2: The (211) planes and [211] direction in a cubic lattice.

base vectors have an equal length, i.e. $a=b=c$, Equation (2.2) can be written as

$$
h x+k y+l z=a .
$$

The Miller indices $h k l$ can be calculated when the intersections of the plane with the lattice axis are known. The use of parentheses around the Miller indices of a plane, $(h k l)$, denotes a particular plane and all parallel planes of the same type, while a set of planes equivalent by symmetry is denoted by using $\{h k l\}$.

In cubic structures, the direction $[u v w]$ is perpendicular to the plane described by the same indices, (uvw).

Using the Miller indices, an orientation of the crystalline structure in a grain can be described, commonly with respect to the Rolling Direction (RD), Transverse Direction (TD) or Normal Direction (ND) of the steel, see Figure 2.3 and [6]. Designating a direction $\langle u v w\rangle$ of the crystal structure in a specific direction leaves a rotation around this direction free. This is common in textures found in drawn wires or fibers, where the grains have a common direction $\langle u v w\rangle$ in the axial direction but, due to symmetry, a random distribution in the radial orientation. The same can occur in steels rolled into sheets. A group of this type of orientation is named a 'fiber'. To designate a fiber, direction $\langle u v w\rangle$ is combined with the direction it is parallel to, e.g. $\langle u v w\rangle \| \mathrm{RD}$ when it is parallel to the Rolling Direction.

To specify an orientation, the rotation around $\langle u v w\rangle$ must be defined. For 


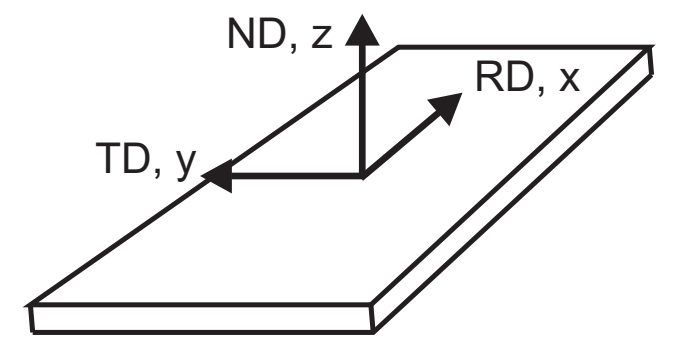

Figure 2.3: Relation between the Rolling Direction (RD), Transverse Direction (TD) and Normal Direction (ND) with the global axis system used when describing orientations with Euler angles.

this, a combination of a plane and a direction is used, $\{h k l\}\langle u v w\rangle$. This gives the direction of the normal on the plane parallel to e.g. the rolling plane normal and a direction in e.g. the RD, where the direction is always contained in the plane. This notation is commonly used to describe texture components. Several common texture components found in rolled FCC materials are shown in Table $2.1[6]$.

While the use of Miller indices is convenient and can be easily visualized for the orientations described in Table 2.1, it is hard to describe the orientation of a grain slightly rotated from this ideal position.

The use of Euler angles to describe an orientation can overcome this problem. The common Bunge definition uses three angles $\left[\phi_{1} \Phi \phi_{2}\right]$ to describe an orientation with respect to the global axis oriented according to Figure 2.3. The angles denote a rotation over the $z, x^{\prime}$ and $z^{\prime \prime}$ axis, respectively, to obtain the orientation of the crystal lattice as shown in Figure 2.4 [8]. Using this, the orientation $g$ can be described with three Euler angles $g=\left[\phi_{1} \Phi \phi_{2}\right]$ within the Euler space $\{[0 ; 2 \pi],[0 ; \pi],[0 ; 2 \pi]\}$. The rotation matrix describing the rotation is easily obtained as well:

$R=\left[\begin{array}{ccc}\cos \phi_{2} & \sin \phi_{2} & 0 \\ -\sin \phi_{2} & \cos \phi_{2} & 0 \\ 0 & 0 & 1\end{array}\right]\left[\begin{array}{ccc}1 & 0 & 0 \\ 0 & \cos \Phi & \sin \Phi \\ 0 & -\sin \Phi & \cos \Phi\end{array}\right]\left[\begin{array}{ccc}\cos \phi_{1} & \sin \phi_{1} & 0 \\ -\sin \phi_{1} & \cos \phi_{1} & 0 \\ 0 & 0 & 1\end{array}\right]$

In Table 2.1, the Bunge angles for several common texture components found in rolled FCC steels are shown. It is clear that, while this method is more flexible, it is less inituitive than the use of Miller indices. 
Table 2.1: Miller indices and Bunge angles from several texture components commonly found in rolled FCC materials.

\begin{tabular}{|c|c|c|}
\hline Name & Indices & Bunge $\left[\phi_{1} \Phi \phi_{2}\right]$ \\
\hline Cube & $\left\{\begin{array}{llllll}1 & 0 & 0\end{array}\right\}\left\langle\begin{array}{llll}0 & 0 & 1\end{array}\right)$ & {$\left[\begin{array}{lll}0 & 0 & 0\end{array}\right]$} \\
\hline Goss & $\left\{\begin{array}{lll}1 & 1 & 0\end{array}\right\}\left\langle\begin{array}{llll}0 & 0 & 1\end{array}\right.$ & {$\left[\begin{array}{lll}0 & 45 & 0\end{array}\right]$} \\
\hline Copper & $\{112\}\langle 111 \overline{1}\rangle$ & {$\left[\begin{array}{llll}9 & 0 & 35 & 45\end{array}\right]$} \\
\hline Brass & $\{110\}\langle\overline{1} 12\rangle$ & {$[35450]$} \\
\hline Taylor & $\{4411\}\langle 1111 \overline{8}\rangle$ & {$\left[\begin{array}{llll}9 & 2 & 2 & 45\end{array}\right]$} \\
\hline S & $\{123\}\langle 63 \overline{4}\rangle$ & 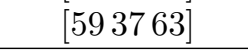 \\
\hline
\end{tabular}

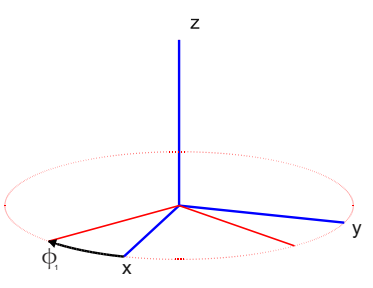

(a)

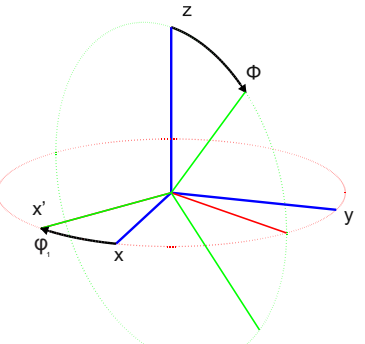

(b)

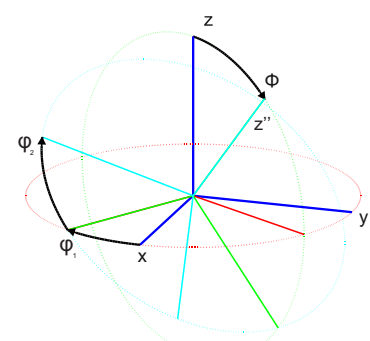

(c)

Figure 2.4: Bunge ZXZ rotation. To obtain an orientation described by $\left[\phi_{1} \Phi \phi_{2}\right]$, the coordinate system is rotated by $\phi_{1}$ around the $z$-axis, followed by a rotation $\Phi$ around the $x^{\prime}$-axis and a subsequent rotation $\phi_{2}$ around the $z$ " axis.

\subsection{Measurement of Textures}

X-Ray Diffraction (XRD) techniques are widely used for the determination of the crystallographic texture in polycrystalline steels. These techniques are based on Bragg's law. It provides the geometrical requirements for diffraction to occur:

$$
2 d_{h k l} \sin \theta=n \lambda .
$$

Here, $\theta$ is the angle between the incident beam and the scattering planes, which is equal to the angle between the scattering planes and the diffracted beam. The wavelength of the $\mathrm{X}$-rays is denoted by $\lambda$ and $n$ is an integer value. The distance 
between the scattering planes is $d_{h k l}$ which, in the case of a cubic lattice, can be calculated by

$$
d_{h k l}=\frac{a}{\sqrt{h^{2}+k^{2}+l^{2}}}
$$

with $a$ the length of the lattice base vector of the cubic lattice and $h, k$ and $l$ the Miller indices of the plane considered.

The diffraction of X-Rays is schematically represented in Figure 2.5. The incident beam is scattered by the atoms in the planes. A high intensity diffracted beam is measured only when the diffracted waves are in phase with each other. This is only the case when the path length difference between scattered waves is exactly the wavelength or an integer multiple $n$ of the wavelength. This only occurs when Equation (2.5) is satisfied. This must be the case for all atoms in the grain, resulting in a requirement that the normal of the reflecting plane should be parallel to the bisect of the incident and diffracted beam, which is called the diffraction vector $\bar{H}$. Therefore, only a part of the planes in a polycrystalline sample will diffract for a given diffraction vector [7]. Figure 2.6 shows part of a diffractogram of an FCC steel measured with Cobalt radiation. The high intensity measured around $2 \theta=50.9^{\circ}, 59.5^{\circ}, 89.2^{\circ}$ and $110.9^{\circ}$ is caused by the $\{111\},\{200\},\{220\}$ and $\{311\}$ planes, respectively.

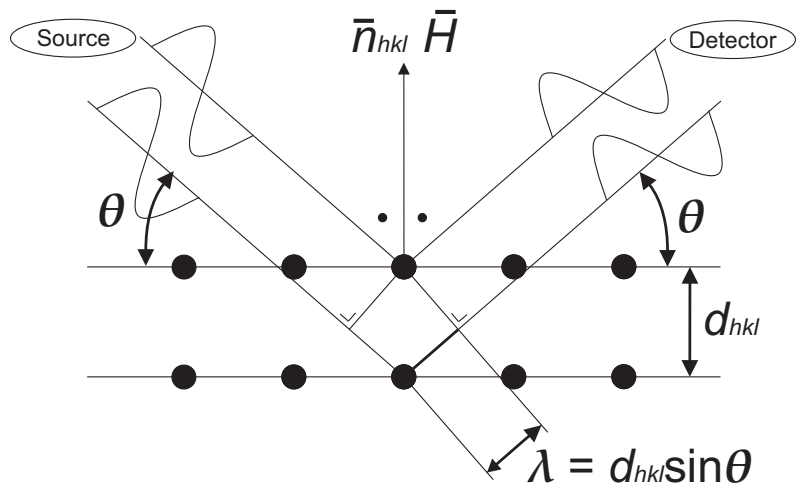

Figure 2.5: Diffraction of X-Rays by atoms.

During a texture measurement the angle $2 \theta$ is chosen such that the reflection of a specific plane $\{h k l\}$ can be measured. In this case, only a small fraction of the grains contribute to the measured intensity: only the grains for which the 


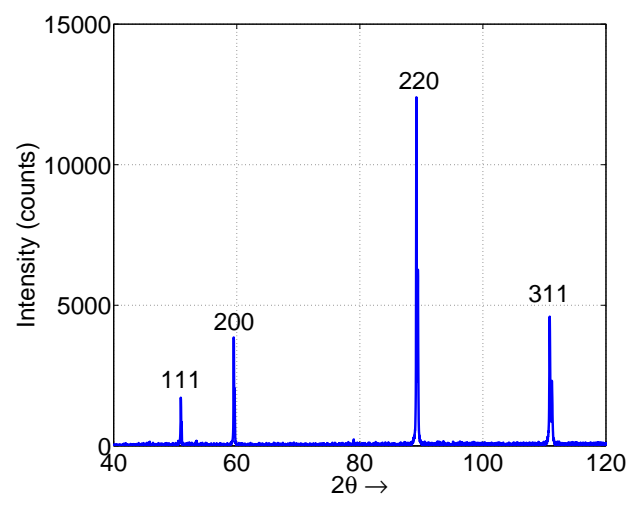

Figure 2.6: Diffractogram of a fully austenitic stainless steel measured with Co $\mathrm{K}_{\alpha}$ radiation.

plane normal is parallel to the diffraction vector. During standard measurements in Bragg-Brentano parafocusing optic these planes are parallel to the surface of the sample. By rotating the sample around the Normal Direction of the sample over angle $\phi$ and by angle $\xi$ around the Transverse Direction, the diffraction of grains with other orientations can be determined as well. This is shown schematically in Figure 2.7. The intensity of the reflected beam is now a function of the two angles $(\phi, \xi)$, which are in the range of $0^{\circ} \leq \xi<90^{\circ}$ and $0^{\circ} \leq \phi<$ $360^{\circ}$. This intensity can be converted to the relative amount of grains for which the normal of plane $\langle h k l\rangle$ is in the direction $(\phi, \xi)$.

The intensity can be mapped on a hemisphere, where each point on the sphere can be described by spherical coordinates $(\phi, \xi)$. A two-dimensional polar plot can be obtained by applying a stereographic projection [6]. Figure 2.8 shows the thus obtained pole figures for the $\{111\},\{200\}$ and $\{220\}$ reflections of the same texture. While these pole figures provide a good indication of the texture, the exact orientation of a grain cannot be retrieved from the figure since only the orientation of the normal on plane $\{h k l\}$ can be obtained. 


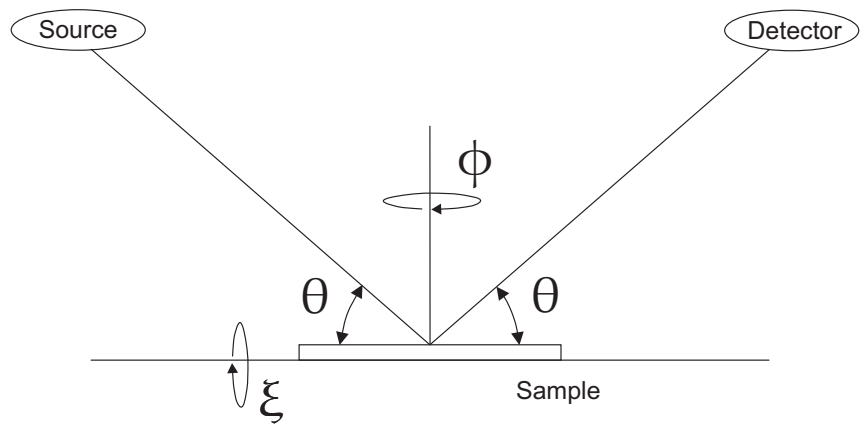

Figure 2.7: Schematic overview of the Bragg-Brentano setup and the rotation angles of the sample.

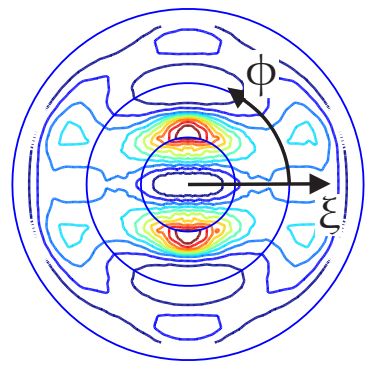

(a) $\{111\}$

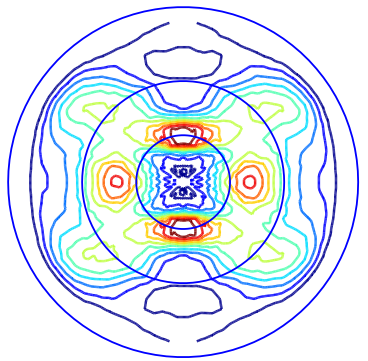

(b) $\{200\}$

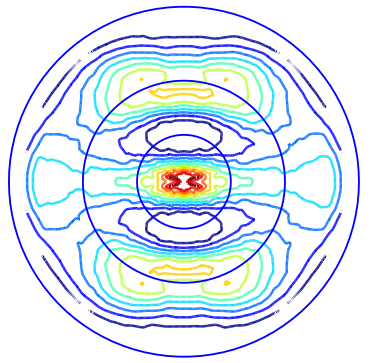

(c) $\{220\}$

Figure 2.8: Pole figures from the $\{111\}$ (a), $\{200\}$ (b) and $\{220\}$ (c) reflections.

\subsection{The Orientation Distribution Function}

The Orientation Distribution Function (ODF) describes a texture in terms of the Euler angles and can be calculated based on measured pole figures obtained from different reflections $\{h k l\}$. The earliest technique used for the analysis of the ODF, developed by Bunge [8], works in Fourier space by expanding the pole figures with generalized spherical harmonics. Later, several direct methods were developed $[9,10,11]$. In this section the method developed by Bunge will be discussed. 
The function describing the texture in Euler space, $f(g)$, becomes

$$
f(g)=\sum_{l=0}^{\infty} \sum_{m=-l}^{l} \sum_{n=-l}^{l} t_{l}^{m n} T_{l}^{m n}
$$

Here, the complex coefficients $t_{l}^{m n}$ are obtained by

$$
t_{l}^{m n}=\frac{2 l+1}{8 \pi^{2}} \int_{0}^{2 \pi} \int_{0}^{\pi} \int_{0}^{2 \pi} f(g) T_{l}^{m n *} \mathrm{~d} g
$$

where $*$ denotes the complex conjugate and $\mathrm{d} g=\sin \Phi \mathrm{d} \phi_{1} \mathrm{~d} \Phi \mathrm{d} \phi_{2}$. The generalized spherical harmonics $T_{l}^{m n}$ are defined by

$$
T_{l}^{m n}=e^{i m \phi_{2}} P_{l}^{m n}(\mu) e^{i n \phi_{1}},
$$

with $\mu=\cos \Phi$ and $P_{l}^{m n}(\mu)$ the generalized associated Legendre function [12]:

$$
P_{l}^{m n}(\mu)=A_{m n}^{l}(1-\mu)^{\frac{-n-m}{2}}(1+\mu)^{-\frac{n+m}{2}} \frac{\mathrm{d}^{l-n}}{\mathrm{~d} \mu^{l-n}}\left[(1-\mu)^{l-m}(1+\mu)^{l+m}\right] \text {, }
$$

with

$$
A=\frac{(-1)^{l-m} i^{n-m}}{2^{l}(l-m) !} \sqrt{\frac{(l-m) !(l+n) !}{(l+m) !(l-n) !}} .
$$

The resulting function $f(g)$ can be seen as the probability density of an orientation in Euler space $\left[\phi_{1} \Phi \phi_{2}\right]$ with $\oint_{g} f(g) \mathrm{d} g=1$. When no texture is present, and thus each orientation has the same chance of occurring, the ODF is described by a constant value. In this work, the measured pole figures from the $\{111\},\{200\}$ and $\{220\}$ reflections are used along with the MATLAB program MTEX [13] for calculation of the ODF for the austenitic phase.

There are several techniques for plotting the ODF in the 3D Euler space. Most commonly, the Euler space is represented by slices over a constant $\phi_{2}$ in the $\left[\phi_{1} \Phi\right]$ plane. Due to the symmetric nature of most rolling textures, the ranges from $0^{\circ} \leq \phi_{1}<90^{\circ}, 0^{\circ} \leq \Phi<90^{\circ}$ and $0^{\circ} \leq \phi_{2}<90^{\circ}$ will suffice [14]. The same texture as shown in the polar plots in Figure 2.8 is plotted in Euler space in Figure 2.9(a). Most of the textures commonly found in FCC materials after rolling have a component in the $\phi_{2}=45^{\circ}$ slice, as shown in Figure 2.9(b) [6]. While there are also common orientations which do not have a component in the $\phi_{2}=45^{\circ}$ slice, such as the ' $S$ ' orientation, these are not present in the textures measured in this thesis. Therefore, only the $\phi_{2}=45^{\circ}$ slice is chosen to represent the textures. 


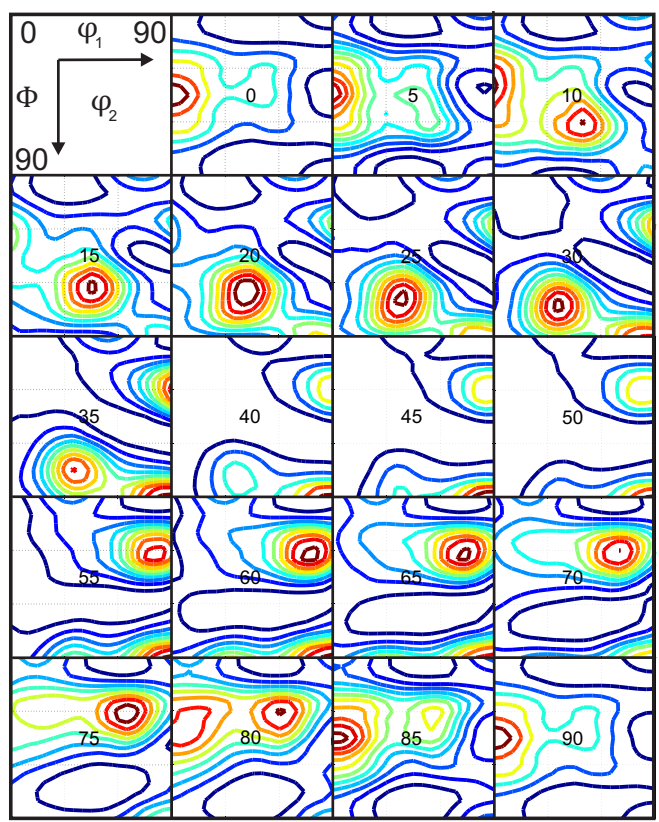

(a)

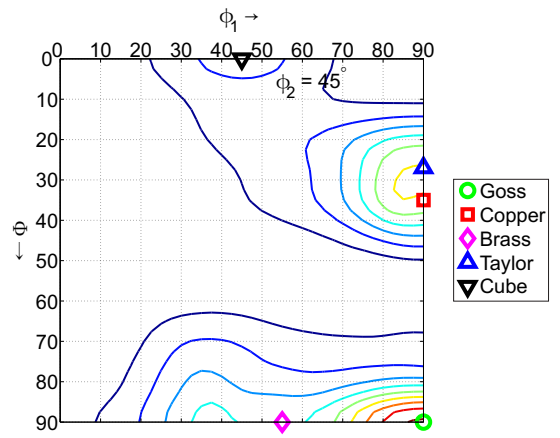

(b)

Figure 2.9: The same texture as shown in figure 2.8 in ODF sections with a $5^{\circ}$ interval over the $\phi_{2}$ Euler angle (a) and the $\phi_{2}=45^{\circ}$ section (b). Commonly found texture components in rolled FCC materials are indicated in (b). (See also Table 2.1) 


\subsection{Discretization of the ODF}

The analytical ODF, as represented by Equation (2.7), is not usable in micromechanical models which require multiple discrete grains to represent a texture. Various discretization schemes are available to convert the analytical ODF to a number of discrete grains representing the texture described by the ODF. The discretization can be achieved in two ways: (i) with multiple grains with varying weight for each orientation $[15,16]$ or (ii) with multiple grains of the same weight [17].

The first method applies a grid with the required amount of points on the ODF space, and the weight of these orientations is chosen such that the ODF is represented. Values of the ODF lower than a certain threshold can be omitted for further reduction of the amount of orientations. This method is applied to a fictive, one-dimensional ODF in Figure 2.10(a)

The other option uses an equal weight for all grains. This method is visualized in Figure 2.10(b). The scheme divides the Euler space in boxes with volumes $\Delta \phi_{1} \cdot \Delta \Phi \cdot \Delta \phi_{2}$. The total intensity in each box $i$ is calculated with:

$$
f_{i}=\oint_{b o x_{i}} f(g) \mathrm{d} g .
$$

The summation of all $f_{i}$ is equal to 1 , e.g. $\sum_{\forall i} f_{i}=1$. Next, a path $j$ is defined through Euler space such that every box is encountered only once. A cumulative distribution function $F(j)$ can be constructed:

$$
F(j)=\sum_{i=1}^{j} f_{i}
$$

with $j$ integer values. A set of $n$ numbers between 0 and 1 is created. These numbers can be uniformly distributed or randomly selected with a uniform probability. The inverse function of $F(j)$ is used to assign an orientation to each number. This way, orientations for which the value of $f_{i}$ is low will be chosen less often since the function $F(j)$ has a gentle slope at these orientations, while $F(j)$ at orientations which contribute a lot to the total intensity is steep and these orientations are selected more often, as is visualized in Figure 2.11 for a fictitious ODF.

Since the total intensity integrated over all $n$ chosen orientations is required to be equal to one, the volume fraction $v_{k}$ of each grain is

$$
v_{k}=\frac{1}{n}
$$




\subsection{Summary}

This chapter dealt with the description of orientations and the measurement, presentation and discretization of textures.

In polycrystalline steels, atoms are arranged in a specific pattern throughout a grain. The orientation of this pattern is different from grain to grain. When there are preferred orientations of grains in the steel, the steel is said to contain a crystallographic texture. XRD techniques can be used to determine this texture, the results of which can be directly plotted in pole figures. From these pole figures, the exact relation between an orientation and the fraction of grains with that orientation cannot be obtained. The use of Orientation Distribution Functions (ODF) yields no such limitation.

The ODF, which can be calculated based on measured pole figures, represent a texture in Euler space. From the ODF, for each orientation the corresponding volume fraction of grains is known. By discretization of the ODF a set of grains can be obtained which represents the texture in numerical simulations.

The crystallographic texture can have a large influence on the material properties of an austenitic stainless steel. In this thesis the influence of the texture on the transformation behavior from the austenitic FCC phase into the martensitic $\mathrm{BCC}$ phase during deformation is investigated. Therefore, additional knowledge of the theory behind transformation is required, which will be discussed in detail in the next chapter. 


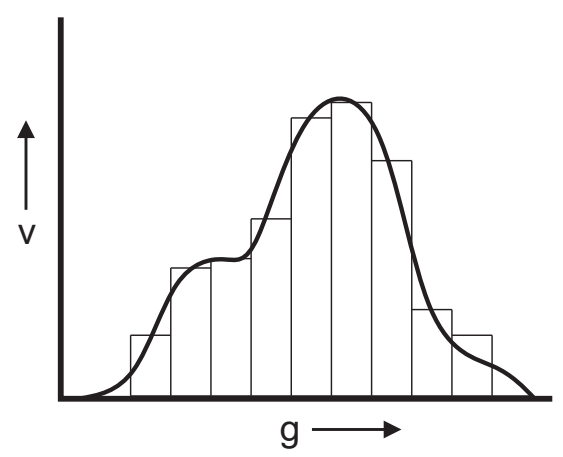

(a)

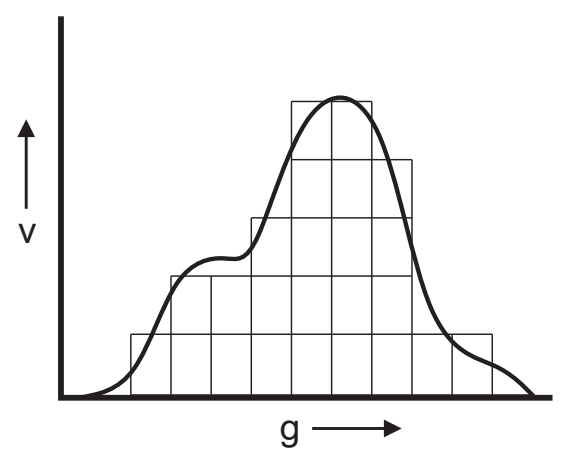

(b)

Figure 2.10: A fictitious one-dimensional distribution function discretized by orientations of different weight (a) and equal weight (b).

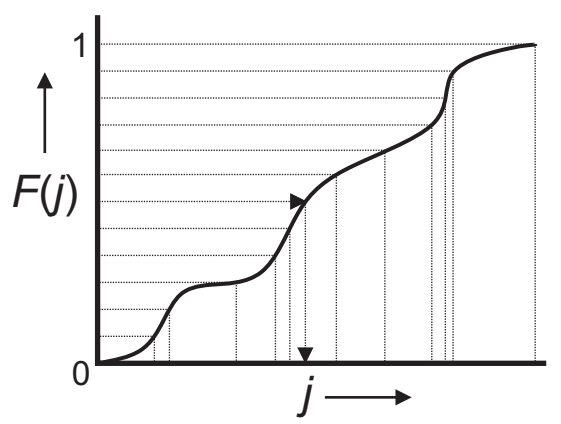

Figure 2.11: The cumulative ODF and the selection of orientations. A uniform distribution over $F(j)$ is chosen to select the orientations $j$ which are used in the discrete texture. 


\title{
Chapter 3
}

\section{Martensitic transformations}

\begin{abstract}
Metastable austenitic stainless steels show an uncommon material behavior during deformation: both hardening and elongation are much higher compared to the expected values based on the properties of the austenitic phase in the steel. The reason for this unusual behavior is the transformation from the austenitic to the harder martensitic phase that can occur in these types of steel.

This chapter will give a background about the production of austenitic stainless steels and the requirements for the austenite to martensite transformation in Section 3.1. The mechanics behind the austenite to martensite transformation are discussed in Section 3.2, followed by a discussion of the stress-induced transformation theory in Section 3.3 and the mechanical behavior of steels showing this type of transformation in Section 3.4. Using the theory explained in this chapter, the influence of the austenitic texture on the transformation behavior is discussed in the final section.
\end{abstract}

\subsection{Martensitic transformations}

During the production of a steel, several different microstructural phases can be obtained, depending on the production methods. Which phases can be present in a iron - carbon mixture, as a function of the temperature and carbon content, is displayed in an equilibrium phase diagram, Figure 3.1(a). The phases displayed here are the phases obtained when there is enough time to reach an equilibrium state through diffusion of atoms. It is clear that, when slowly cooling a low carbon content steel from the austenitic $\gamma$ phase, a steel con- 
taining the ferritic $\alpha$ phase is obtained. The cooling rate during production processes can be higher than the rate needed to obtain the equilibrium phases and non-equilibrium phases can be obtained. This can be described by a TTT (Time, Temperature, Transformation) diagram, which shows the phase transformation as a function of time, Figure 3.1(b). It shows that by cooling the austenitic phase at such a rate that the temperature-time curve stays left of the pearlite and bainite noses to a temperature above $M_{s}$, the martensite start temperature, no other phases are created. Cooling further, transformation of the austenitic phase starts. Due to the low temperature, diffusion of atoms is slow and the preferred $\alpha$ structure cannot be quickly obtained. Instead, the martensitic structure, $\alpha^{\prime}$, appears by collective displacement of atoms, which resembles the $\alpha$ structure. Since no diffusion occurs, the chemical composition of both martensite and austenite after the quenching step is the same.

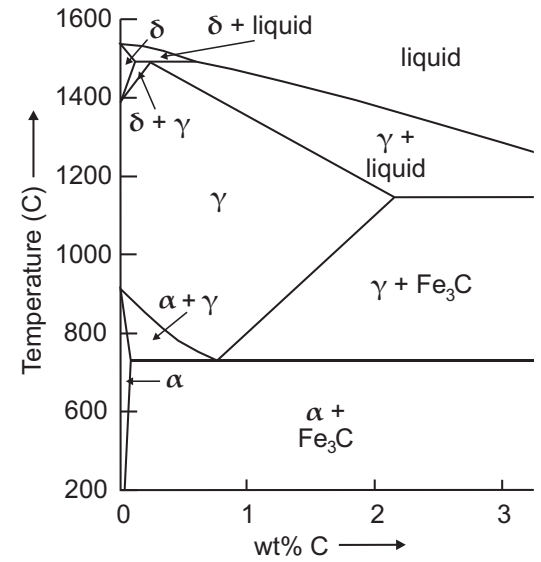

(a)

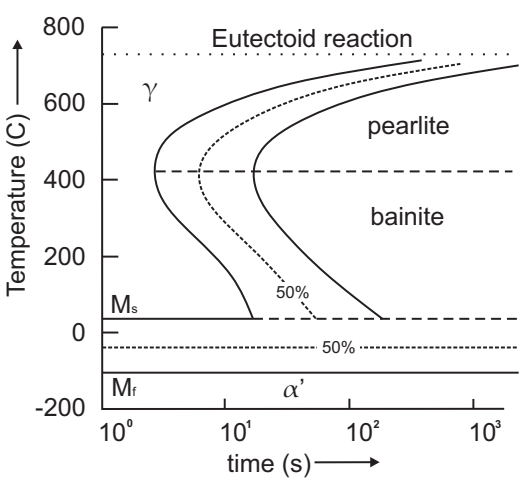

(b)

Figure 3.1: The Iron - Carbon equilibrium phase diagram (a) and a schematic representation of the TTT diagram of a $0.77 \%$ carbon steel.

Figure 3.2 shows schematically the relation between the chemical free energy and the temperature of both the austenite and martensite phase $[18,5]$. The phase with the lowest chemical free energy is the preferred phase in the steel. At temperature $T_{0}$ both phases are in equilibrium, while at temperatures lower than $T_{0}$ the martensite phase is preferred and at temperatures above $T_{0}$ the austenite phase. 
From experiments it is known that austenite grains are not transformed directly into martensite as soon as the temperature drops below $T_{0}$; only when the temperature drops below the martensite start temperature, $M_{s}$, will martensite form. At this temperature, the difference in free energy $\Delta G$, also called the chemical driving force, is high enough to start transformation. A certain value of the chemical driving force is required for e.g. the creation of the martensiteaustenite interface, which is required for transformation to start. The same goes for the reverse transformation which, starts only when the austenite start temperature, $A_{s}$, is surpassed. Due to this difference in transformation temperature both the austenite and martensite phase can be present in the material simultaneously.

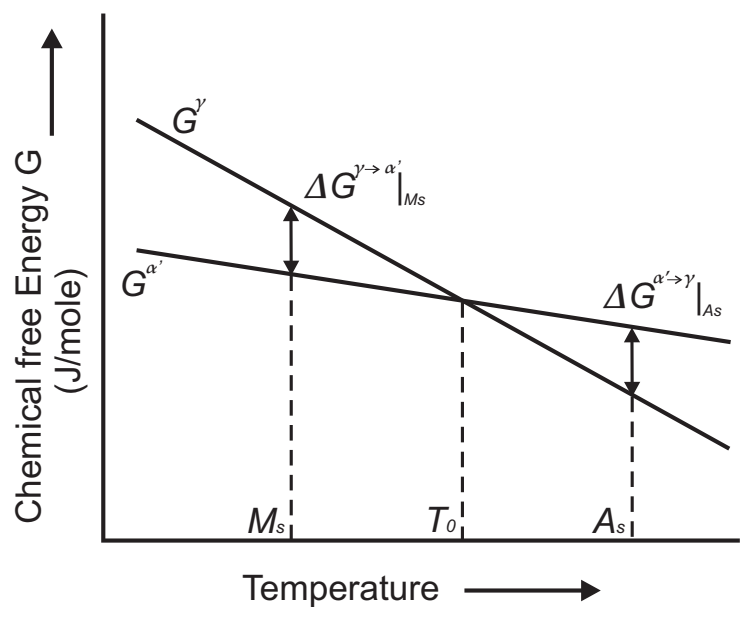

Figure 3.2: Schematic representation of the Gibbs free energy of the austenitic $\gamma$ phase and the martensitic $\alpha^{\prime}$ phase.

\subsubsection{The $M_{s}$ temperature}

The $M_{s}$ temperature strongly depends on both the chemical composition of the steel and the austenitic grain size.

The effect of several individual alloying elements on the $M_{s}$ temperature for iron-based alloys is shown in [19]. The presence of $\mathrm{Al}, \mathrm{Ti}, \mathrm{V}$ and Co causes an increase in the $M_{s}$ temperature, whereas the elements $\mathrm{Nb}, \mathrm{Cu}, \mathrm{Cr}, \mathrm{Mo}, \mathrm{Ni}$, 
$\mathrm{C}$ and $\mathrm{N}$ decrease the $M_{s}$ temperature. Of these, the Carbon content has the largest influence. Over the years several linear and non-linear models based on the influence of individual alloying elements on the $M_{s}$ temperature of ironbased steels were developed. A comparison between some of these models and experiments can be found in e.g. [20].

Several authors studied the relation between the austenitic grain size and the $M_{s}$ temperature $[21,22,23,24]$. Experiments show that a smaller grain size results in an increase of the $M_{s}$ temperature. Yang and Bhadeshia [24] described this behavior as a function of the average austenitic grain volume $V_{\gamma}$ using

$$
M_{s}^{0}-M_{s}=\frac{1}{b} \ln \left[\frac{1}{a V_{\gamma}}\left\{\mathrm{e}^{-\frac{\ln \left(1-f_{M_{s}}\right)}{m}}-1\right\}+1\right]
$$

with $a$ and $b$ fitting parameters, $f_{M_{s}}$ the first detectable fraction of martensite, $m$ the aspect ratio of the martensite plate, which was assumed to be around 0.05. $M_{s}^{0}$ is the fundamental martensite start temperature for an infinitely large austenite grain size, calculated based on thermodynamics alone. They showed that this model was able to reasonably represent the experiments performed by several authors. However, simulations on multiphase carbon steel performed by Turteltaub and Suiker [25] showed that the influence of the grain size on the $M_{s}$ temperature depends on the orientation of the grain with respect to the strain direction as well.

During deformation of austenitic stainless steels transformation can occur above the $M_{s}$ temperature. In this thesis, the stress-induced transformation theory is used to describe the transformation during deformation of austenitic steels. To understand this theory, more knowledge about the crystallography of the martensite transformation is needed.

\subsection{Crystallography of martensitic transforma- tions}

The austenite to martensite transformation is displacive in nature [26]. A group of atoms displaces at the same time to form the martensitic BCC structure out of the austenitic FCC structure. The transformation process happens without diffusion of atoms: after transformation, each atom still has the same neighbors as before transformation. The displacive nature of the transformation is confirmed by measuring the transformation speed, which approaches the speed of sound in the metal and is too high to be caused by diffusion [27, 28]. 
The high speed of transformation can only be obtained when the interface between the austenite and martensite, the so-called habit plane, is both undistorted and unrotated [29,30]. This reduces the strain energy and allows the interface to move easily. For this coherent plane to exist, the transformation strain needs to be an Invariant Plane Strain (IPS) [31]. This places some limitations on the displacement of the atoms while forming the BCC structure. The mathematical derivation shows that, due to symmetry and the IPS requirement, there are 24 possible displacements of atoms to form the BCC structure and still satisfy the IPS condition. These 24 different displacements to form the martensite are called variants.

The deformation caused by the displacement of the atoms during transformation can be described by the normal on the habit plane $\boldsymbol{n}$ and a shape strain vector $s$. The deformation gradient due to transformation of a variant is obtained with

$$
\mathbf{F}=\mathbf{I}+\boldsymbol{s} \otimes \boldsymbol{n} .
$$

Calculating $\boldsymbol{n}$ and $\boldsymbol{s}$ for one variant and permutating the indices of $\boldsymbol{n}$ and $\boldsymbol{s}$ will lead to the remaining 23 variants. The mathematical derivation of the transformation can be found in $[32,33]$ and in Appendix A.

\subsection{Stress-induced transformation}

Now more information about the crystallography of the martensitic transformation is known, the transformation during deformation of the austenite phase according to the stress-induced transformation theory can be explained. It is already stated that a difference in chemical free energy, $\left.\Delta G^{\gamma \rightarrow \alpha^{\prime}}\right|_{M_{s}}$, is needed for transformation to start. As long as the temperature is above $M_{s}$, the chemical driving force is not high enough for transformation to start spontaneously. Still, transformation can be observed during deformation above $M_{s}$. The stressinduced transformation theory states that the additional energy required for the transformation to start can be obtained by applying a stress on the austenitic phase $[5,34]$. As is shown in Figure 3.3, the required additional energy $U_{c r}$ increases with increasing temperature.

Take, for example, a temperature $T$ above the $M_{s}$ temperature. At this temperature, the difference in free energy between the two phases is smaller than the required energy difference for transformation to start:

$$
\left.\Delta G^{\gamma \rightarrow \alpha^{\prime}}\right|_{M_{s}}>\left.\Delta G^{\gamma \rightarrow \alpha^{\prime}}\right|_{T}
$$




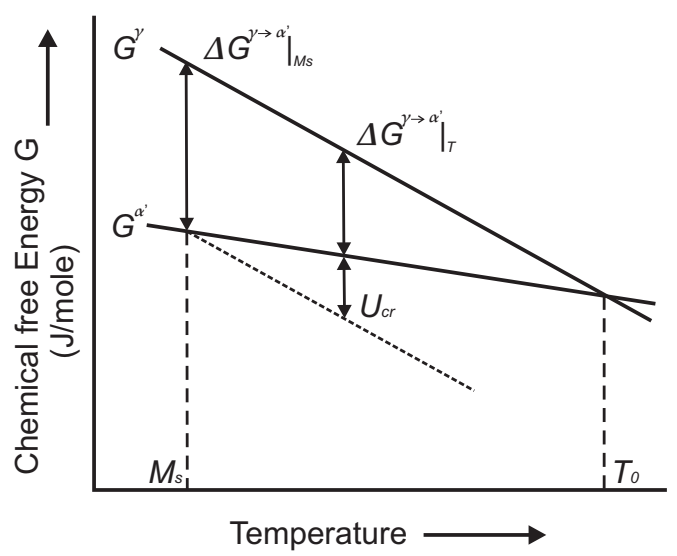

Figure 3.3: Schematic representation of the Gibbs free energy of the austenitic $\gamma$ phase and the martensitic $\alpha^{\prime}$ phase. The required additional energy from the stress for transformation to start increases with increasing temperature.

In this case, the austenite phase will not transform into martensite. However, by applying a stress, the displacement of the atoms in the austenite phase is aided by the stress. If this direction is the same direction in which the atoms will move when transformation takes place, less energy is required to start transformation in that direction. The mechanical work $U$, the mechanical driving force, supplied by the stress in the direction of the transformation is calculated by

$$
U^{i}=\boldsymbol{\sigma}_{\gamma}:\left[\boldsymbol{s}^{i} \otimes \boldsymbol{n}^{i}\right]
$$

where $i$ is the number of the variant for which the driving force is calculated, $s$ and $\boldsymbol{n}$ the shape strain vector and the normal to the habit plane, respectively, as calculated in the previous section, which describes the displacement of atoms when transformation according to the $i$-th variant takes place. The tensor $\boldsymbol{\sigma}_{\gamma}$ is the stress in the austenite phase. Since $\boldsymbol{\sigma}_{\gamma}$ is symmetric, Equation (3.4) can be written as

$$
U^{i}=\boldsymbol{\sigma}_{\gamma}:\left[\frac{1}{2}\left(\boldsymbol{s}^{i} \otimes \boldsymbol{n}^{i}+\boldsymbol{n}^{i} \otimes \boldsymbol{s}^{i}\right)\right]
$$

The value of $U^{i}$ is different for each variant, depending on whether the stress is aiding or suppressing transformation in that direction. As soon as the 
mechanical driving force for one of the 24 variants reaches a critical driving force,

$$
U_{c r}=\left.\Delta G^{\gamma \rightarrow \alpha^{\prime}}\right|_{M_{s}}-\left.\Delta G^{\gamma \rightarrow \alpha^{\prime}}\right|_{T},
$$

the energy required for transformation of that variant to start is obtained, and the austenite phase transforms into martensite according to that variant. The variant selection mechanism can be studied using the orientation of the martensite phase in its parent austenite grain after deformation and comparing it with calculations for the martensitic orientations with and without the variant selection mechanism $[35,36]$.

\subsubsection{Stepwise transformation}

When transformation of an austenite grain under stress occurs, only a part of the grain transforms. This is contributed to the constraint of the environment on the grain: the strain occurring in a grain due to the transformation is opposed by the surrounding grains. This results in a reduction of stress and driving force in the transforming grain and stops further transformation. The result is a thin lenticular plate or lath as is shown in 2D in Figure 3.4 and an only partly transformed grain [33]. Transformation starts again when additional stress is applied, increasing the driving force up to the critical value.

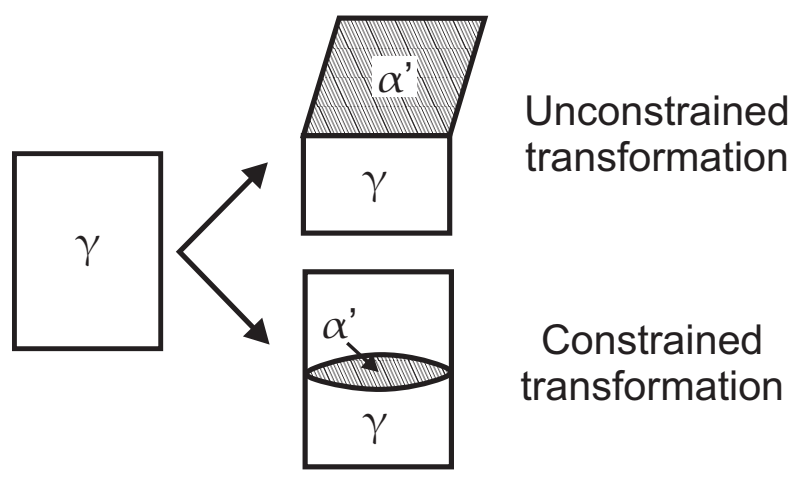

Figure 3.4: Unconstrained versus constrained transformation 


\subsection{Material behavior}

An example of a stress - strain curve of an austenitic stainless steel is shown in Figure 3.5. In this steel, deformation up to a strain of 0.04 shows that the normal Swift strain hardening is present in the material as expected when deforming the austenite phase. At a strain of 0.04 there are grains present in the material in which the driving force is high enough for transformation to start from the austenite into the martensitic structure. The transformation is accompanied by the transformation strain. Due to this extra strain, the stress-strain curve of the transforming steel drops below the stress-strain curve of the austenite phase only. This softening contribution of the transformation on the material properties is clearly visable in Figure 3.5(a). At low martensite fractions, both the austenite and martensite phase are expected to have the same stress. If the fraction of martensite is increased enough the martensite, which is much harder than the parent austenite, is loaded more and a strong hardening is observed, see above a strain level of 0.13 in Figure 3.5(a). Perdahcioglu showed that this behavior can be accurately described using the stress-induced transformation theory in combination with a homogenization scheme [37, 38, 39].

\subsubsection{Determination of the critical driving force}

Based on the results shown in Figure 3.5, the critical driving force for the presented steel can be calculated. Transformation in a polycrystalline austenitic stainless steel starts as soon as the critical driving force is reached in a grain. From Equation (3.5) it is known that the driving force depends on the orientation of a grain with respect to the stress. The highest possible driving force, $U_{\max }$, is obtained in a grain which is oriented such that the principal strains of the transformation are in the same direction as the principal stresses. This reduces Equation (3.5) to

$$
U_{\max }=\sum_{j} \sigma_{j}^{*} \lambda_{j}
$$

with $\sigma_{j}^{*}$ the ordered principal stresses in the austenite and $\lambda_{j}$ the ordered principal deformations of the transformation which can be expressed in terms of the austenitic lattice parameter $a_{0}$ and martensitic lattice parameter $a$ as

$$
\lambda=\left[\begin{array}{c}
\frac{a}{a_{0}} \frac{\sqrt{2} a}{a_{0}} \\
1 \\
\frac{\sqrt{2} a}{a_{0}}
\end{array}\right]-1 .
$$




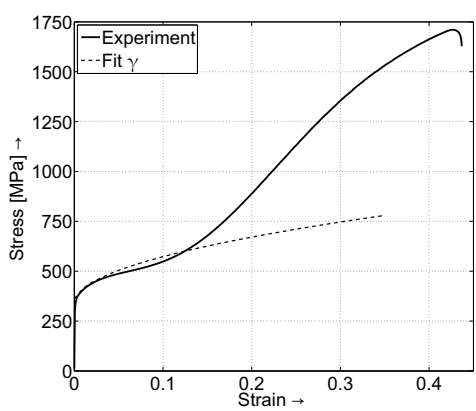

(a) Strain - Stress

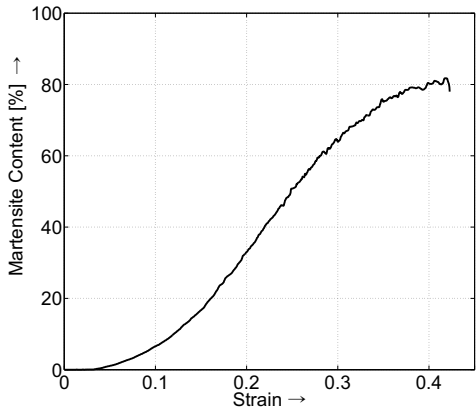

(b) Strain - Martensite Content

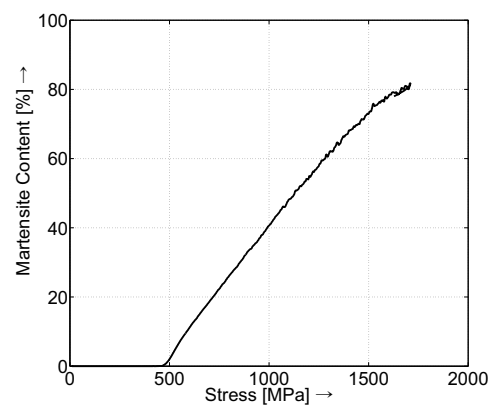

(c) Stress - Martensite Content

Figure 3.5: Results of a uniaxial tensile test of a metastable austenitic stainless steel which shows transformation during deformation. Figure a shows the predicted behavior of the austenite phase as well.

Assuming this grain is present in the material, the critical driving force can be obtained by performing an experiment where a sample is loaded with a known stress state. Using the stress at which transformation starts, in combination with Equation (3.7), results in the critical driving force.

As long as there are grains in the polycrystalline steel which agree with the conditions for Equation (3.7), transformation during the deformation of the steel starts at the same driving force, independent of the global stress state. Experiments with different stress states, performed by Perdahcioglu et al. [38], confirmed that this is indeed the case. 


\subsubsection{TRansformation Induced Plasticity (TRIP)}

Section 3.2 and Appendix A discussed the formation of martensite in an austenite grain. It was shown that the displacement of atoms during the transformation results in a transformation strain. This transformation strain has a large influence on the material behavior of a polycrystalline material. In a single grain, the transformation strain will be in the direction in which the stress aids the transformation the most. It was found that in a polycrystalline steel the average transformation strain will be in the deviatoric stress direction $[4,40]$. The overall transformation deformation rate $\mathbf{D}^{T}$ can be calculated with

$$
\mathbf{D}^{T}=\dot{f}^{\alpha^{\prime}}\left(A \mathbf{N}+\frac{\delta V}{3} \mathbf{I}\right)
$$

with $\dot{f}^{\alpha^{\prime}}$ the rate of transformation, the scalar $A$ depending on the stress state and martensite fraction and $\delta V$ the volume change during transformation. $\mathbf{N}$ is the direction of the deviatoric part of the applied stress,

$$
\mathbf{N}=\frac{\sigma^{\prime}}{\sqrt{\sigma^{\prime}: \sigma^{\prime}}}
$$

with $\boldsymbol{\sigma}^{\prime}$ the deviatoric stress.

The transformation strain aids the deformation and its effect is clearly visible as a softening in the stress-strain curves presented in Figure 3.5(a).

\subsubsection{Temperature \& transformation during deformation}

From the theory discussed in Section 3.1, it is clear that the transformation is strongly temperature dependent. At temperatures below the $M_{s}$ temperature, transformation starts spontaneously, while at increasing temperatures the chemical driving force decreases, which means that a higher mechanical driving force is required for transformation to start. This can be achieved by applying a higher stress. Since the required stress for transformation is higher, the transformation starts at higher strains and the final martensite content will be lower, as shown in the experimental work performed by Angel [1] and Post [41], represented in Figure 3.6.

From the Gibbs energy plot in Figure 3.2 it is also clear that when transformation occurs, the total free energy of the structure is lowered. This energy is converted into heat, called the latent heat. Experiments with one of the steels used in this research indicate that the latent heat for that steel is approximately 
$65 \mathrm{~kJ}$ per $\mathrm{kg}$ transformed material. This means that in adiabatic conditions the temperature can rise by over $100 \mathrm{~K}$ when the steel is fully transformed. This causes a strong dependency of the material behavior on the strain rate. When the increase of heat due to plasticity and transformation is higher than the conduction and convection of heat to the environment, the temperature rises and transformation slows down. This results in a lower martensite fraction after deformation with higher strain rates.
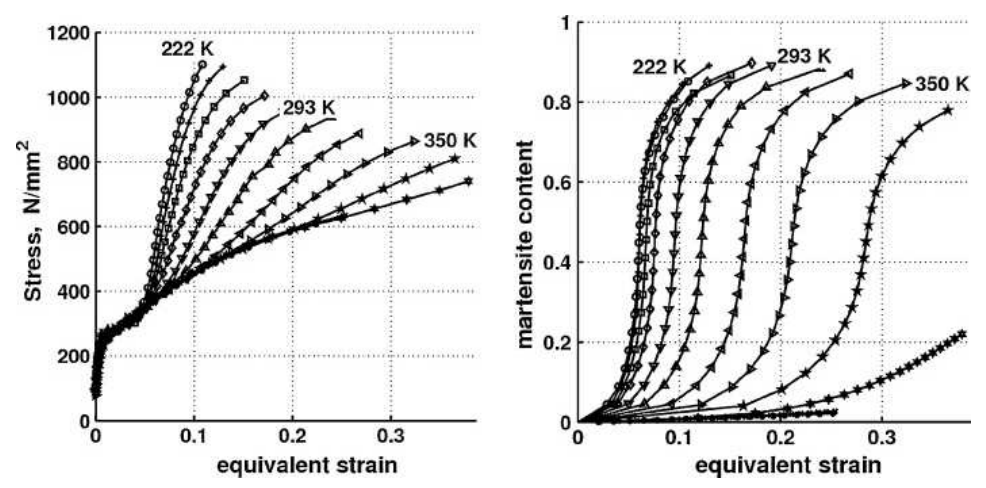

Figure 3.6: Temperature dependency of the material behavior of metastable austenitic stainless steel [41].

\subsection{Transformation \& austenitic texture}

According to the stress-induced transformation theory, when the orientation of a grain is such that the displacement of the atoms during transformation is in the direction of the stress, only a low amount of stress is needed to reach a sufficiently high amount of mechanical driving force for transformation to start. However, when a grain is not oriented favorably for transformation, transformation can only occur at higher stress levels. For example, in the case of a uniaxial stress, a grain with a $\langle 111\rangle$ in the direction of the uniaxial stress needs four times as much stress to reach the critical driving force than a grain with a $\langle 100\rangle$ direction in the stress direction.

The behavior of individual grains can also have an influence on the total transformation behavior of a polycrystal. When no crystallographic texture is 
present, the orientation distribution of the grains with respect to the stress direction is independent of the direction and no difference in global transformation behavior is expected. However, following the stress-induced transformation theory, this might not be the case during the deformation of highly textured steels. In this case, there is a certain distribution of grain orientations with respect to the stress present in the steel. By changing the stress direction, the orientation distribution of the grains with respect to the stress direction changes and thus also the transformation behavior.

This is easily visualized by plotting the mechanical driving force in a slice of the Euler space. In Figure 3.7 the driving force as a function of the orientation of a grain is plotted in the case of several stress states in the RD and in the TD. Creuziger showed similar plots for several additional stress states [42]. The distributions in these figures show the propensity of an austenite crystal with a particular orientation to transform to martensite irrespective of its presence in the material. Clearly, some orientations are more prone to transformation than others. Also, a clear difference between the same stress state in the RD and the TD is visible. For instance, it is clear that grains with orientations $\left[\phi_{1} \Phi \phi_{2}\right]$ around [90 9045 ] have a high driving force in the uniaxial RD case, but a much lower one in the corresponding TD case. When only grains with such an orientation are present in the polycrystal, the global transformation behavior can be different. The effect of the austenitic texture on the transformation behavior is investigated in the next chapters.

\subsubsection{Driving Force in Generalized Spherical Harmonics}

As with the texture, the driving force as a function of the Euler angles can be expressed with generalized spherical harmonics as described in Section 2.3. Describing the driving force in terms of the generalized spherical harmonics yields a quick evaluation of the driving force for each orientation and stress state. The driving force according to the $i$-th variant is calculated using Equations (2.4) and (3.5) as

$$
U^{i}=\mathbf{R}\left(\phi_{1}, \Phi, \phi_{2}\right) \boldsymbol{\sigma} \mathbf{R}\left(\phi_{1}, \Phi, \phi_{2}\right)^{T}:\left[\frac{1}{2}\left(\boldsymbol{s}^{i} \otimes \boldsymbol{n}^{i}+\boldsymbol{n}^{i} \otimes \boldsymbol{s}^{i}\right)\right],
$$

with $\mathbf{R}$ the rotation matrix needed to rotate the stress in the global coordinate system to the coordinate system of the austenite grain. From this equation it is clear that the driving force not only depends on the Euler angles, but on the stress $\boldsymbol{\sigma}$ as well. This makes the complex coefficients $t_{l}^{m n}$ also dependent on $\boldsymbol{\sigma}$. 


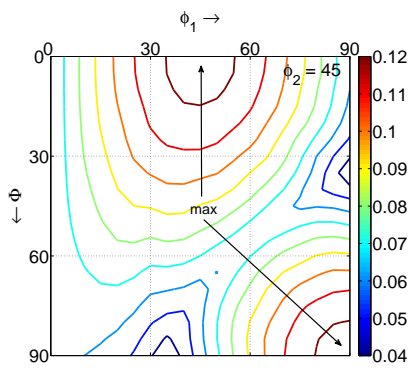

(a) Calculated distribution of the driving force based on a uniaxial stress in the RD

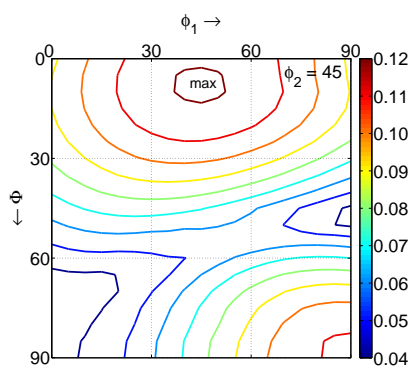

(c) Calculated distribution of the driving force when applying a plane strain in the RD

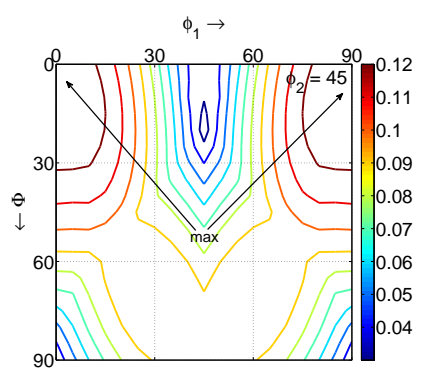

(e) Calculated distribution of the driving force when applying a shear strain in the RD

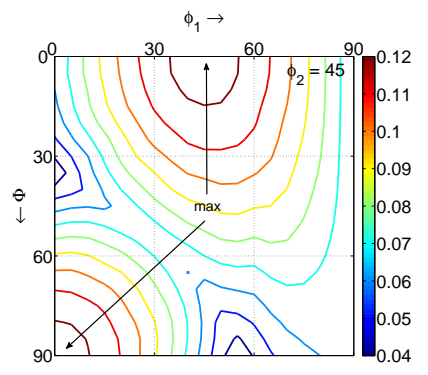

(b) Calculated distribution of the driving force based on a uniaxial stress in the TD

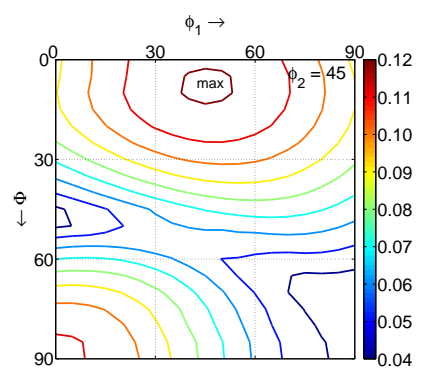

(d) Calculated distribution of the driving force when applying a plane strain in the TD

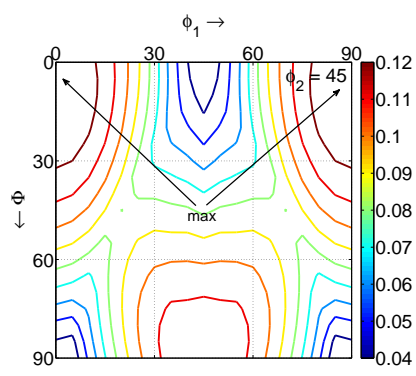

(f) Calculated distribution of the driving force when applying a shear strain in the TD

Figure 3.7: The driving force plotted in the $\phi_{2}=45^{\circ}$ ODF section for several stress states in both the RD and TD. Colors of the iso lines denote the amount of driving force per MPa applied stress. 
Further investigation of Equation (3.11) shows that the influence on the driving force of each component of $\boldsymbol{\sigma}$ is independent:

$$
U^{i}=\sum_{k=1}^{3} \sum_{p=1}^{3} f_{k p}^{i}\left(\phi_{1}, \Phi, \phi_{2}, \sigma_{k p}\right) .
$$

Result is that the influence of each stress component $\sigma_{k p}$ on the driving force can be described with a generalized spherical harmonic with the complex coefficients depending on the stress components as $t_{l, \sigma k p}^{m n, i}$. The total driving force for the $i$-th variant can be described with a linear combination with the complex coefficient based on the different stress components:

$$
t_{l}^{m n, i}(\sigma)=\sum_{k=1}^{3} \sum_{p=1}^{3} \sigma_{k p} \cdot t_{l, \sigma_{k p}}^{m n, i} .
$$

Calculations show that a second order generalized spherical harmonic is sufficient to represent Equation (3.11). The influence of the different stress components according to Equation (3.11) and its second order generalized spherical harmonic are shown in Figure 3.8.

The driving force as a function of the stress and orientation of a grain for a single variant can be calculated with a low order generalized spherical harmonic. However, for transformation purposes the maximum driving force acting on all 24 variants is required. The resulting non-harmonic function requires a higher order generalized spherical harmonic function which is different for each stress state. 

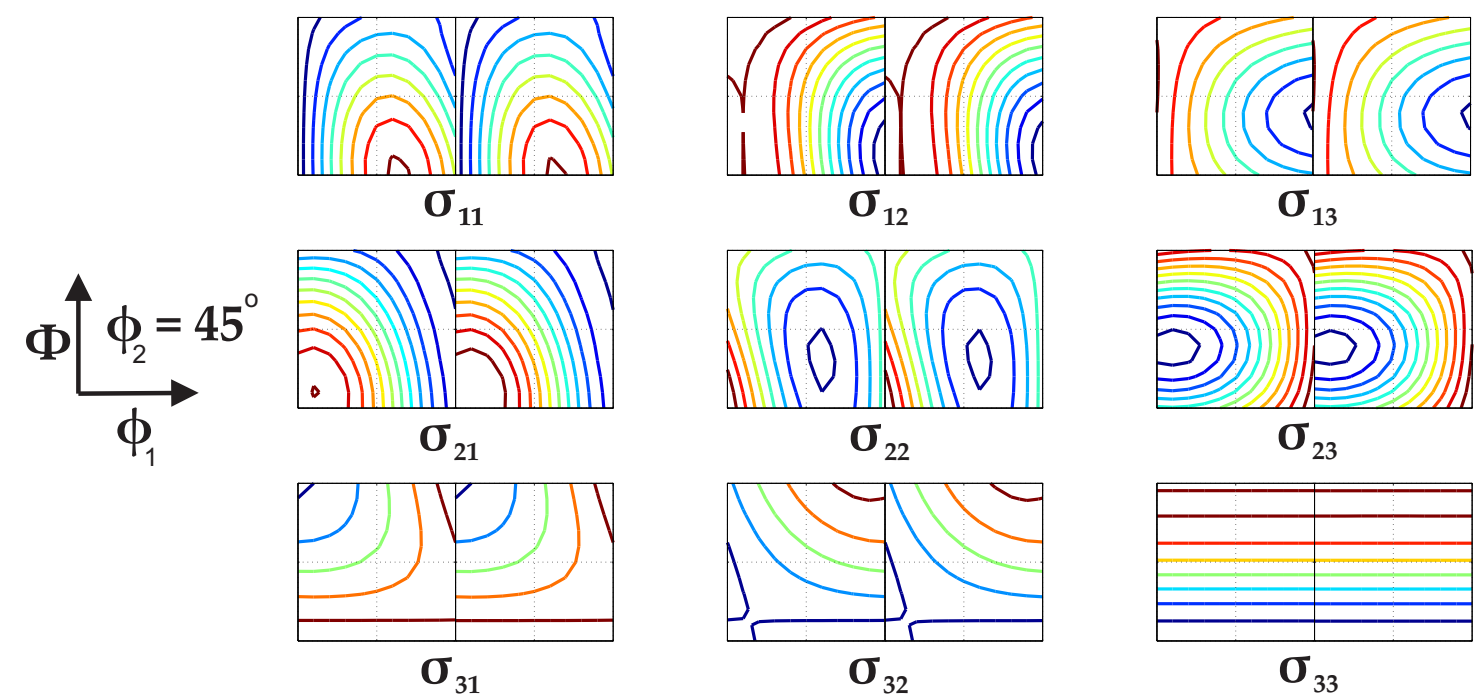

$\sigma_{13}$
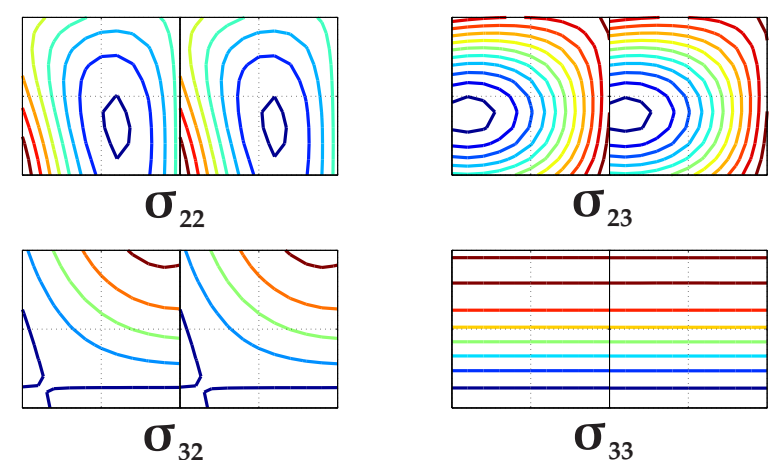

Figure 3.8: Driving force distribution based on a single variant and on several stress components. Results using Equation (3.11) are displayed left, the ones from the second order generalized harmonic on the right. 


\subsection{Summary}

In this chapter, the austenite to martensite transformation is discussed. The austenite phase in metastable austenitic stainless steels can transform: the martensitic BCC structure is thermodynamically preferred over the austenitic FCC structure. If the temperature of the steel is below the $M_{s}$ temperature, transformation starts spontaneously. According to the stress-induced transformation theory, a stress can be applied to initiate transformation at temperatures above $M_{s}$.

The formation of one of the 24 possible martensite variants in the FCC lattice was mathematically described, as well as the strain accompanying the transformation.

The austenite to martensite transformation in a polycrystalline steel has a large influence on the material behavior of the steel. While initially there is a softening contribution of the transformation strain to the mechanical properties, the formed martensite is harder than the austenite and a high hardening is observed at higher martensite fractions at subsequent plastic deformations.

Based on the stress-induced transformation theory, the orientation of an austenite grain, and thus the austenitic texture as well, has a large influence on the transformation behavior. This will be investigated in the following chapter. 


\section{Chapter 4}

\section{Influence of texture on transformation}

This chapter is based on the article: P. Hilkhuijsen, H.J.M. Geijselaers, T.C. Bor, E.S. Perdahcioglu, A.H. v.d. Boogaard and R. Akkerman, Strain direction dependency of martensitic transformation in austenitic stainless steel: The effect of $\gamma$ texture, Materials Science and Engineering: A, Volume 573, Pages 100-105.

Based on the theoretical work discussed in the previous chapter and observations by several authors, [43, 44, 45, 46, 47], it is expected that the orientation of a grain with respect to the load applied on the grain has an influence on its transformation behavior. The stress-induced transformation theory can be extended to incorporate the crystallographic austenitic texture. Based on this theory, the transformation in a material without any crystallographic texture is independent of the stress direction. This is in contrast to a steel with a strong austenitic texture present, where the transformation behavior depends on the strain direction. This will influence the material behavior when straining in different directions as well.

To investigate whether the theory is correct, experiments using two metastable austenitic stainless steels were performed. The properties of the steels are discussed in Section 4.1. Three stress states were selected and applied on samples of these steels which had their main axis in the Rolling Direction (RD) or in the 
Transverse Direction (TD). The results of these experiments are presented in Section 4.2. The stress-induced transformation theory can also be validated by comparing the austenitic textures after transformation with the ones of the asreceived materials. This is discussed in Section 4.3. Combining the as-received austenitic texture with the stress-induced transformation theory results in a qualitative model capable of simulating the trends found in the experiments. This model, the Texture Based Stress Induced Transformation (TBSIT) model, is presented in Section 4.4, the comparison with the experiments in Section 4.5.

\subsection{Material}

In light of the observed direction dependent transformation behavior of grains described in the literature and the description of the stress-induced transformation theory in the previous chapter, two austenitic $\mathrm{Cr}-\mathrm{Ni}$ stainless steels were selected. The steels have different types of texture and different chemical compositions, see Table 4.1. Annealing after rolling resulted in fully austenitic stainless steels. Both steels show austenite-to-martensite transformation during deformation. X-Ray Diffraction (XRD) techniques were used to measure the austenitic textures on the surface of the steels prior to experiments. It is assumed that these textures are representative for the entire sample. In the asreceived condition, Steel 1 showed no significant texture, whereas Steel 2 showed a strong texture, where most intensity was found around the 'Goss' orientation $(\{110\}\langle 001\rangle,[909045])$ and around the $\{111\} / /$ RD fiber, which includes the 'Copper' orientation $(\{112\}\langle 11 \overline{1}\rangle,[903545])[6]$. The texture of this steel, described by the ODF and presented in the $\phi_{2}=45^{\circ}$ slice of the Euler space, is shown in Figure 4.1. Crystal size and shape can have an influence on the transformation behavior as well $[48,49,23]$. In the steels used in this research, no relation between crystal size, shape and orientation was found, indicating that the crystal morphology has no effect on the transformation behavior when straining in different directions.

Table 4.1: Chemical composition (nominal \%) of the non-textured steel (Steel 1) and the highly textured steel (Steel 2).

\begin{tabular}{|c|c|c|c|c|c|c|c|c|c|c|}
\hline Element & $\mathrm{C}+\mathrm{N}$ & $\mathrm{Cr}$ & $\mathrm{Ni}$ & $\mathrm{Mo}$ & $\mathrm{Ti}$ & $\mathrm{Al}$ & $\mathrm{Si}$ & $\mathrm{Cu}$ & $\mathrm{Mn}$ & $\mathrm{Fe}$ \\
Steel 1 \% & 0.1 & 16.5 & 7.0 & - & - & - & 1.2 & - & 1.3 & Balance \\
Steel 2\% & $\leq 0.02$ & 12.0 & 9.0 & 4.0 & 0.9 & 0.50 & $\leq 0.40$ & 2.0 & $\leq 0.5$ & Balance \\
\hline
\end{tabular}




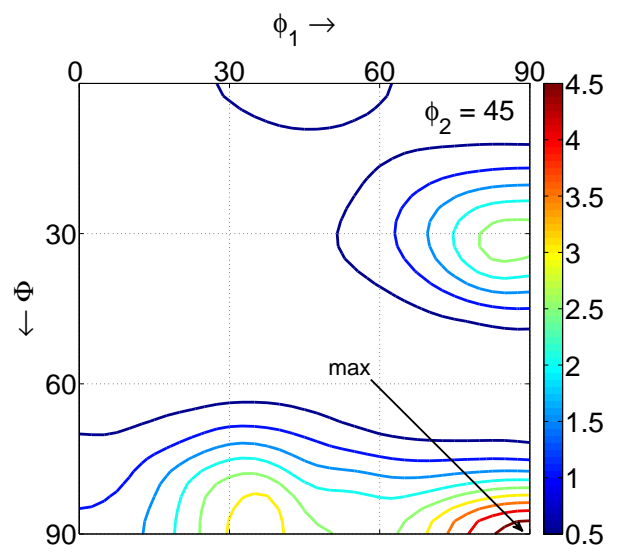

Figure 4.1: The $\phi_{2}=45^{\circ}$ section of the Orientation Distribution Function (ODF) based on the measured texture of Steel 2.

\section{$4.2 \quad$ Experiments}

Experiments were performed using both uniaxial test samples for use in a standard tensile machine and 'butterfly' samples for use in an ARCAN fixture [50]. Using this fixture, the samples can be deformed in various ways including by a shear strain, plane strain or several combinations of these strains. A schematic drawing of the fixture and the 'butterfly' sample is shown in Figure 4.2.

From both steels, specimens with the main axis in the RD or TD were taken by laser cutting. The deformation zone in the uniaxial tensile samples of Steel 1 measured $100 \times 15 \times 0.8 \mathrm{~mm}^{3}$, while the samples of Steel 2 had a slightly smaller deformation zone of $80 \times 10 \times 0.5 \mathrm{~mm}^{3}$. The shape of the 'butterfly' samples, with a deformation area of $30 \times 5 \mathrm{~mm}^{2}$, is presented in Figure $4.2(\mathrm{~b})$.

During all experiments, the strain at the surface of the samples was measured optically. The martensite fraction during the experiments was determined using a magnetic induction sensor $[41,51]$ and the fraction at the end of the tensile test was verified by XRD measurements $[52,53]$. 


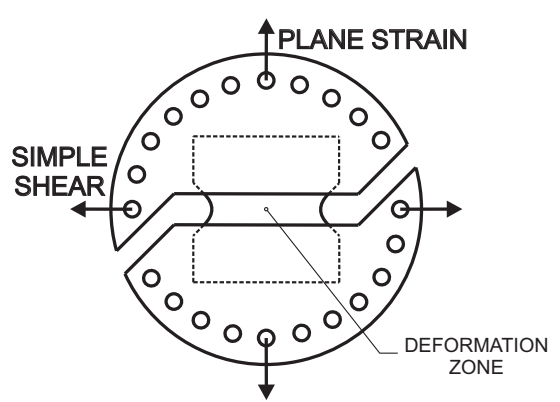

(a) Fixture

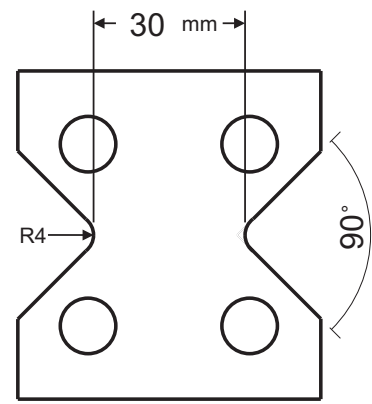

(b) Sample

Figure 4.2: Schematic drawing of the ARCAN fixture and the 'butterfly' sample used for plane strain and simple shear experiments

\subsubsection{Steel 1 (Untextured)}

Steel 1 showed no significant austenitic texture in the as-received condition. According to the theory, the transformation behavior while applying an elastic and/or plastic strain is independent of the strain direction.

Both the RD and TD samples were deformed by three types of strain: a uniaxial, plane and a simple shear strain. The strain rate during all experiments was around $0.001 / \mathrm{s}$. At this deformation speed, no significant increase in temperature was observed during deformation. The uniaxial experiments were performed at $253 \mathrm{~K}$ and the experiments using the ARCAN fixture were performed at $263 \mathrm{~K}$ to obtain a sufficient amount of martensite.

Results of the experiments with different strain paths are shown in Figure 4.3. The von Mises equivalent strain and stress is used in the figures. It is clear that no difference in material or transformation behavior between the RD and the TD samples for the respective strain paths can be observed.

Figure 4.5(a) shows the martensite content versus the maximum possible driving force based on the global stress during the experiments. From the figure it is observed that the driving force at which transformation starts is independent of the strain state and is calculated to be $56.7 \mathrm{MPa}$ at $253 \mathrm{~K}$. 


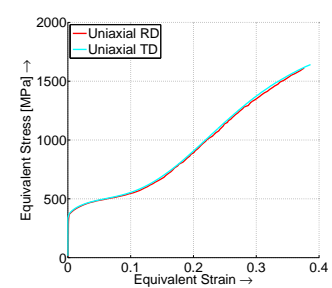

(a) Stress-Strain

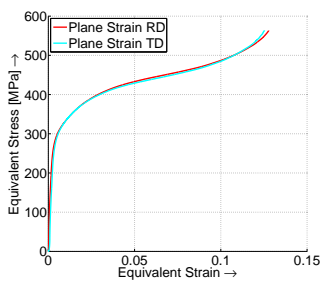

(d) Stress-Strain

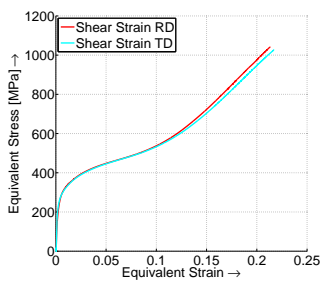

(g) Stress-Strain

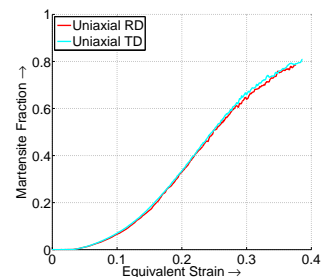

(b) Martensite - Strain

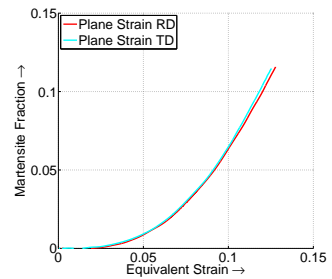

(e) Martensite - Strain

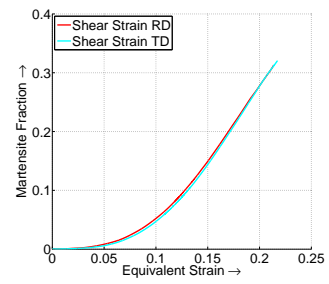

(h) Martensite Fraction - Strain

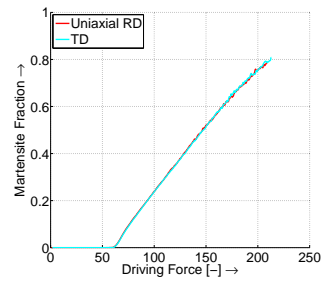

(c) Martensite Fraction - Driving Force

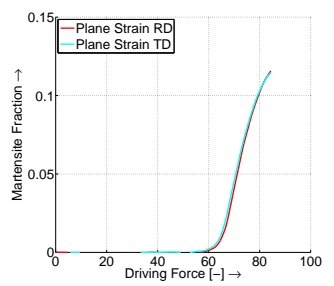

(f) Martensite Fraction - Driving Force

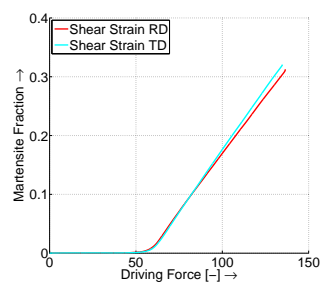

(i) Martensite Fraction - Driving Force

Figure 4.3: Stress-Strain, Martensite Fraction - Strain and Martensite Fraction - Stress curves measured during the different experiments on Steel 1 in the RD and TD. Figures (a) - (c) show the results for the uniaxial tensile experiments, (d) - (f) for the plane strain and (g) - (i) for the shear experiments. 


\subsubsection{Steel 2 (Textured)}

Steel 2 showed a strong austenitic texture in the as-received condition, as displayed in Figure 4.1. Based on the stress-induced transformation theory, a direction dependency of the transformation during plastic deformation in different directions is expected, resulting in a difference in material behavior when applying the same strain to the RD or TD sample.

The same three strain paths and strain rates as during the experiments on Steel 1 were applied. These experiments were performed at room temperature.

Results for the experiments with different strain paths are shown in Figure 4.4, where the von Mises equivalent strain and stress is used. It is clear that the yield stress is independent of the strain direction: there is no difference in material behavior up to the start of the transformation. In the case of the uniaxial and plane strain experiments, transformation started at significantly lower stresses and strains in the RD case compared to the TD case. This results in the earlier softening and hardening due to the transformation, which is evident in Figures 4.4(a) and 4.4(d). No difference in material behavior is found when applying a shear strain to the RD and TD samples.

Figure 4.5(b) shows the martensite content versus the maximum possible driving force based on the measured global stress during both the RD and TD experiments. From this figure, it is observed that the driving force at which transformation starts varies between the different experiments. In the case of uniaxial deformation in the $\mathrm{RD}$, it is known that grains with an orientation such that the highest possible driving force is obtained are present in the sample, in this case the 'Goss' orientation. Thus the start of transformation in the uniaxial $\mathrm{RD}$ experiment can be used for the calculation of the critical driving force, which is calculated to be $54 \mathrm{MPa}$. 


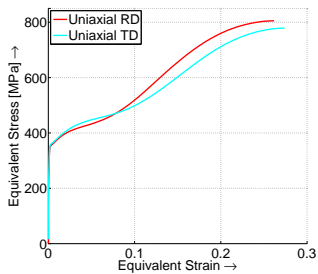

(a) Stress-Strain

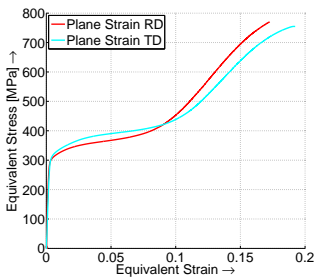

(d) Stress-Strain

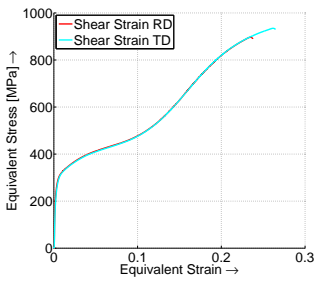

(g) Stress-Strain

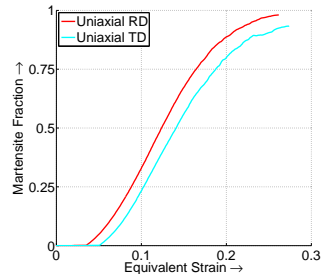

(b) Martensite Fraction - Strain

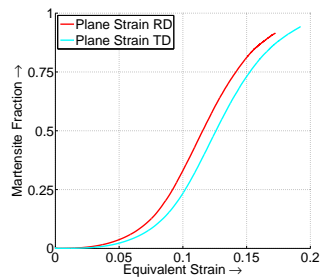

(e) Martensite - Strain

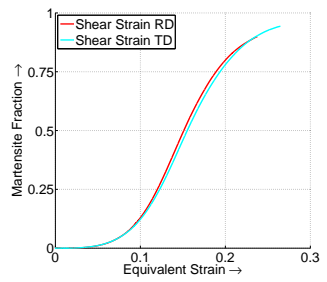

(h) Martensite Fraction - Strain

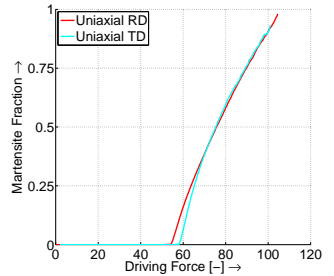

(c) Martensite Fraction - Driving Force

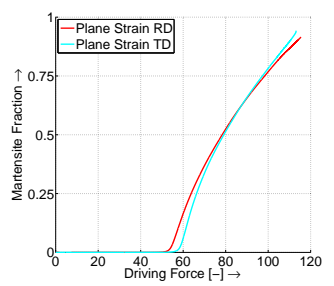

(f) Martensite Fraction - Driving Force

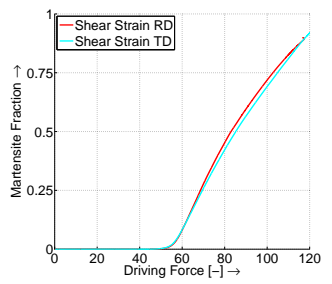

(i) Martensite Fraction - Driving Force

Figure 4.4: Stress-Strain, Martensite Fraction - Strain and Martensite Fraction - Stress curves measured during the different experiments on Steel 2 in the RD and TD. Figures (a) - (c) show the results for the uniaxial tensile experiments, (d) - (f) for the plane strain and (g) - (i) for the shear experiments. 


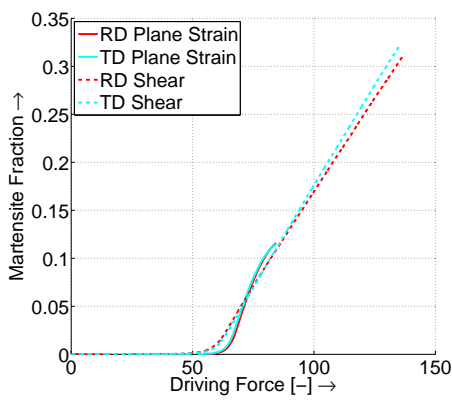

(a)

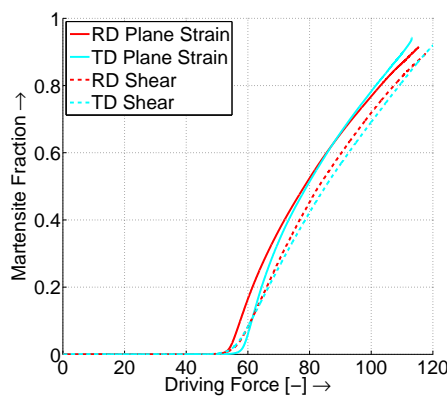

(b)

Figure 4.5: The driving force versus the martensite fraction measured during various experiments using Steel 1 (a) and Steel 2 (b).

\subsection{Austenitic textures}

According to the stress-induced transformation theory, grains with a low calculated value of the driving force per $\mathrm{MPa}$ applied stress need a high stress to transform. The grains with the lowest driving force require the highest stress to transform. Result is that at higher stresses fewer of these grains are transformed and thus will be represented more in the austenitic texture at high fractions of martensite. This can be validated by comparing the austenitic textures after transformation with the ODF plots of the driving force as shown in Figure 3.7.

Uniaxial tensile samples from Steel 1 and 2 were strained up to a martensite fraction of approximately 0.7 and austenitic textures were measured before and after deformation.

\subsubsection{Steel 1 (Untextured)}

Steel 1 showed no texture before deformation. After deformation up to a martensite fraction of approximately 0.7 was reached, a strong texture is present in the austenitic phase, as shown in Figure 4.6(a) for the RD case and 4.6(b) for the TD case.

The austenitic textures after deformation in the RD and TD are very similar with respect to the strain direction. Since all texture plots are measured with the $\mathrm{RD}$ in the same direction, this results in a $90^{\circ}$ rotation of the angle $\phi_{1}$ in the ODF. 


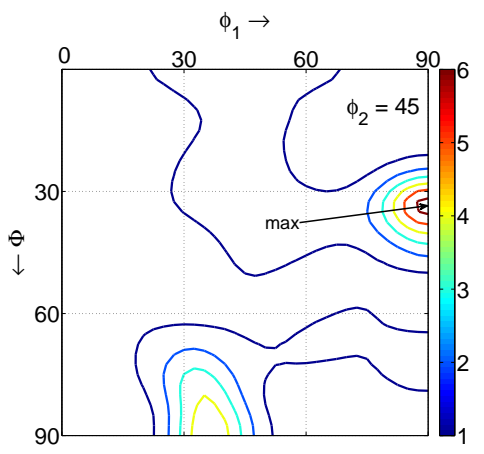

(a) RD

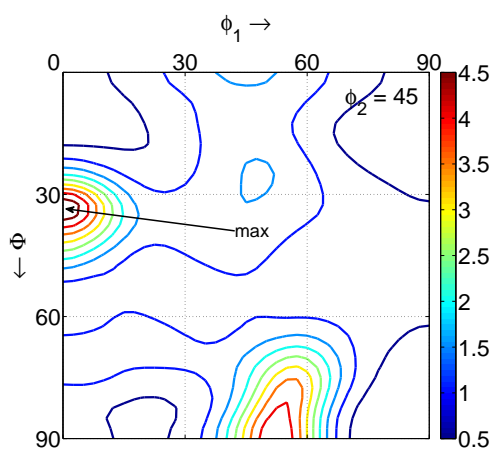

(b) TD

Figure 4.6: Measured austenitic texture after uniaxial deformation of Steel 1 in the RD (a) and TD (b). Martensite fraction $\approx 0.7$.

\subsubsection{Steel 2 (Textured)}

Steel 2 showed a strong austenitic texture in the as-received condition, containing grains around the 'Goss' orientation and the $\{111\} / /$ RD fiber. The texture in the as-received state is shown in Figure 4.1, while the austenitic textures after straining a sample up to a martensite fraction of 0.7 is shown in Figure 4.7(a) for the RD case and Figure 4.7(b) in case of deformation in the TD.

The textures measured after deformation of Steel 2 in the RD and TD are both different from each other and from the original texture. From the two major texture components found in the starting texture, only the $\{111\} / / \mathrm{RD}$ grains are still present after deformation in the RD. The texture after straining in the TD, Figure 4.7(b), shows another texture, but most grains have orientations around an orientation with a $\{111\}$ direction parallel to the stress direction as well. 


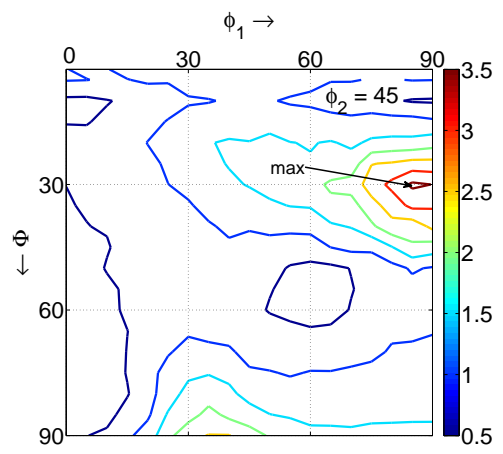

(a) $\mathrm{RD}$

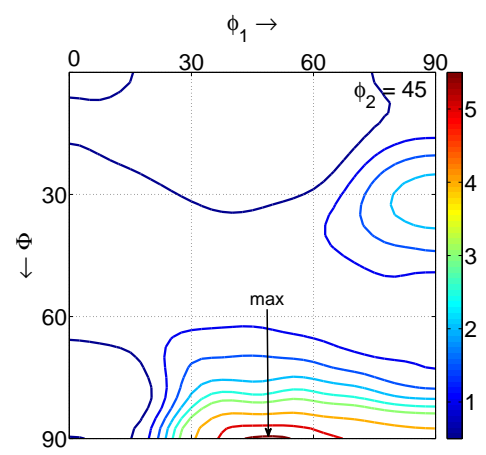

(b) TD

Figure 4.7: Measured austenitic texture after uniaxial deformation of Steel 2 in the $\mathrm{RD}(\mathrm{a})$ and TD $(\mathrm{b})$. Martensite fraction $\approx 0.8$ for a) and $\approx 0.7$ for $\mathrm{b}$ ).

\subsection{Texture Based Stress Induced Transforma- tion model}

The transformation model describing the austenite-martensite transformation according to the stress-induced transformation theory has been combined with the texture found in Steel 1 and Steel 2. In the first step of this Texture Based Stress Induced Transformation (TBSIT) model, the driving force per unit applied stress for all possible orientations of austenite crystals calculated as discussed in Section 3.5. This was done for various stress states in the RD and TD. The resulting plots of the driving force distribution are shown in Figure 3.7 .

The measured textures of both steels before deformation are used to model the overall transformation behavior of each steel as a function of the applied stress. For each possible crystal orientation, the driving force per MPa applied stress, calculated by Equation (3.5) and as represented by Figure 3.7, and the fraction of crystals with that orientation, as represented by the texture of the steel, are combined to determine the distribution of the driving force per $\mathrm{MPa}$ applied stress over all grains. Evidently, crystals with high driving forces, as visible in Figure 3.7, only contribute to the overall transformation if they are actually present in the steel as follows from its texture. 
The resulting driving force distributions are shown in Figure 4.8. In the case of no texture (Steel 1), the driving force distribution is independent of the sample orientation, and no difference in transformation behavior appears while applying a stress in the RD or in the TD. In the case of the textured steel (Steel 2 ), different driving force distributions are calculated when the stress state is in the $\mathrm{RD}$ or the TD. The difference in driving force distribution leads to a different overall transformation behavior. These distributions are different from the driving force distributions of the untextured sample as well. Due to the 90 degree rotation of the stress state, no difference between the RD and TD case is observed when applying a simple shear to the samples.

Subsequently, a transformation curve can be computed by increasing the applied stress and calculating the fraction of grains that have reached the critical energy barrier, assuming that grains surpassing this barrier transform fully into martensite. The results are plotted in Figure 4.8. For comparison purposes, the critical energy barrier is assumed to be equal for Steels 1 and 2, although from the experiments it is known that this is not the case. In Figure 4.9(a), the calculated transformation curves based on the three stress states and the untextured Steel 1 are shown, while Figure 4.9(b) shows the same for Steel 2.

\subsection{Discussion}

From the experiments and the modeling it is clear that the transformation and material behavior of the untextured Steel 1 are independent of the tensile direction, see Figures 4.5(a) and 4.9(a). It was found that this is not the case for the highly textured Steel 2. During deformation of this steel, the material behavior was different in the RD and TD, as can be seen clearly in Figures $4.5(\mathrm{~b})$ and $4.9(\mathrm{~b})$.

\subsubsection{Texture evolution}

The observed difference in material behavior of both steels can be explained by a difference in transformation behavior. This is evidenced by the austenitic textures measured after the uniaxial tensile tests, see Figures 4.6 and 4.7 for Steel 1 and 2, respectively. The figures show the remaining austenite grains after a significant amount of transformation has occurred. It indicates that the orientation of the grain has an influence on whether or not it transforms at a certain stress. All textures measured after deformation show that most grains have orientations around the fiber containing grains with a [111] direction 


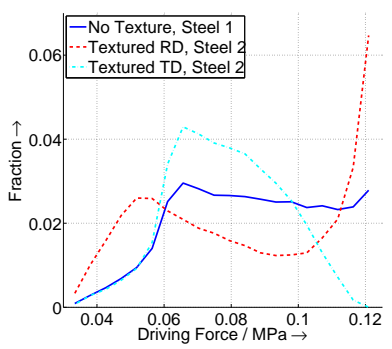

(a) Distribution uniaxial stress

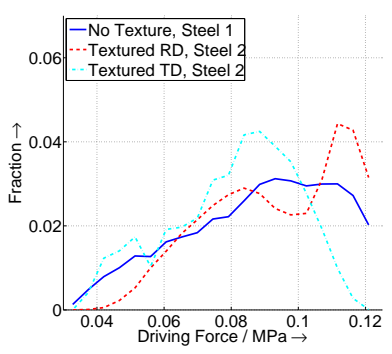

(c) Distribution Plane Strain

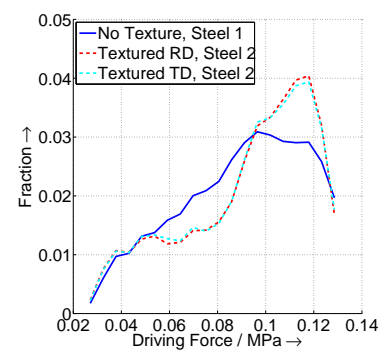

(e) Distribution Shear Strain

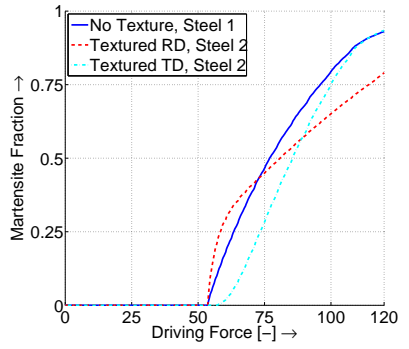

(b) Transformation curves uniaxial stress

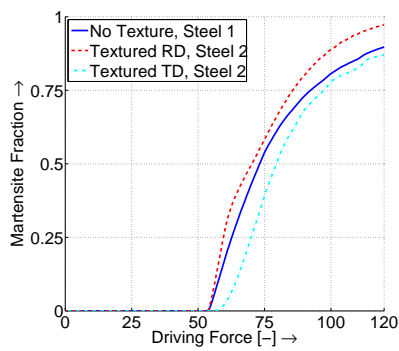

(d) Transformation curves Plane Strain

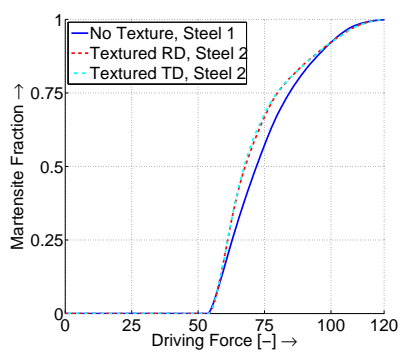

(f) Transformation curves Shear Strain

Figure 4.8: The distribution and the transformation curves from the model for both steels for different stress states calculated with the TBSIT model. The critical driving force is assumed to be equal in all cases. 


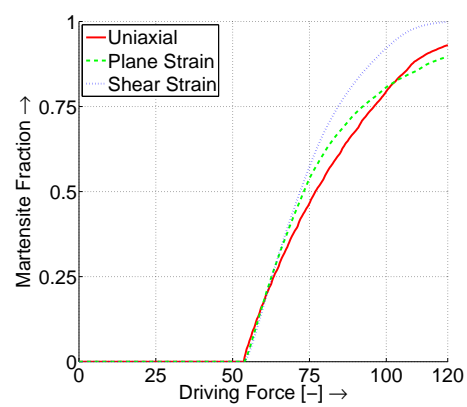

(a)

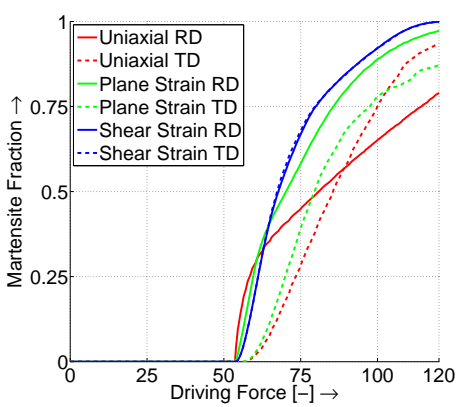

(b)

Figure 4.9: Modeled driving force curves for the different stress states for Steel 1 (a) and Steel 2 (b)

parallel to the stress direction.

When the calculations of the driving force, Figure 3.7, are compared to the measured textures after the corresponding deformation in Figures 4.6 and 4.7, it appears that these remaining grains have an orientation with a low driving force. The stress in the tensile test has not been high enough for these crystals to transform. Grains with a high driving force are not visible anymore in the texture plot, as these have already transformed to martensite at lower stress levels.

\subsubsection{Driving Force Distribution}

In general, the crystallographic texture of austenite changes during deformation by the rotation of grains $[54,55,56]$ as well as by transformation to martensite of preferred orientations. The contribution of deformation respectively trnasformation to the texture evolution can be investigated using the driving force distributions before and after deformation.

Based on crystal plasticity theory and experimental work, it is known that FCC grains will rotate during a uniaxial tensile test towards an orientation with either a [111] or a [100] direction parallel to the direction of the strain $[54,55,56]$. The stress-induced transformation theory states that grains with a [100] direction in the direction of the uniaxial stress have a high driving force, while grains with a [111] direction parallel to the stress have a low value. 
Thus, while deformation causes an increase in intensity around both orientations, transformation results in the decrease in one of the orientations while the other is unaffected. This difference in texture evolution due to deformation and transformation is used to evaluate the austenitic textures after deformation and determine whether transformation or deformation is the main cause of the texture evolution.

The distribution of the driving force over the grains before and after the experiments is shown in Figure 4.10(a) for Steel 1 and Figure 4.10(b) for Steel 2. These are calculated based on the measured texture after deformation (Figures 4.6 and 4.7) and the driving force distributions (Figures 3.7(a)and 3.7(a)).

The distributions after deformation in both the RD and TD direction of Steel 1 are similar. The amount of grains with a driving force per unit stress between 0.07 and 0.1 is reduced the most after the experiments. The corresponding grains are subjected to both transformation and a rotation toward either an orientation with a higher or lower driving force per unit stress. The fraction of grains with a low amount of driving force per unit stress $(<0.06)$ has increased due to the rotation of grains toward these orientations. The fraction of grains with a higher driving force value $(>0.11)$ has decreased, which is not expected when considering texture evolution due to plastic deformation alone. This indicates that the decrease of the amount of grains with a specific orientation by transformation has a larger influence on the texture compared with the effect of crystal rotations due to deformation.

The distributions based on the experiments of Steel 2 show a similar behavior. In the $\mathrm{RD}$ case most grains are already distributed around stable orientations, which results in a low amount of crystal rotations. In the distribution, the grains with a high driving force have disappeared. Since these grains have a [100] direction parallel to the stress, no rotation of the grains away from this orientation is expected and transformation into martensite is the cause of the texture evolution. The grains with a low driving force, around the [111] fiber, show no rotation due to plastic deformation and do not reach a driving force high enough for transformation.

In the TD case, a high degree of crystal rotations due to plastic deformation is expected, influencing the texture. Nevertheless, the grains rotating toward orientations with a high driving force have transformed and only a small amount of grains are observed around the high driving force orientations. The grains around low driving force orientations are unaffected by the transformation and deformation. 


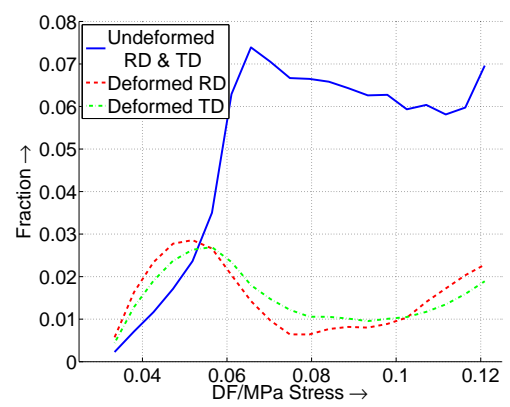

(a) Steel 1

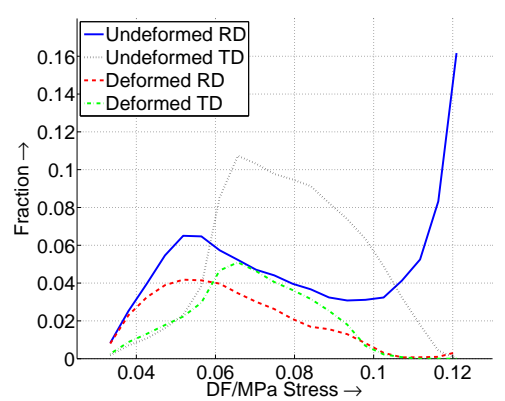

(b) Steel 2

Figure 4.10: Driving force distribution obtained before and after tensile tests

\subsubsection{TBSIT Model}

Combining the stress-induced transformation theory and the austenitic texture before deformation results in the Texture Based Stress Induced Transformation (TBSIT) model, see Section 4.4. The simulated stress versus martensite curves obtained with this model are shown in Figure 4.9(a) and 4.9(b). These compare well in a qualitative way with the measurements shown in Figure 4.5(a) and 4.5(b) for untextured and textured steel, respectively. For both steels the martensite fraction strongly increases with increasing applied stress.

For the untextured Steel 1 no direction dependency is present in the experimental results and the model, as explained above. Applying a plane strain, shear strain or uniaxial strain in either the RD or TD had no influence on the driving force at which the transformation starts: in all cases, some grains with the highest possible driving force are present.

However, in the case of the textured Steel 2, transformation seems to start at a lower global stress for the uniaxial and the plane strain RD case compared to the respective TD cases, Figure 4.5(b). From the model results of Figure 4.9(b) it is learned that the transformation of RD samples indeed starts at lower stress levels compared to the TD samples, and the initial rate of transformation for the RD samples is much larger, as reflected in the experimental results. Since transformation in the TD case starts at higher stresses, the martensite fraction will surpass the fraction in the RD case in both the model and experiments at some level of the applied stress. The simple shear experiment shows no difference 
in transformation behavior between the RD and TD case, and neither does the model.

For progressive stages of the transformation process the modeled behavior of the martensite fraction as a function of the applied stress deviates more and more from the experimentally observed ones. Apparently, for a fully quantitative description of the transformation behavior up to large degrees of transformation, the current model should be further extended to include factors that influence the transformation and deformation behavior. These factors are the occurrence of crystallographic slip, the contribution of transformation strain, the stepwise transformation of an austenite grain to martensite and the redistribution of stress and strain fields over the martensite and austenite phases. The extension of the model will be the subject of Chapter 5. Nevertheless, the proposed relatively simple model is capable enough of explaining the overall transformation behavior and its dependency on the initial austenite texture in a semi-quantitative way.

\subsection{Summary}

In this chapter, two metastable austenitic stainless steels were subjected to various strains in the Rolling Direction (RD) and Transverse Direction (TD). It was found that the transformation behavior of an untextured steel is independent of the deformation direction, whereas by deforming a textured steel this was not the case.

A study of the austenitic textures after deformation showed that the austenitic grains remaining in the texture have orientations with a low calculated driving force, as expected from the stress-induced transformation model.

The Texture Based Stress Induced Transformation (TBSIT) model was constructed by combining the stress-induced transformation theory with the austenitic texture of a steel before deformation. This model is capable of accurately predicting the transformation behavior of a steel at low martensite fractions. A more refined model, capable of predicting the transformation behavior up to higher martensite contents, is presented in the next chapter. 


\section{Chapter 5}

\section{Influence of texture evolution on transformation}

The Texture Based Stress Induced Transformation (TBSIT) model, developed in Section 4.4, is capable of describing the overall transformation behavior and its dependency on the initial austenite texture in a semi-quantitative way. While the start of the transformation is predicted accurately, the model diverges from experimentally obtained results at higher martensite fractions.

A more advanced model is required to quantitatively describe the material behavior in various industrial forming processes in which a high amount of transformation occurs. Several micro-mechanical models exist that can simulate the effect of the stress direction on the transformation, see e.g. [57, 58]. However, these models have not been used to simulate the strain direction dependency of the transformation in textured metastable austenitic stainless steels.

To investigate the strain direction dependency of the transformation in textured polycrystalline austenitic stainless steels, a new model was developed. Since the TBSIT model showed good results predicting the start of the transformation, this is chosen as a base for the new model. The most important mechanisms required for an accurate transformation behavior during a mechanical deformation process were included. These will be discussed in the next section. These mechanisms have an influence on the transformation behavior and/or the texture evolution during the deformation of a steel. A number of simulations are performed to investigate the effects of these mechanisms. These simulation results of the extended model are presented in Section 5.2. 
Validation of the simulations was done by performing dedicated experiments at various temperatures. At different temperatures, different mechanisms are dominant during the experiments. These experiments for validation of the model, as well as experiments at room temperature during which all the mechanisms in the model are active, are presented in Section 5.3. A comparison between simulations and experiments is provided in Section 5.4.

\subsection{Extended macro-mechanical transformation model}

Based on the TBSIT model, a more refined model is developed. Besides the mechanisms already present in the TBSIT model, such as the presence of texture and stress-induced transformation, additional mechanisms associated with the mechanical deformation process are included.

The mechanisms implemented in the new model are:

1. Initial austenite texture

a) Representation of the austenite texture by a finite number of grains

2. Stress-induced transformation behavior of individual grains

a) The thermodynamic driving force supplied by applied stress

b) Partial transformation of a grain due to constraint by the environment

c) Transformation strain

3. Plastic deformation of grains

a) Interaction between grains by the Voigt-Taylor constraint

b) Homogenization of applied strain

c) Isotropic elasto-plastic deformation of a grain

d) Rotations of the grains due to crystallographic slip associated with plastic deformation

In the current extended model, some additional mechanisms for the description of the transformation behavior have been implemented compared to the TBSIT model. Firstly, the transformation of an austenite grain is restricted to 
part of the grain only, contrary to the TBSIT model where full transformation of a grain takes place once the critical driving force was reached. This partial transformation is observed in experiments performed by several authors, i.e. $[47,59,60,61]$. It is assumed that this partial transformation is caused by the constraint by the environment of a grain. Implementing this stepwise transformation of grains in the model will yield a more realistic transformation behavior up to higher martensite fractions.

Transformation from the austenite to the martensite phase is accompanied by a transformation strain, which is also implemented in the model. This transformation plasticity causes stress relaxation in the transforming grain.

Secondly, plastic deformation is incorporated in the extended model as well. Since, due to the partial transformation behavior, a grain can consist of both austenite and the harder martensite, the strain applied on the grains must be distributed over the two phases, which is accomplished by using a homogenization scheme.

The crystallographic slip, which occurs during plastic deformation, results in a rotation of the crystal lattice. Since the orientation of a grain determines to a large extent the transformation behavior of the grain, this effect is incorporated as well.

Finally, an interaction between the grains is implemented. If a grain transforms, the transformation strain not only has an influence on the grain itself but, due to the Voigt-Taylor constraint, also on the surrounding grains. This changes the stress state and thus the transformation behavior of the surrounding grains.

\subsubsection{General Overview}

The new model requires several input parameters. These are

\section{Material Parameters}

a) The critical driving force $U_{c r}$ at which transformation occurs.

b) The fraction of the austenite grain transforming into martensite once the critical driving force is reached in that grain. This fraction is designated with $\mu_{f}$.

c) The material properties of the austenite and martensite phase, expressed in the parameters used in the Swift hardening law.

d) An ODF describing the starting texture in the austenite phase. 


\section{Process Parameters}

a) The prescribed global stress state (e.g. uniaxial stress, plane stress, shear stress, etc.).

Figure 5.1 shows a flow diagram of the model. After an initiation step, a simulation procedure starts where during each simulation cycle a strain increment is calculated and applied. Each step in the simulation cycle is discussed below.

In the initiation step of the model, the material is represented by a finite number of grains. Each of these grains has an orientation, expressed by Euler angles $\left[\phi_{1} \Phi \phi_{2}\right]$ with respect to an external coordinate system, see Figure 2.3, such that together, they represent the austenitic texture provided by the ODF. The discretization scheme used in this work is discussed in Section 5.1.2. It is assumed that all grains undergo the same strain (Voigt-Taylor constraint). Therefore, the locations of the grains with respect to each other are not relevant. Since the strains in all grains are equal, there is no direct interaction between grains when transformation occurs in a grain. Instead the global average stress is used for an interaction mechanism, as will be discussed later.

The strain increment $\mathrm{d} \varepsilon$ is divided in two parts: a prescribed part $\mathrm{d} \varepsilon_{0}$ and an unknown part $\mathrm{d} \varepsilon_{1}$. Strain $\mathrm{d} \varepsilon_{0}$ is the strain imposed by the type of simulation (e.g. uniaxial, plane, shear) and is applied to the grains in the first step in the simulation cycle.

The average stress over all grains during a simulation must agree with the type of simulation performed and is prescribed at the beginning of the simulation. The unknown part of the strain increment, $\mathrm{d} \varepsilon_{1}$, follows from this prescribed stress state. This is calculated in step two of the simulation cycle. Now, the total strain increment $\mathrm{d} \varepsilon$ is known.

In step three of the cycle it is determined whether a grain can transform from the austenite to the martensite phase given the strain increment $\mathrm{d} \varepsilon$. This is based on the criterion for transformation provided by the stress-induced transformation theory, which was discussed in Section 3.3. The criterion for transformation, provided by this theory, is based on the stress in the austenite phase of the grain. To calculate this stress, the strain increment in the austenite phase must be calculated first. At the start of the simulation, all grains are austenitic. Therefore, the strain in the austenite is equal to the strain increment $\mathrm{d} \varepsilon$, determined in step one. At later stages, when part of a grain has transformed into the martensite phase, the strain in the grain is distributed over both phases. The martensite has different mechanical properties from the austenite phase, and 


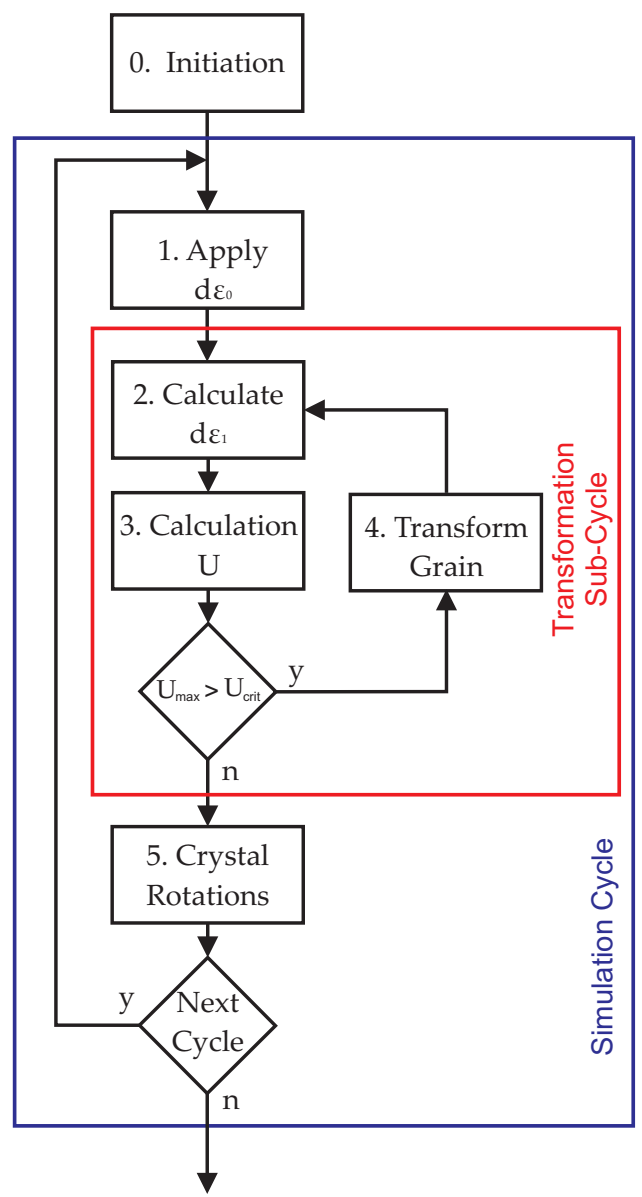

Figure 5.1: Flow diagram of the model. 
the strain in the two phases is, in general, not equal when plastic deformation occurs in one or both of the phases. To calculate the strain distribution over the phases, a homogenization scheme is used, which is discussed in Section 5.1.3. After the strain in the austenite phase of the grain is determined, the stress is calculated using a return mapping algorithm and the Swift hardening law. This method for calculation of the stresses in the phases provides sufficiently accurate results within an acceptable calculation time. Based on the thus obtained stress and the stress-induced transformation theory, the driving force acting on all grains is calculated for the strain increment $\mathrm{d} \varepsilon$.

If no grains can transform in the current simulation cycle, the simulation continues directly to step five. If the driving force in a grain reaches the critical value $U_{c r}$ and transformation will occur, first a sub cycle is started calculating the transformation of the grain. Multiple grains can be viable for transformation, but only the grain with the highest driving force is considered for transformation in each sub cycle in step four of the model. A fraction $\mu_{f}$ of the austenite phase in the grain transforms into martensite. The strain increment for all grains is the same, as imposed in step one and two of the simulation. Therefore, the strain accompanying the transformation must be compensated by an opposite strain in the rest of the grain. This reduces the stress in - and thus the transformation potential of - the grain. The theory and procedure of transformation are discussed in Section 5.1.5.

Due to the transformation of part of the grain, the stresses in the grain are changed. This has an influence on the average stress over all grains. The strain increment $\mathrm{d} \varepsilon_{1}$ is adjusted and recalculated such that the strain increment results in the prescribed global stress state. The new strain increment results in different stresses in the grains and thus the driving force in the grains changes. This way, transformation in a grain has an influence on the transformation behavior of the other grains and interaction between grains is incorporated.

The sub-cycle containing step two, three and four of the simulation is repeated until no more grains transform during the current strain increment. At this point, all strains in the austenite phase of the grains are known, and the rotation of the austenite crystal lattice, caused by crystallographic slip occurring during plastic deformation, can be calculated in step five. The model implemented to describe the grain rotations is discussed in Section 5.1.6.

The calculation of the crystal rotation concludes the simulation cycle and a new simulation cycle is started with a new strain increment. This is repeated until the desired final strain path is obtained according to the required mechanical deformation process. The next sections will discuss several parts of the model in detail. 


\subsubsection{Discretization}

The ODF of the austenitic texture is discretized to obtain the orientations of the grains used in the simulation. Several different discretization schemes are available from the literature $[15,16,17]$, as discussed in Section 2.4.

The discretization scheme employed in the model is found in [17]. Using this scheme, all grains have the same volume, which results in a high number of grains at high intensity orientations in the ODF, opposed to a grain at each point in the ODF with a volume relative to the intensity of the ODF at that point.

While the method used requires more grains to represent a texture, it provides a more realistic representation of the material. This is required in the model since, due to the interaction between grains when transformation occurs, a single large grain behaves differently compared to a number of grains with the same orientation. Therefore, the discretization result is the most realistic representation of the material is chosen.

\subsubsection{Homogenization}

When two phases in a grain have different material properties, the stresses and strains in the phases will differ. A homogenization scheme provides the strain distribution between the phases.

In the homogenization model, the strain concentration tensor $\mathcal{A}$ is used to calculate the distribution of the applied strain increment $\mathrm{d} \varepsilon$ over both phases. The average strain in the martensite phase, $\langle\mathrm{d} \varepsilon\rangle_{\alpha^{\prime}}$, is obtained by

$$
\langle\mathrm{d} \varepsilon\rangle_{\alpha^{\prime}}=\mathcal{A}: \mathrm{d} \varepsilon
$$

while the average strain in the austenite phase is calculated with

$$
\langle\mathrm{d} \varepsilon\rangle_{\gamma}=\frac{1}{1-f}(\mathbb{I}-f \mathcal{A}): \mathrm{d} \varepsilon
$$

with $f$ the martensite fraction in the grain and $\mathbb{I}$ the $4^{\text {th }}$ order identity tensor. The strains in the martensite phase are related to the strains in the austenite phase by

$$
\langle\mathrm{d} \varepsilon\rangle_{\alpha^{\prime}}=(1-f) \mathcal{A}:(\mathbb{I}-f \mathcal{A})^{-1}:\langle\mathrm{d} \varepsilon\rangle_{\gamma}=\hat{\mathcal{A}}:\langle\mathrm{d} \varepsilon\rangle_{\gamma} .
$$

The strain concentration tensor determines the strain distribution. The two extremes for such a distribution are the Voigt (equal strain) and the Reuss (equal stress) distributions. According to Eshelby's solution for a matrix containing an 
inclusion, a realistic strain distribution lies between these two extremes $[62,63]$. Models using Eshelby's solution show that at low martensite fractions the Reuss model is approached, while at higher fractions the strain concentration is more similar to the Voigt model. The Bound-Interpolation scheme [64] provides an interpolation between the Voigt and the Reuss models. The strain concentration tensor becomes

$$
\hat{\mathcal{A}}=\left[\phi(f) \mathbb{I}+(1-\phi(f)) \mathcal{C}_{\gamma}^{e p-1}: \mathcal{C}_{\alpha^{\prime}}^{e p}\right]^{-1}
$$

with $\mathcal{C}^{e p}$ the respective elastic-plastic material stiffness tensors. The interpolation function $\phi$ is used as proposed by Lielens [65]:

$$
\phi(f)=\frac{f+f^{2}}{2} .
$$

The bound interpolation scheme shows a good approximation of the physically based models with low computation time.

It is assumed that the austenite and martensite phase have the same elastic stiffness. Therefore, in the elastic regime, the strains in both phases are equal. In the plastic regime, the softer phase is relatively strained more, whereas the harder phase is stressed more.

\subsubsection{Stress-induced transformation}

Transformation is, like in the TBSIT model, described by the stress-induced transformation theory. This theory has been discussed in Section 3.3. It states that once the driving force $U$, depending on the stress and the orientation of an austenite grain, reaches a critical driving force $U_{c r}$, transformation occurs. Transformation will only occur according to the variant $i$ with the highest driving force. Thus, for each grain of a polycrystalline material it holds that

$$
U\left(\boldsymbol{\sigma}_{\gamma}, \phi_{1}, \Phi, \phi_{2}\right)=\max _{i}\left(U^{i}\left(\boldsymbol{\sigma}_{\gamma}, \phi_{1}, \Phi, \phi_{2}\right)\right) .
$$

The relation between the orientation of a grain and the applied stress can be displayed by showing a slice of the Euler space, see Section 2.3. The results from uniaxial tensile tests in the RD and TD will be presented in Section 5.3 to validate the model developed in this chapter. The driving force per unit stress for these two cases is plotted in Figure 3.7(a) and 3.7(b). 


\subsubsection{Transformation}

The transformation procedure is as follows. A strain increment $\mathrm{d} \varepsilon$ is applied to the grain, as shown in Figure 5.2a. From this strain increment a stress increment is calculated. If the driving force of the grain reaches the critical driving force $U_{c r}$, transformation occurs. While the average transformation strain is in the direction of the deviatoric stress, as stated in Section 3.4.2, the transformation in an individual grain is not.

Equation A.29 shows the deformation gradient of the transformation for each variant $i$ as

$$
F_{t r}^{i}=\mathbf{I}+\boldsymbol{s}^{i} \otimes \boldsymbol{n}^{i}
$$

When austenite transforms unconstrained into martensite according to variant $i$, a transformation strain

$$
\boldsymbol{\varepsilon}_{t r}^{i}=\frac{1}{2}\left[\boldsymbol{s}^{i} \otimes \boldsymbol{n}^{i}+\boldsymbol{n}^{i} \otimes \boldsymbol{s}^{i}\right]
$$

occurs. In general in a polycrystalline material, only a fraction $\mathrm{d} f$ of the austenite phase is transformed at once, as shown in Figure 5.2b. In the model it is assumed that when transformation occurs, a fixed fraction $\mu_{f}$ of the remaining austenite in the grain transforms:

$$
\mathrm{d} f=\left(1-f^{n}\right) \mu_{f},
$$

with $f^{n}$ the volume fraction of martensite in the grain at the start of the simulation cycle. The martensite fraction after transformation, $f^{n+1}$, becomes

$$
f^{n+1}=f^{n}+\mathrm{d} f .
$$

The average transformation strain in the grain in this increment now becomes

$$
\mathrm{d} \varepsilon_{t r}=\varepsilon_{t r} \mathrm{~d} f .
$$

The stress in the newly formed martensite is initially assumed to be equal to the stress in the parent phase. Then a transforming grain consists of austenite, newly formed martensite and possibly also martensite that has been formed earlier during the process. In the model, the average stress in the martensite is obtained by averaging the stresses in the newly formed and already existing martensite. Moreover, newly formed martensite is assumed to initially be unstrained. Hence, the average stress and the equivalent strain in the martensite 
phase become

$$
\begin{aligned}
\boldsymbol{\sigma}_{\alpha^{\prime}} & =\frac{f^{n} \boldsymbol{\sigma}_{\alpha^{\prime}}+\mathrm{d} f \boldsymbol{\sigma}_{\gamma}}{f^{n+1}} \\
\varepsilon_{\mathrm{eq}, \alpha^{\prime}} & =\frac{f^{n} \varepsilon_{\mathrm{eq}, \alpha^{\prime}}}{f^{n+1}} .
\end{aligned}
$$

It can also be observed from Figure 5.2b that the strain of a grain in which transformation occurs is now a combination of the strain increment $\mathrm{d} \varepsilon$ and the transformation strain $\mathrm{d} \varepsilon_{t r}$. As stated in section 5.1.1, all grains are assumed to have the same deformation. Therefore, if transformation occurs in a grain, the average deformation of the grain must remain the same. As a result, the transformation strain must be compensated by an inverse strain $-\mathrm{d} \varepsilon_{t r}$ in the remainder of the grain, as shown in Figure 5.2c.

After transformation, the stress in the austenite phase of the grain decreases due to the transformation strain. As a result, the driving force of the grain is decreased and transformation in the grain does not occur until enough additional strain is applied such that the driving force again reaches $U_{c r}$.

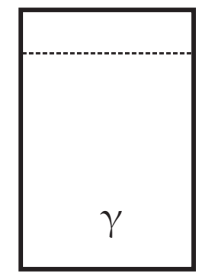

(a)

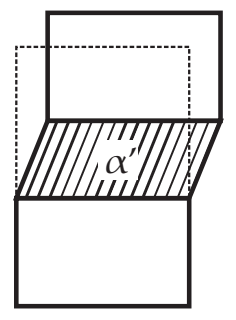

(b)

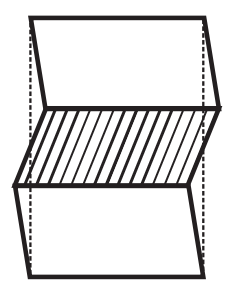

(c)

$$
<\varepsilon>=\varepsilon_{0}+\mathrm{d} \varepsilon \quad\left\langle\varepsilon>=\varepsilon_{0}+\mathrm{d} \varepsilon+\mathrm{d} \varepsilon_{\mathrm{tr}} \quad\left\langle\varepsilon>=\varepsilon_{0}+\mathrm{d} \varepsilon\right.\right.
$$

Figure 5.2: Schematic overview of the steps of the austenite to martensite transformation of part of a grain in the model. (a) The grain before the transformation when the strain increment $\mathrm{d} \varepsilon$ is applied, (b) the grain after unconstrained transformation of a fraction $\mu_{f}$ and (c) the grain when the average strain in the transformed grain is equal to that in the untransformed grain (c). Angular brackets $\langle\cdot\rangle$ denote the average strain. 


\subsubsection{Crystal Rotations}

The rotation of the crystal lattice due to crystallographic slip is calculated at the end of each simulation cycle, when all strains to which the austenite phase is subjected are known. Due to the Taylor-Voigt constraint applied in the model, the Taylor-Bishop-Hill (TBH) model for crystallographic slip is used $[56,66]$ instead of more advanced models which take the interaction between grains into account, see $[67,68,69]$. While the TBH model can also provide a stress, in the simulations the model is only used for the update of the crystal orientation.

Table 5.1: Slip systems in FCC materials

\begin{tabular}{|c|c|c|c|c|}
\hline Pla & (111) & (111) & (111) & (111) \\
\hline $\begin{array}{l}\text { Slip Increment } \mathrm{d} \gamma \\
\text { Slip Direction } \boldsymbol{b}\end{array}$ & $\begin{array}{ccc}a_{1} & a_{2} & a_{3} \\
{[0 \overline{1} 1]} & {[10 \overline{1}]} & {[\overline{1} 10]}\end{array}$ & $\begin{array}{ccc}b_{1} & b_{2} & b_{3} \\
{[011]} & {[\overline{1} 0 \overline{1}]} & {[1 \overline{1} 0]}\end{array}$ & $\begin{array}{ccc}c_{1} & c_{2} & c_{3} \\
{[0 \overline{1} 1]} & {[\overline{1} 0 \overline{1}]} & {[110]}\end{array}$ & $\begin{array}{ccc}d_{1} & d_{2} & d_{3} \\
{[011]} & {[10 \overline{1}]} & {[\overline{1} \overline{1} 0]}\end{array}$ \\
\hline
\end{tabular}

In FCC crystals there are 12 possible slip systems consisting of a slip plane and a slip direction, which are shown in Table 5.1. The strain increment of the grain can be expressed on these slip systems as

$$
\mathrm{d} \varepsilon^{p}=\sum_{k=1}^{12} \frac{1}{2}\left(\boldsymbol{b}^{k} \otimes \boldsymbol{m}^{k}+\boldsymbol{m}^{k} \otimes \boldsymbol{b}^{k}\right) \mathrm{d} \gamma^{k}
$$

where $\boldsymbol{m}^{k}$ is the slip plane normal and $\boldsymbol{b}^{k}$ the slip direction of the $k^{\text {th }}$ slip system. The slip increment of the $k^{t h}$ system is represented by $\mathrm{d} \gamma^{k}$. Now, the strain increment tensor $\mathrm{d} \varepsilon$ can be expressed in terms of slip increments,

$$
\begin{gathered}
\sqrt{6} \mathrm{~d} \varepsilon_{11}^{p}=a_{2}-a_{3}+b_{2}-b_{3}+c_{2}-c_{3}+d_{2}-d_{3} \\
\sqrt{6} \mathrm{~d} \varepsilon_{22}^{p}=-a_{1}+a_{3}-b_{1}+b_{3}-c_{1}+c_{3}-d_{1}+d_{3} \\
\sqrt{6} \mathrm{~d} \varepsilon_{33}^{p}=a_{1}-a_{2}+b_{1}-b_{2}+c_{1}-c_{2}+d_{1}-d_{2} \\
2 \sqrt{6} \mathrm{~d} \varepsilon_{23}^{p}=-a_{2}+a_{3}+b_{2}-b_{3}-c_{2}+c_{3}+d_{2}-d_{3} \\
2 \sqrt{6} \mathrm{~d} \varepsilon_{31}^{p}=a_{1}-a_{3}-b_{1}+b_{3}-c_{1}+c_{3}+d_{1}-d_{3} \\
2 \sqrt{6} \mathrm{~d} \varepsilon_{12}^{p}=-a_{1}+a_{2}-b_{1}+b_{2}+c_{1}-c_{2}+d_{1}-d_{2}
\end{gathered}
$$

where $a_{1} \cdots d_{3}$ are the slip increments of the corresponding slip system as shown in Table 5.1. The deformation tensor consists of five independent components. 
As a result, the strain increment can be described by 384 independent combinations of five slip systems. It is assumed that only the set with the lowest plastic work increment, $\mathrm{d} w$, is active. The plastic work increment can be calculated by

$$
\mathrm{d} w=\sum_{j}^{5}\left(\tau^{c} \mathrm{~d} \gamma\right)_{j},
$$

where $\tau_{j}^{c}$ is the critical strength of the $j^{t h}$ slip system. In the case where several sets of slip systems have the same plastic work increment, the average slip criterion is adopted [70]. The criterion states that when $n$ sets have the same work increment, the slip increment of the $k^{t h}$ slip system becomes the average over these $n$ sets of slip systems:

$$
\mathrm{d} \gamma^{k}=\frac{1}{n} \sum_{1}^{n} \mathrm{~d} \gamma_{n}^{k}
$$

Now, the slip increments on all slip systems are known, the lattice spin $L_{s}$ can be calculated by:

$$
L_{s}=\sum_{k=1}^{12} \frac{1}{2}\left(\boldsymbol{b}^{k} \otimes \boldsymbol{m}^{k}-\boldsymbol{m}^{k} \otimes \boldsymbol{b}^{k}\right) \mathrm{d} \gamma^{k} .
$$

The critical strength $\tau^{c}$ of a slip system has a large influence on the plastic work increment calculated in Equation (5.16). When slip occurs on a slip system, not only does the critical strength of that slip system increase, but the slip has an influence on the other slip systems as well. There are several hardening theories available describing this interaction mechanism [55]. In this work, the hardening model developed by Pierce, Asaro and Needleman, the PAN rule, has been implemented [71]. This hardening model shows the best performance for the texture development based on experiments performed in this work. It states that the hardening of the $k^{t h}$ system can be calculated by

$$
\mathrm{d} \tau_{k}^{c}=\sum_{j}\left(h-\operatorname{tr}\left(N_{k} \cdot \boldsymbol{\sigma}_{\gamma} \cdot \Omega_{j}\right)-\operatorname{tr}\left(\Omega_{k} \cdot \boldsymbol{\sigma}_{\gamma} \cdot N_{j}\right)\right) \mathrm{d} \gamma_{j},
$$

where $h$ is a hardening parameter, $N_{k}=\operatorname{sym}(\boldsymbol{b} \otimes \boldsymbol{m})_{k}$ and $\Omega_{k}=\operatorname{skw}(\boldsymbol{b} \otimes \boldsymbol{m})_{k}$.

In the case of a uniaxial tensile strain, the implemented crystal rotation model described in this section results in a rotation of grains towards orientations with a $\langle 111\rangle$ or a $\langle 100\rangle$ direction in the strain direction. This behavior has also been observed in the experiments, which will be described in Section 5.3.2. 


\subsection{Simulations}

In this section several simulations of a metastable austenitic stainless steel will be presented to investigate the effect of various implemented theories in the model. The texture of the austenitic stainless steel employed in this chapter is the same as in Chapter 4. A slice of the Euler space showing the texture before deformation is shown in Figure 4.1. It is discretized according to the method described in Sections 2.4 and 5.1.2. The resulting 4000 orientations are used in all simulations.

For the material behavior of the austenite and martensite phase, $\mathrm{J}_{2}$ plasticity is assumed and the hardening is described by the Swift hardening law:

$$
\sigma^{f}=\sigma^{0}+K\left(\varepsilon^{0}+\varepsilon^{p}\right)^{m}
$$

where $\sigma^{f}$ is the flow stress and $\varepsilon^{p}$ the plastic strain. The values of the material parameters $\sigma^{0}, K, \varepsilon^{0}$ and $m$ are presented in Table 5.2.

The following simulations will be considered. First, the relation between the implemented - partial - transformation behavior and the orientation of a grain is investigated in Section 5.2.1. Second, the influence of both implemented mechanisms of austenitic texture evolution, transformation and crystal rotations due to plastic deformation, are investigated by performing simulations in which only one of these mechanisms is active. Results are discussed in Section 5.2.2.

The texture evolution observed in these simulations can be verified by performing experiments at relatively high or low temperatures with respect to the $M_{s}$ temperature. At high temperatures, the austenite phase is plastically deformed and no transformation occurs, while at low temperatures transformation starts during the elastic loading of the samples. The results from these experiments will be discussed in Section 5.3.

Finally, a simulation incorporating both mechanisms was performed to simulate the material behavior during experiments at room temperature. The stressstrain response, transformation behavior and texture evolution are presented in Section 5.2.3 and will be compared with experiments in Sections 5.3 and 5.4. The effect of the value of the critical driving force and the parameter $\mu_{f}$ is discussed in Section 5.2.3 as well. 


\subsubsection{Individual Grain Behavior}

As discussed in Section 5.1, due to the constrained behavior of a grain, only part of the austenite phase in a grain generally transforms once the critical driving force is reached. The strain accompanying this partial transformation will relax the stress in the remaining austenite phase of the grain, resulting in a lower mechanical driving force. Transformation of the grain can start again if additional strain on the grain is applied such that the critical driving force is reached again. To investigate this behavior, a simulation of a uniaxial tensile test in the RD is simulated. The texture used in this simulation is described by 4000 orientations of grains. The transformation behavior of two grains, one with a 'Goss' and one with a 'Copper' orientation, is monitored. Grains with a $\langle 100\rangle$ direction in the direction of the applied uniaxial stress, i.g. the 'Goss' orientation, transform at low stresses while grains with a $\langle 111\rangle$ direction in the direction of the applied uniaxial stress, such as the 'Copper' orientation, require a high stress before transformation can occur. This also is clear in the driving force plot from Figure 3.7(a). The 'Goss' orientation, with the Euler angles [90 90 45], is subjected to a high driving force while the 'Copper' orientation, [90 3545$]$, is subjected to a low one.

The driving force in the austenite phase of the two grains during the simulation is shown in Figure 5.3(a). The development of the martensite fraction in the grains is shown in Figure 5.3(b). It is assumed that the critical driving force has a value of $58 \mathrm{MPa}$ as indicated by the dotted horizontal line in Figure 5.3(a). This value for the critical driving force is based on experiments described in Chapter 4. Each time the critical driving force $U_{c r}$ is reached in a grain, $7 \%$ of the remaining austenite in that grain transforms to martensite (i.e. $\mu_{f}=0.07$, see Equation (5.9)).

The results of the tensile test simulation show that, as soon as the grain with the 'Goss' orientation reaches the critical driving force, transformation occurs, which results in a strong decrease of the stress and therefore the driving force. If the tensile test is continued and more strain is applied, it results again in an

Table 5.2: Material parameters for the austenite and martensite phases at room temperature [72].

\begin{tabular}{|c|c|c|c|c|c|c|}
\hline Phase & $E(\mathrm{GPa})$ & $\nu$ & $\sigma^{0}(\mathrm{MPa})$ & $\varepsilon^{0}$ & $K(\mathrm{MPa})$ & $m$ \\
Austenite & 210 & 0.3 & 280 & 0.01 & 1000 & 0.51 \\
Martensite & 210 & 0.3 & 800 & 0.001 & 1000 & 0.07 \\
\hline
\end{tabular}


increase of the driving force. Due to the interaction of the grains, discussed in section 5.1.1, additional stress components are introduced in all other grains. This is visible in the driving force evolution in the grain with the 'Copper' orientation as an increase in driving force once transformation occurs in the other grains. It results in a stronger increase than expected in the driving force in the grain with the 'Copper' orientation based on the development of the overall stress state.

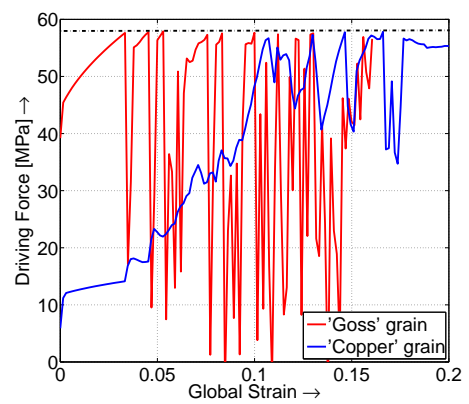

(a)

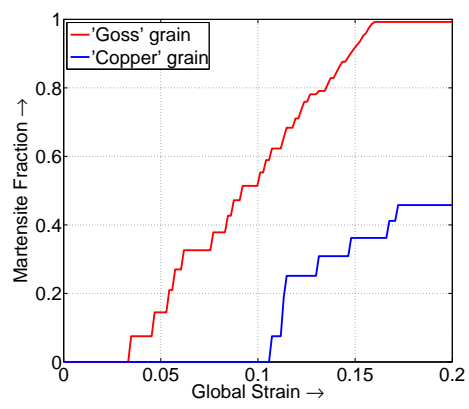

(b)

Figure 5.3: Simulated development of the driving force (a) and martensite fraction (b) of two grains, one with a 'Goss' orientation and one with a 'Copper' orientation.

\subsubsection{Simulated Texture Evolution}

The austenitic texture has a large influence on the transformation behavior in metastable austenitic stainless steels as observed during the experiments described in Chapter 4. The correct prediction of the texture evolution is important in the simulations when an accurate transformation behavior is required. As discussed in Section 5.1, the two mechanisms causing austenitic texture evolution in the model are the disappearance of austenite grains from the texture due to transformation into martensite and the grain rotations due to crystallographic slip. The effects of the two mechanisms on the austenitic texture are simulated separately for the case of uniaxial tensile tests in the RD and TD. The measured texture of the austenite shown in Figure 4.1 is used as a starting texture for the simulations. 


\section{Texture evolution due to transformation only}

During transformation, part of an austenite grain transforms into martensite. The transformation results in a corresponding reduction of intensity in the ODF at the orientation of the transforming grain. In this way, the austenite texture evolves, as grains disappear and the martensite texture develops concomitantly due to the appearance of grains. Here, only the austenitic texture is considered. According to the implemented stress-induced transformation theory, whether a grain transforms or not depends on the orientation, stress state and magnitude of the stress as discussed in Section 5.1.4. In the simulations, the influence of the transformation alone on the austenitic texture can be investigated by decreasing the critical driving force at which transformation occurs, representing low temperature tests. If the critical driving force is reached in the elastic regime and the applied stress is kept below the austenitic flow stress, no plastic deformation occur and thus no crystal rotations due to crystallographic slip occurs. During the simulations, the stress was increased up to the point where $20 \%$ of the austenite was transformed, while no crystallographic slip had occurred. Results of the simulations in the RD and TD are presented in Figure 5.4(a) and $5.4(\mathrm{~b})$, respectively.

The simulated textures, after applying a stress in the RD, show a decrease in intensity around the $\langle 100\rangle / / \mathrm{RD}$ oriented grains, reflected in the $\phi_{2}=45^{\circ} \mathrm{ODF}$ slice as a decrease around [90 90 45], the 'Goss' orientation. This indicates a significant amount of transformation in grains with these orientations. The grains with a $\langle 111\rangle$ direction in the stress direction, such as the grains around [90 35 45], show no transformation. The driving force distribution as plotted in Figure 3.7(a) shows that this is the expected behavior according to the stressinduced transformation theory: the grains around [90 90 45] experience a high driving force and thus transform at low stresses, whereas those around [90 35 45] have a very low driving force and remain untransformed as indicated by the high intensity which remains around this orientation in the ODF of Figure 5.4(a).

The texture after applying a stress in the TD (Figure 5.4(b)) is similar to the starting texture (Figure 4.1). This can be explained by comparing the driving force distribution for this case, Figure 3.7(b), with the starting texture. This comparison shows that the main texture components have approximately an equal, but low, driving force. Hence, most transformation comes from grains with different orientations from the main texture components and the main features of the texture are preserved. 


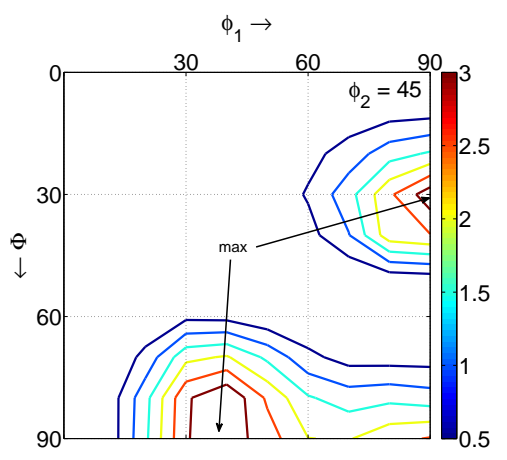

(a)

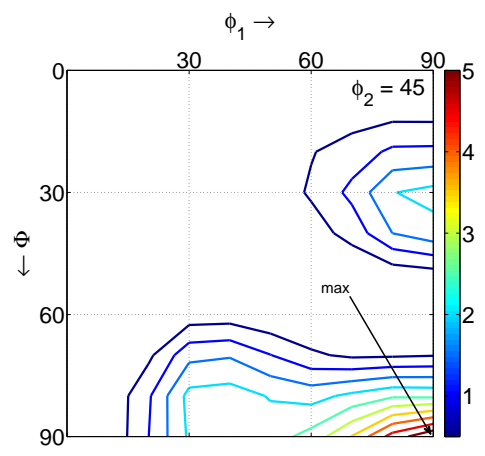

(b)

Figure 5.4: The $\phi_{2}=45^{\circ}$ section of the Euler space showing the simulated austenitic texture after $20 \%$ transformation when applying a uniaxial stress in $\mathrm{RD}$ (a) and TD (b), obtained without plastic deformation for a metastable austenitic stainless steel.

\section{Texture evolution due to deformation only}

The crystallographic slip occurring during plastic deformation can cause a rotation of austenite grains, which will be observed as an evolution of the crystallographic texture. In the simulations, the critical driving force is set artificially to such a high value that no transformation occurs. Figures 5.5(a) and 5.5(b) show the austenitic texture after a simulated uniaxial tensile test in the RD and TD, respectively. Both textures are obtained after a total strain of $20 \%$ has been applied.

In the case of deformation in the $\mathrm{RD}$, both main texture components found in the starting texture remain present in the sample, as can be observed by comparing Figures 5.5(a) and 4.1. After the simulation of the tensile test, the intensity around the texture components has even increased, indicating a further sharpening of the existing texture.

The austenite texture after deformation in the TD does not resemble the starting texture any more as can be observed by comparing Figures 4.1 and $5.5(\mathrm{~b})$. In this case, only a small number of grains was oriented according to stable orientations in the starting texture and a high amount of crystal rotation 
occurred during the simulated tensile test.

The observed texture evolution from the simulation agrees with the implemented Taylor-Bishop-Hill model in combination with the PAN hardening rule. Such behavior has also been observed in experiments: crystal orientations with either a $\langle 100\rangle$ or a $\langle 111\rangle$ direction parallel to the strain direction are stable orientations and grains will rotate towards these orientations in the case of deformation of FCC steels [55].

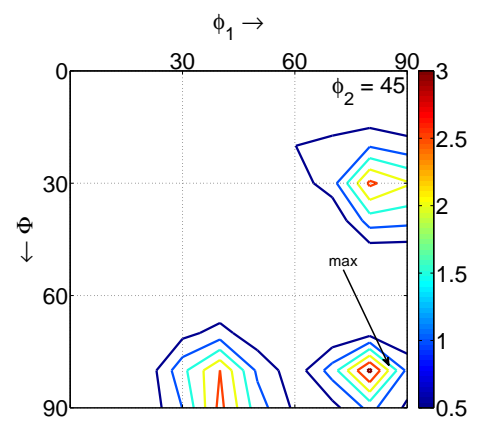

(a) $\mathrm{RD}$

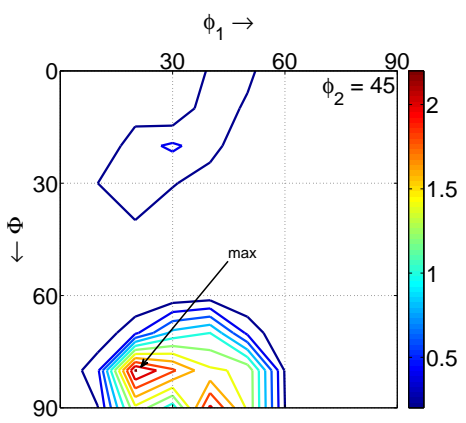

(b) TD

Figure 5.5: The $\phi_{2}=45^{\circ}$ section of the Euler space showing the simulated austenitic texture after $20 \%$ uniaxial deformation without transformation in the RD (a) and TD (b) for a metastable austenitic stainless steel.

\subsubsection{Full Model Calculations}

When transformation and deformation can occur simultaneously during a tensile test, the austenitic texture evolves both due to crystal rotations and transformation. The amount and rate of transformation depend on the critical driving force $U_{c r}$ and the fraction of transformed austenite $\mu_{f}$ once the critical driving force is reached in a grain. The effect of these two parameters is displayed in Figures 5.6(a) and 5.6(b), respectively. Raising the critical driving force delays the onset of transformation to higher strain and stress values. It also affects the transformation rate to some extent. From Figure 5.6(b) it is clear that increasing the fraction of transformed austenite $\mu_{f}$ substantially increases the transformation rate. 
For the simulation of a uniaxial tensile test at room temperature the values of $U_{c r}$ and $\mu_{f}$ of the metastable austenitic stainless steel employed need to be determined. The critical driving force can be obtained from a uniaxial tensile test in the RD in the case of the steel used in this work. During such an experiment, the stress at which transformation occurs can be determined. From the stress-induced transformation theory and the measured austenitic texture, it is known that the 'Goss' orientation, present in significant quantities in the steel used in this work, transforms first. Now, Equations (3.5) and (5.6) can be used to calculate the driving force acting on the grain when the transformation starts. Based on experiments performed on the same steel in Chapter 4 (see Figure 4.4), the critical driving force at room temperature is determined as 58 $\mathrm{MPa}$. The fraction $\mu_{f}$ of austenite transforming once the critical driving force is reached, is used as a fitting parameter. It is assumed that a value for $\mu_{f}$ between 0.05 and 0.1 is realistic. Based on a uniaxial tensile test in the RD presented in Figure 4.4, a value of 0.075 was obtained for $\mu_{f}$.

For a uniaxial tensile test at room temperature, the austenitic textures at a martensite content of $70 \%$ for the RD and TD are shown in Figures 5.7(a) and 5.7(b), respectively. Comparing these textures with the textures obtained from the simulations with only transformation (Figure 5.4) or only plastic deformation (Figure 5.9), shows that both mechanisms of texture evolution are active during deformation at room temperature.

While the effect of the austenitic texture on the transformation behavior became clear from the experiments in Chapter 4, the effects of crystal rotations during the deformation of a steel on the transformation cannot be derived from the TBSIT model. To investigate this further, two simulations in the TD were performed: one with and one without crystal rotations due to plastic deformation. The results of these simulations are presented in Figure 5.8. It is clear that the martensite fraction is higher when no crystal rotations occur with respect to the simulation in which crystal rotations do occur. This is because a significant amount of grains will rotate toward orientations with a low driving force orientation. At this new orientation, the grains require a higher stress before transformation can occur compared to the orientation the grains had in the starting texture. It shows that the accurate simulation of grain rotations is important. It also explains the overestimation of the predicted transformation behavior by the TBSIT model during a uniaxial tensile test in the TD. 


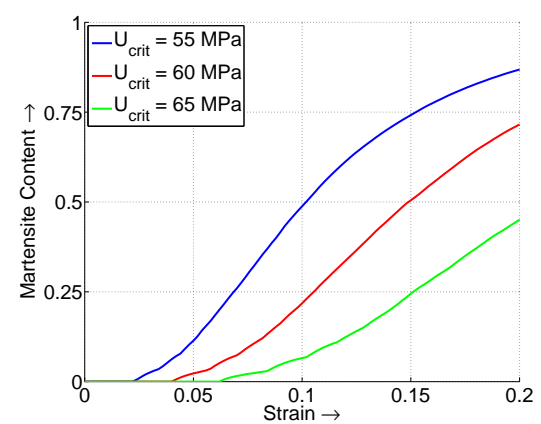

(a)

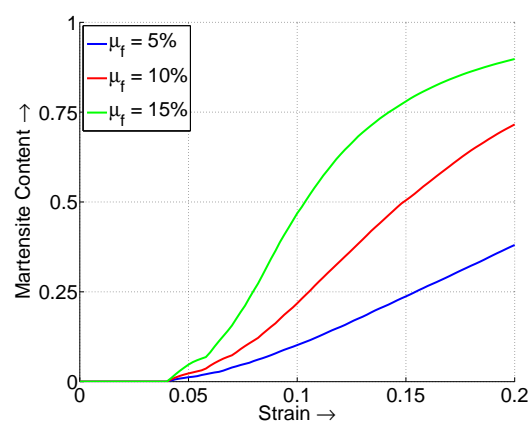

(b)

Figure 5.6: Influence of the critical driving force $U_{\text {crit }}$ (a) and the fraction of transformed volume $\mu_{f}$ (b) on the simulated transformation behavior.

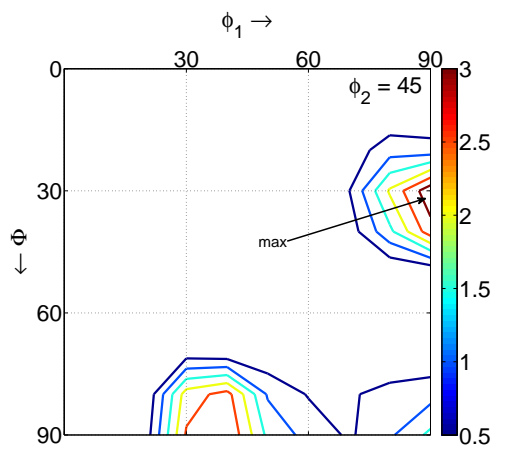

(a)

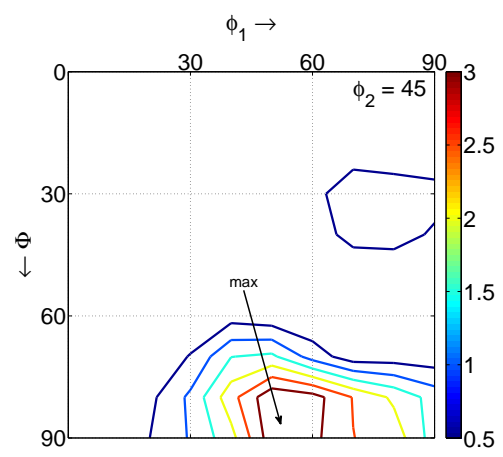

(b)

Figure 5.7: The $\phi_{2}=45^{\circ}$ section of the Euler space showing the simulated austenitic texture after $70 \%$ transformation obtained during uniaxial tensile test in RD (a) and TD (b). The texture evolution is caused by both transformation and crystal rotations due to crystallographic slip. 


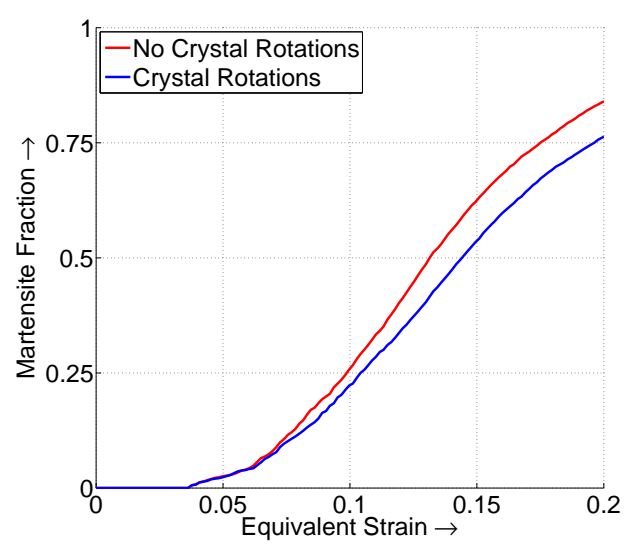

Figure 5.8: The influence of plastic deformation induced crystal rotations on the transformation behavior during a simulation in the TD.

\subsubsection{Influence of step size}

The strain increment applied to each step of the simulation has an influence on the obtained transformation behavior. The origin of this behavior is the amount of austenite which can transform in each step, $\mu_{f}$. When the strain increment is larger than the transformation strain occurring during transformation, a grain can transform multiple times in a single step of the simulation. Since in between the transformations no plastic deformation is applied, a different stress state compared to a simulation with a smaller step size is obtained, and different variants will transform, which in turn also changes the transformation behavior.

In Figure 5.9(a) the effect of the step size is presented. It is clear that the transformation behavior for three simulations, with strain increments of 0.002 , 0.001 and 0.0005 , is similar at low martensite fractions. The transformation behavior in the case of a strain increment of 0.0005 diverges at higher martensite fractions. This is because when a high fraction of martensite is present in a grain, the amount of martensite formed in a grain during transformation is small. More transformation is required to release the stress in the austenite grain with a higher transformation rate as result. This is evident when observing the transformation behavior of two grains with a similar orientation in two of the 
simulations, Figure 5.9(b). While the transformation in both cases is similar at low martensite fractions, at a strain of 0.13 the transformation in the $\mathrm{d} \epsilon=0.002$ case is much higher compared to the $\mathrm{d} \epsilon=0.0005$ case.

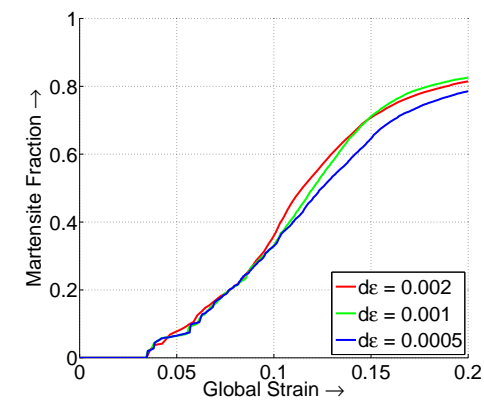

(a)

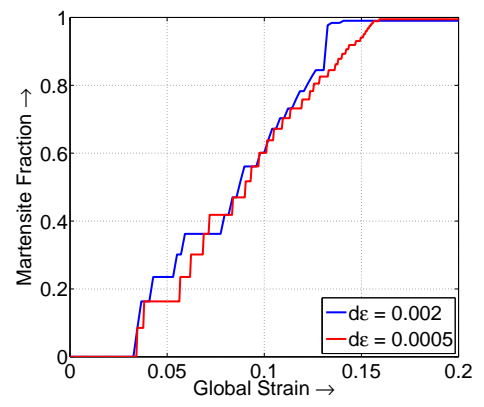

(b)

Figure 5.9: Transformation behavior obtained from simulations with a different strain increment per simulation step. The global transformation behavior for various strain increments is presented in (a), while the behavior of two similar oriented grains is presented in (b).

\subsection{Experiments}

The simulations presented in Section 5.2.2 show the effect of the implemented models for transformation and crystal rotations due to crystallographic slip on the austenite texture and material behavior during and after a tensile test in various directions. The simulation results will be validated by dedicated experiments.

The chemical composition of the steel used in the experiments is shown in Table 4.1. The metastable austenitic stainless steel is fully austenitic and shows transformation during deformation at room temperature. The strong initial austenitic texture of the steel is presented in Figure 4.1.

The experiments were performed on uniaxial tensile specimens with a deformation zone of $80 \times 10 \times 0.5 \mathrm{~mm}^{3}$. The strain at the surface of the samples was measured optically. The martensite fraction during the experiments was measured using a magnetic induction sensor $[41,51]$ and the martensite fraction at the end of the tensile tests was verified by XRD measurements. The 
$\{111\},\{200\}$ and $\{220\}$ pole figures of the austenitic textures were measured using appropriate XRD techniques employing Co radiation. The Matlab toolbox MTEX [13] was used for the calculation of the ODF from the results of the texture measurements.

The relation between the critical driving force $U_{c r}$ and the temperature is exploited to obtain textures which are evolved due to either transformation or plastic deformation only. It is assumed that the transformation behavior, apart from a different critical driving force $U_{c r}$, is similar for the temperatures in the considered range. This is also assumed for the effect of deformation on the texture evolution in the steel. The austenitic textures obtained from experiments at different temperatures are compared with the textures obtained from the corresponding simulations in sections 5.3.1 and 5.3.2.

Uniaxial experiments at room temperature in the $\mathrm{RD}$, during which both transformation and plastic deformation occurs, are used to fit $\mu_{f}$. The effect on the transformation behavior of the texture orientation with respect to the applied stress is investigated by performing a tensile test in the TD.

\subsubsection{Texture evolution due to Transformation Only (Low Temperature)}

At temperatures below the $M_{s}$ temperature, transformation can initiate spontaneously. This is termed athermal transformation and does not require an external stress. In this section, the austenitic texture evolution due to athermal transformation is discussed as well as the austenitic texture evolution when transformation occurs at stresses below the yield stress at a temperature above $M_{s}$, which is called stress assisted transformation.

\section{Athermal Transformation}

At temperatures below the $\mathrm{M}_{s}$ temperature, the chemical driving force alone is enough to start transformation. The absence of a stress results in a transformation behavior independent of the orientation of the grain.

The austenitic texture after storage at $230 \mathrm{~K}\left(<M_{s}\right)$ for a prolonged period of time $(\approx 1$ month) is shown in Figure 5.10 . Here, $50 \%$ of the austenite has transformed into martensite. The texture is still very similar to the texture of the as-received material (Figure 4.1), indicating that there are no preferred orientations for transformation when no external stress is applied. In other words, since all grains have the same 'likelihood' of transformation, the original texture is preserved. 


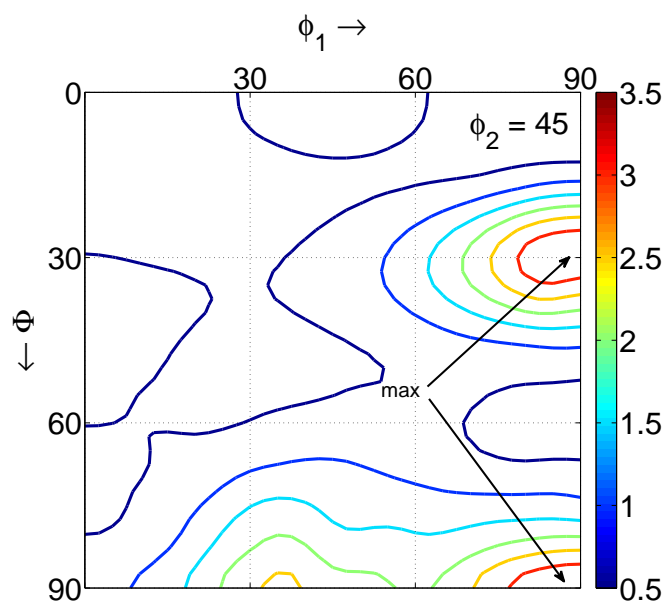

Figure 5.10: The $\phi_{2}=45^{\circ}$ section of the Euler space showing the measured austenitic texture after $50 \%$ transformation due to storage for prolonged time at $230 \mathrm{~K}$ in absence of mechanical loading.

\section{Stress Assisted Transformation}

The stress-induced transformation theory can be validated by the austenitic texture evolution due to transformation. Transformation under the influence of stress results in a texture evolution in correspondence with the stress-induced transformation theory.

A temperature above $\mathrm{M}_{s}$ is chosen such that transformation occurs at a stress lower than the flow stress of the steel. Uniaxial tensile bars were cooled down to $253 \mathrm{~K}$ and stressed up to $250 \mathrm{MPa}$. At this stress, plastic deformation does not occur. Due to the transformation strain, a relaxation of the stress occurs. To obtain a continuing transformation, the stress was kept constant until $20 \%$ of the austenite transformed into martensite. No plastic deformation occurred in the samples, other than the local plastic deformation due to transformation within a grain. Therefore, the austenitic texture evolution is exclusively caused by transformation. The austenitic textures for the RD and TD experiments after $20 \%$ transformation are shown in Figure 5.11.

From a comparison of Figure 4.1 with Figure $5.11(\mathrm{a})$, it is clear that the 
reduction in intensity in the $\mathrm{RD}$ case is found around the [9090 45], which is an orientation with a high driving force as can be seen in Figure 3.7(a). In the TD case, presented in Figure 5.11(b), the main texture components are unchanged after transformation. This is expected since the main texture components represent grains with a low driving force, as can be observed from Figure 3.7(b). Transformation occurred in grains with orientations different from the main components, such as around [45 045$]$ and [0 9045$]$, which are the high driving force orientations in the TD case.

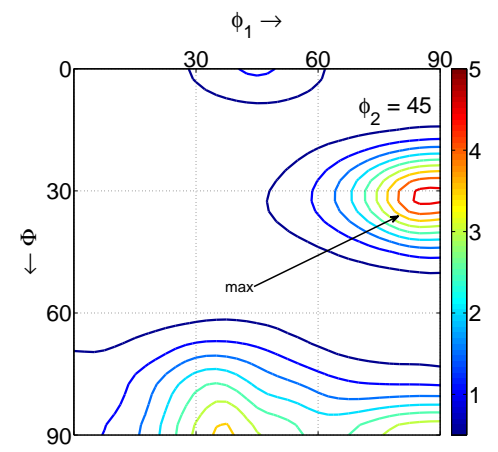

(a) $\mathrm{RD}$

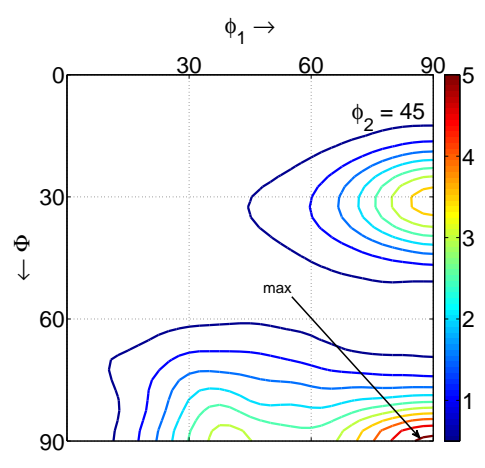

(b) TD

Figure 5.11: The $\phi_{2}=45^{\circ}$ section of the Euler space showing the measured austenitic texture after applying a uniaxial stress beneath the flow stress in the RD (a) and TD (b) at a temperature above $M_{s}$. In both cases, the results after $20 \%$ of the austenite has transformed into martensite are shown. 


\subsubsection{Texture evolution due to deformation only (High Temperature)}

The mechanical driving force required for transformation depends on the temperature at which the experiments are performed. At increasing temperatures, the mechanical driving force required for transformation increases as well. When a temperature is selected such that during deformation the critical driving force is never reached, no transformation occurs during the experiments and the texture evolution in the steel is solely caused by plastic deformation.

The steel used in this work shows no transformation at 410K. Uniaxial tensile tests at $410 \mathrm{~K}$ were performed in both the RD and TD. The austenitic textures after 20\% plastic strain were measured and are shown in Figure 5.12.

The texture in Figure 5.12(a) shows that after deformation in the RD a similar texture is present in the material as the texture found before deformation shown in Figure 4.1. The only difference is that the texture after deformation has sharpened due to crystal rotations towards orientations with a $\langle 111\rangle / / \mathrm{RD}$ or $\langle 100\rangle / / \mathrm{RD}$.

From the texture obtained after the TD experiment, Figure 5.12(b), it is clear that a large amount of crystal rotation occurred during deformation. In this case, both the grains around the $\langle 111\rangle / / \mathrm{RD}$ and $\langle 100\rangle / / \mathrm{RD}$ orientation are not stable and will rotate to a stable orientation. Therefore, the texture does not have any similarity with the original texture.

\subsubsection{Texture evolution due to Transformation and Defor- mation (Room Temperature)}

The steel used in this work shows transformation during plastic deformation at room temperature. The evolution of the austenitic texture is thus caused by the effects of both transformation and plastic deformation. Uniaxial tensile tests were performed in the RD and the TD, for which the results are already presented in the previous Chapter 4 . The austenitic textures when $70 \%$ martensite was present in the samples are shown in Figure 5.13 for both experiments.

The texture found after the tensile test in the RD, Figure 5.13(a), shows a relatively large decrease in intensity around [90 9045 ] compared to the starting texture shown in Figure 4.1. The remaining grains have orientations around the $\langle 111\rangle / /$ RD fiber. This texture is mainly caused by transformation. After straining in the TD, the texture shown in Figure 5.13(b) is obtained. Most remaining grains have orientations around orientations with a $\langle 111\rangle$ direction in the direction of the global stress. In this texture both the effects of transformation and deformation can be observed. 


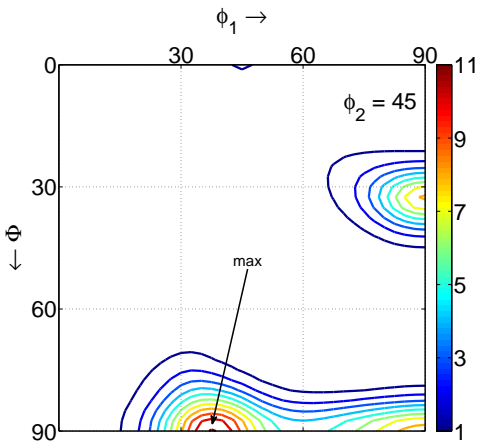

(a)

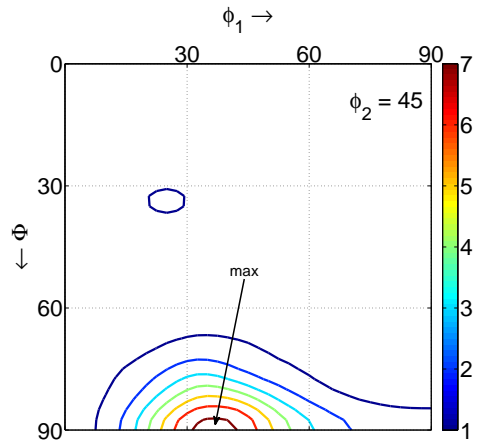

(b)

Figure 5.12: The $\phi_{2}=45^{\circ}$ section of the Euler space showing the measured austenitic texture after deformation at 410K in the RD (a) and TD (b). Texture evolution is only caused by crystallographic slip during plastic deformation.

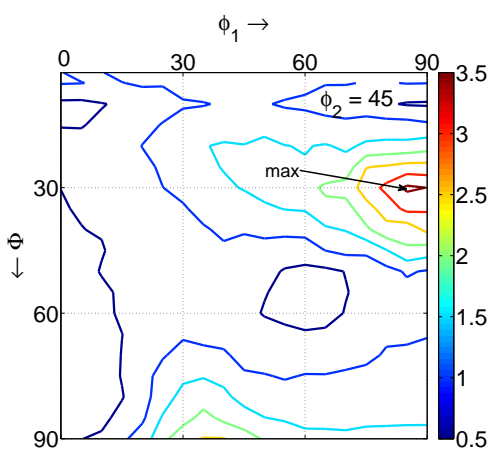

(a)

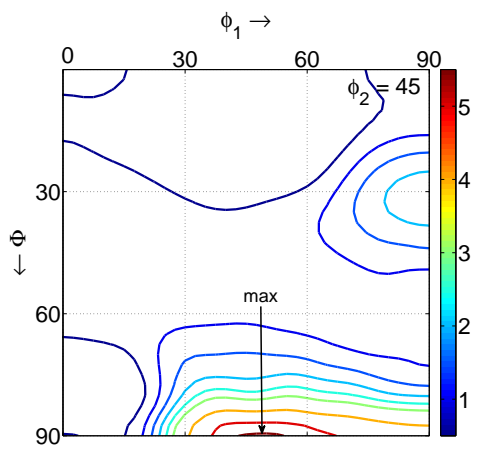

(b)

Figure 5.13: The $\phi_{2}=45^{\circ}$ section of the Euler space showing the measured austenitic texture after deformation at room temperature in the RD (a) after $\approx 80 \%$ and TD (b) after $\approx 70 \%$ martensite was formed. Texture evolution is caused by both transformation and crystallographic slip during plastic deformation. 


\subsection{Discussion}

In Chapter 4 it was shown that the start of transformation during plastic deformation can be predicted by a combination of the stress-induced transformation theory and the austenitic texture, the TBSIT model. This model combines the ODF of the austenitic texture of the steel with the stress-induced transformation theory. For a more accurate prediction of the whole transformation behavior during mechanical loading, the model has been extended in this chapter by implementing several mechanisms considered most important for a more accurate transformation model.

\subsubsection{Austenitic texture}

The austenitic texture has a large influence on the global transformation behavior. Therefore, an accurate model to describe the texture evolution in the austenitic phase during plastic deformation is needed. The Taylor-Bishop-Hill model, in combination with a PAN hardening rule, was implemented. Experiments at high temperatures $\left(410 \mathrm{~K},>M_{s}\right)$ showed an austenitic texture evolution due to crystal rotations only, see Figure 5.12. From the corresponding simulations similar austenitic textures were obtained, see Figure 5.9. It is assumed that there is no difference in behavior with respect to the crystal rotations due to crystallographic slip between experiments at $410 \mathrm{~K}$ and room temperature.

It follows from the stress-induced transformation theory that the orientation of a grain with respect to the applied stress has an influence on its transformation behavior: the transformation potential is based on the orientation of the crystal lattice with respect to the stress. To verify this, experiments were performed at 253K $\left(>M_{s}\right)$ during which transformation occurred under elastic loading. At this temperature, no athermal transformation occurs in the steel. Comparing the austenitic textures after 20\% transformation, shown in Figure 5.11, with the corresponding driving force distributions presented in Figure 3.7 and the original texture presented in Figure 4.1, shows that, indeed, grains with a high calculated transformation potential are no longer present in the austenitic texture. Calculations corresponding to these experiments show the same behavior, Figure 5.4.

When transformation occurs during deformation, both mechanisms causing an evolution of the austenitic texture are present. The austenitic textures measured after experiments where both plastic deformation and transformation occurred, are presented in Figure 5.13. The corresponding simulations of the austenitic textures, Figure 5.7, show good agreement. 
The mechanisms implemented in the model can describe the evolution of the austenitic textures well. This is important for an accurate description of the transformation behavior of a metastable austenitic stainless steel during deformation.

\subsubsection{Transformation behavior}

The transformation behavior of a metastable austenitic stainless steel during deformation is presented in Figure 5.14(b). It is clear that transformation starts at higher strains in the TD case compared to the RD case. The model is fitted on the transformation curves obtained from the tensile test in the RD. It is shown that the experimental transformation behavior can be fitted well by the simulations, see Figure 5.14(b). The critical driving force, $U_{c r}$, is obtained by the start of transformation in the RD case. The amount of the austenite phase in a grain transforming to martensite when the grain can transform, $\mu_{f}$, is obtained from the slope of the transformation and is used as a fitting parameter, yielding $\mu_{f}=0.075$ as mentioned before.

The validity of the value of $\mu_{f}$ can be tested by looking at the transformation behavior of two groups of grains during a tensile test in the RD. The first group of grains has a $\langle 100\rangle$ direction parallel to the stress direction, the second group has a $\langle 111\rangle$ direction in the stress direction. The first group has a high transformation potential and will transform at low stresses, the second group has a low transformation potential and will thus transform at high stresses. The ratio between the amount of grains with a $\langle 100\rangle$ and a $\langle 111\rangle$ direction in the stress direction will provide a measure for the transformation speed in the grains: a constant ratio indicates an equal transformation rate in both groups of grains, a decreasing ratio indicates more transformation in the $\langle 100\rangle$ group. Several samples were strained in the RD up to intermediate strains and martensite contents. The ratio between the intensity of the grains with a $\langle 100\rangle$ and a $\langle 111\rangle$ direction in the stress direction is shown in Figure 5.15. It is clear that there is a gradual decrease of the ratio, caused by the transformation of the $\langle 100\rangle$ grains. The simulation results, also shown in Figure 5.15, show approximately the same decrease. Since this decrease is strongly influenced by $\mu_{f}$, the value for $\mu_{f}$ used to simulate the experiments is valid.

It is known that the rate of transformation during plastic deformation is higher than predicted by stress-induced transformation alone, i.e. the critical driving force during plastic deformation appears lower than expected from theory. Several authors $[3,4,73]$ model this behavior as a strain effect, introducing an additional mechanism. Here it is assumed that the increase in transformation 
rate is due to additional stress concentrations in the grains, triggering transformation at lower stresses than expected based on the overall stress, conform to the model of Tamura [5]. This behavior is simulated in the model by the interaction of grains due to the prescribed overall stress.

The results of the TD experiment can be obtained from simulations using the parameters of the RD experiment and the austenitic texture before the mechanical loading process. The TBSIT model showed an overestimation of the transformation at high martensite fractions when performing a simulation of a uniaxial tensile test in the TD. In the new model, transformation at high martensite fractions - and thus at high strains- during the same type of simulation is delayed by the rotation of a significant amount of grains toward an orientation with a low driving force. Figure 5.14(b) shows that the model can accurately predict the influence of the strain direction on the transformation in textured austenitic steels.

\subsubsection{Material behavior}

During the tensile tests, the force as well as the strain and the martensite content were measured. The results are presented in Figure 5.14. It is clear that there is a significant difference in material behavior between the RD and TD experiment, while the initial yield stress and hardening behavior in both tests are similar. The difference occurs as soon as transformation starts, which happens at lower stresses and strains when loading in the RD compared to the TD. As a result, the softening contribution due to the transformation strain starts earlier, followed by an earlier increased hardening as a result of the additional strengthening effect of the martensite.

While the transformation behavior, its dependence on the strain direction and the texture evolution have been modeled and simulated accurately, the magnitude of the stress is less accurately predicted. As soon as transformation starts in the simulations, the stress in the transforming grains drops. This drop in stress is only partly compensated by surrounding grains due to the Voigt-Taylor constraint and thus the average overall stress decreases as well. This behavior is clearly visible in the average stress - strain curves presented in Figure 5.14(a). With an increasing amount of grains used to simulate the texture, this effect will be reduced. 


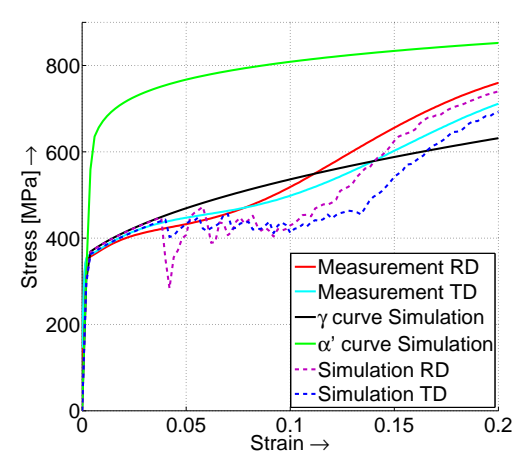

(a)

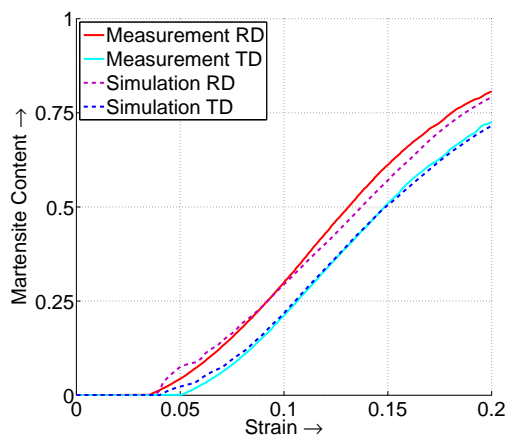

(b)

Figure 5.14: Results for the stress-strain (a) and martensite content-strain (b) response obtained from simulations and experiments in the RD and TD. The flow curves of the austenite and martensite phase are shown in (a) as well.

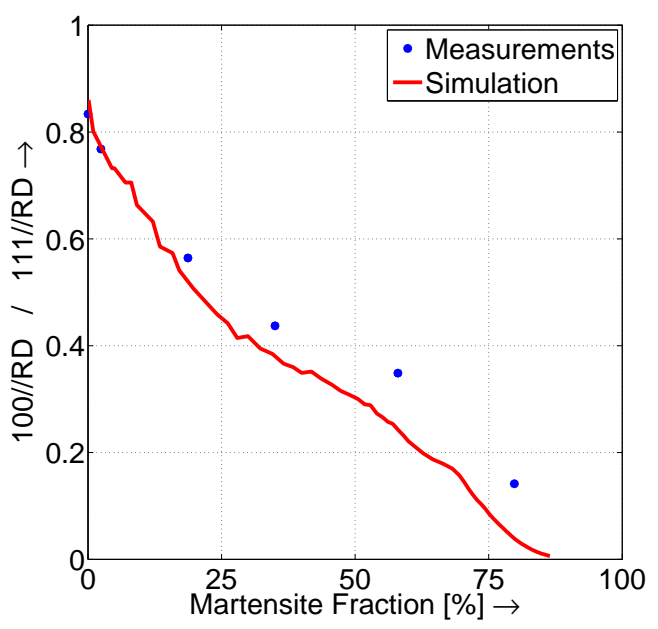

Figure 5.15: Ratio between the fraction of austenite grains with a $\langle 100\rangle$ parallel to the $\mathrm{RD}$ and grains with a $\langle 111\rangle$ direction parallel to the $\mathrm{RD}$ during a uniaxial tensile test in the RD. 


\subsection{Summary}

As shown in Chapter 4, the presence of an austenitic texture in a metastable stainless steel causes a strain direction dependent transformation behavior during deformation. While the stress-induced transformation theory alone can predict the relation between the stress direction and the start of transformation, for a more accurate prediction of the transformation behavior during deformation more mechanisms needed to be taken into account, such as the austenitic texture evolution during plastic deformation. In this chapter it has been shown that the austenitic texture evolution in metastable austenitic stainless steels can be described by the transformation from austenite to martensite in combination with a crystallographic slip model. With these models for an accurate texture evolution, supplemented with several additional mechanisms such as stepwise transformation of grains, a model has been constructed to predict the effect of austenitic texture and strain direction on the transformation behavior of a steel during deformation. Due to the nature of the model, the global stress is not simulated accurately. However, the model is capable of predicting the evolution of the austenitic texture and the transformation of a steel during deformation accurately, as well as the effect of the strain direction on the transformation.

During most forming processes, non-monotonic strain paths can occur. It is known that such a strain path has an influence on the material behavior of a steel, while the effect of a non-monotonic strain path on the transformation behavior of a steel is not yet known. In the next chapter the material behavior of a metastable austenitic stainless steel is studied, simulated with the model developed in this chapter and discussed. 


\section{Chapter 6}

\section{Transformation \& Non-Monotonic Deformation}

In multi-stage forming processes, where multiple deformations are applied to obtain the desired shape of a product, the material is subjected to various nonproportional strain paths and strain direction reversals. The non-proportional or reverse loading of steel can result in a material behavior different from the expected behavior known from proportional experiments. A well known example is the decrease in flow stress after a strain path reversal, called the Bauschinger effect, which can be found in numerous steels. This change in material behavior can have an influence on the transformation behavior as well.

Beside the difference in material behavior due to the Bauschinger effect, the change in stress direction itself can also have an influence on the transformation of the steel. Experiments performed in Chapters 4 and 5 show that the deformation direction can have a large influence on the transformation behavior in textured austenitic stainless steels. In the same chapters two models were presented which can simulate the transformation behavior of such steels during monotonic strain paths accurately.

In this chapter the influence of a changing strain path on the transformation behavior of a metastable austenitic stainless steel is studied by performing proportional strain reversal experiments. The models described in Chapters 4 and 5 will be used in simulations of the experiments. 


\subsection{Experimental Setup}

The textured metastable austenitic stainless steel, employed during the experiments presented in Chapters 4 and 5, is also used for the non-monotonic experiments. The mechanical loading experiments have been performed on the Twente Biaxial Tester [74]. As with the Arcan fixture used for several experiments presented in Chapter 4, this test setup allows various strain paths ranging from simple shear to plane strain extension. The Twente Biaxial Tester is chosen because changing the strain path is achieved more easily compared to the Arcan fixture. A schematic representation of the possible displacements of a Biaxial specimen and its dimensions is shown in Figure 6.1.

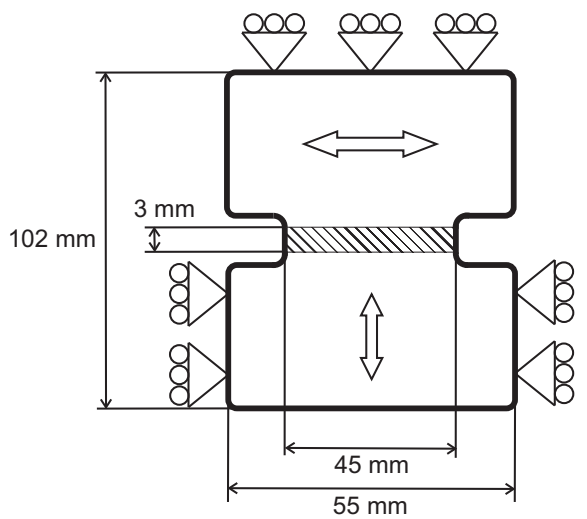

Figure 6.1: Schematic representation of the Twente Biaxial Tester. The hatched area is the deformation zone.

The strains at the surface of the gauge section of the specimen were measured optically and the martensite content was measured using a magnetic induction sensor during the experiments. An increase in magnetic induction indicates primarily an increase of the martensite content in the sample. The output of the magnetic induction sensor is also influenced by the stress in the martensite phase [41, 51], which must be kept in mind when analyzing the results in Section 6.2. Since the exact stress in the martensite phase is not known a priori, the signal cannot be compensated for the stress after the strain path change and hence the raw measurement data of the mechanical loading tests are displayed for these non-monotonic experiments. 
The strain reversal experiments were carried out by first imposing a shear strain in one direction, followed by a shear strain in the opposite direction. A non-proportional experiment was performed as well. During this experiment, a plane strain was followed by a stress release and a shear strain. During the experiments, strain rates were kept low enough (in the order of $0.001 / \mathrm{s}$ ) to avoid heating of the sample during deformation. The chemical composition of the steel is shown on page 36 in Table 4.1 (Steel 2). Experiments were performed at room temperature.

In addition, a strain reversal experiment was conducted on an untextured steel as well. The chemical composition of this steel is shown in Table 4.1 as well (Steel 1). To obtain sufficient transformation during deformation of this steel, the experiments are performed with the Arcan fixture in a climate chamber at $253 \mathrm{~K}$.

\subsection{Experimental Results}

In the next section the results of some proportional (intermittent) shear strain experiments, as well as some strain reversal experiments, are presented. The shear reversal experiments are performed on both a textured and an untextured austenitic stainless steel. In addition, a non-proportional experiment is performed.

\subsubsection{Proportional Experiments}

A straightforward shear experiment was performed on approximately $35 \%$ shear strain. The results of this experiment are shown in Figure 6.2. The material behavior commonly observed during deformation of metastable austenitic stainless steel, as described in Section 3.4, is easily recognized.

As a second test an intermittent proportional shear test was done where during the experiment at various strains the specimen was unloaded. The results are plotted in Figure 6.2 as well. At shear strains of approximately 0.22 and 0.35 , where a considerable fraction of the austenite has transformed to martensite, the stress was reduced. Subsequently, the stress was increased again to continue the shear experiment. From Figure 6.2 it is clear that the continuation of the shear test follows the expected behavior as if the interruption has not occurred. This holds for the stress-strain behavior as well as for the magnetic induction signal as a function of the shear strain and shear stress: the transformation restarts 
at the same strain levels (Figure 6.2(b)) and stress levels (Figure 6.2(c)) before and after the temporary stress reductions.

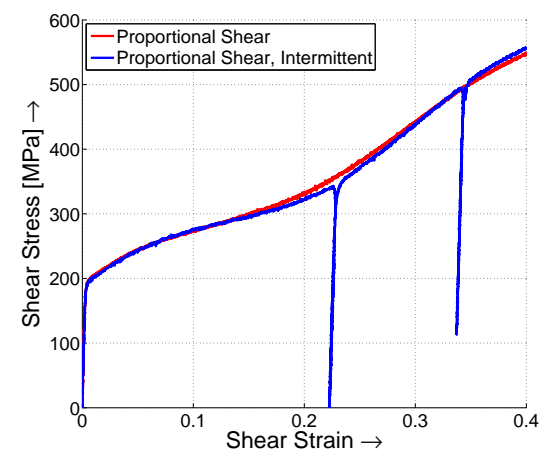

(a)

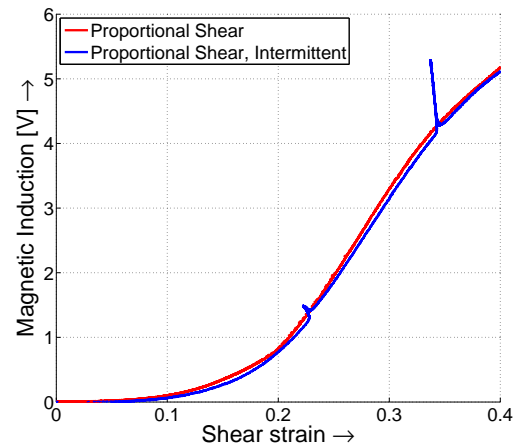

(b)

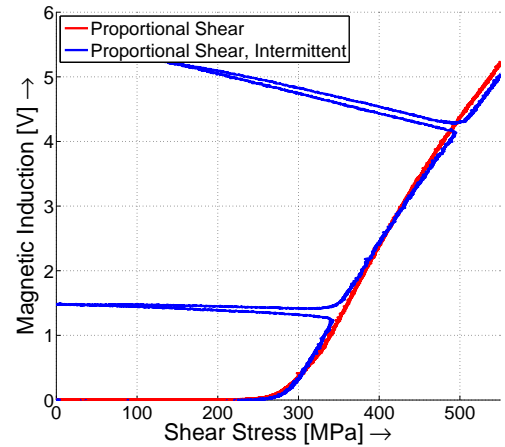

(c)

Figure 6.2: Material behavior of the austenitic steel during a proportional shear strain experiment and during an intermittent shear strain experiment. The stress-strain curves are shown in (a), the relations between shear strain and shear stress with respect to the magnetic induction are shown in (b) and (c), respectively. 


\subsubsection{Strain reversal experiments}

Strain reversal experiments were performed under the same testing conditions as the experiments described above. Various strain values were chosen as the point of strain reversal during the experiment. The results are presented in Figure 6.3. The measured shear stress versus shear strain curves of the steel are shown in Figure 6.3(a). The line indicated with $\mathrm{R} 0$ indicates the behavior of the deforming steel without shear reversal up to high strain values. The other lines display the behavior of the steel during the shear experiment up to consecutively higher strain values followed by a shear reversal down to opposite stresses in the order of $500 \mathrm{MPa}$. The data are indicated by ' $\mathrm{Rxx}$ ', where ' $\mathrm{xx}$ ' is the shear strain (\%) at which the strain reversal was initiated: $\mathrm{xx}=(04,10,17,20,27)$. To compare the material behavior during the strain reversal experiments with the proportional results (as indicated by the line R0 in Figure 6.3(a)), the total shear strain is plotted against the absolute value of the shear stress in Figure 6.3(b). When the strain reversal is applied at low strains, a softening behavior can be observed, which seems similar to the Bauschinger effect. The behavior can be seen best from the experiment designated R04 in Figure 6.3(b). After the strain reversal, which happened at around $4 \%$ strain, an additional $4 \%$ strain in the opposite direction was required for the flow stress to reach the value of approximately $220 \mathrm{MPa}$ which it had before the strain reversal. However, when the strain reversal is applied at higher strain and stress levels, the flow stress after the strain reversal increases beyond the measured flow stress before the strain reversal. This can be observed most clearly from the strain reversal experiment with the highest strain before reversal as designated R27 in Figure 6.3(b). While the flow stress before the strain path change is around $400 \mathrm{MPa}$ (at a strain of approximately 0.27 ), the flow stress after the strain reversal is much higher and goes beyond that of the black line indicating the behavior of the material without strain reversal.

The transformation behavior during these experiments is presented in Figures $6.3(\mathrm{c})$ and $6.3(\mathrm{~d})$. The results show that when the strain reversal is applied, the transformation after the strain reversal starts at higher stresses and strains compared to the martensite evolution obtained from the proportional test without strain reversal. As can be observed from the experiments, this effect increases with higher martensite fractions. While the transformation starts at higher stresses after the load reversal, the transformation rate with respect to the stress is increased, whereas the transformation rate with respect tot eh strain is decreased. 


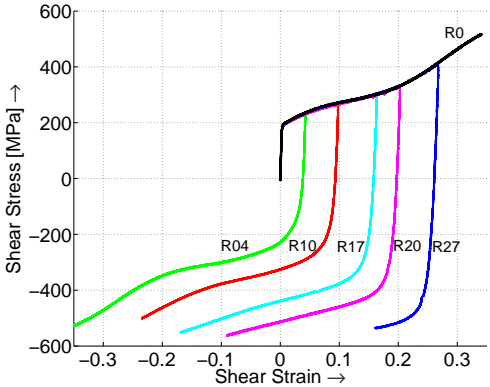

(a)

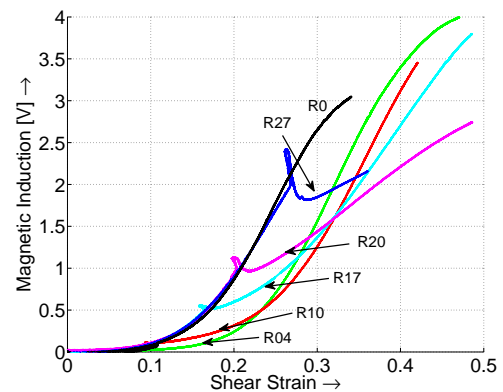

(c)

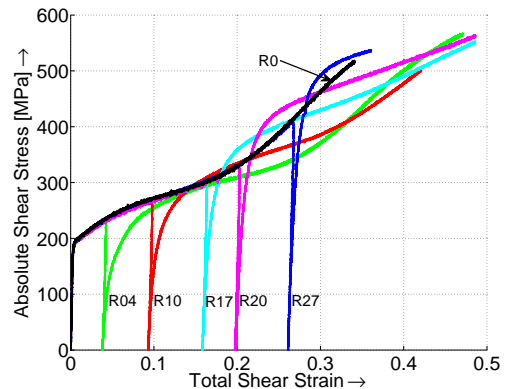

(b)

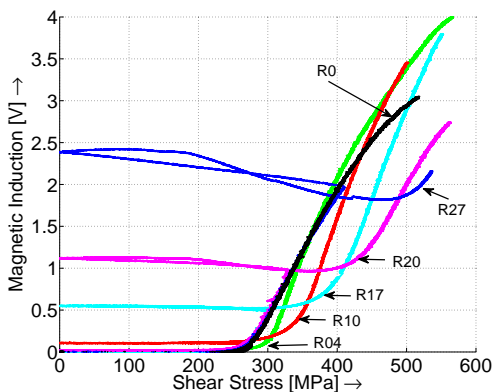

(d)

Figure 6.3: Material behavior of the austenitic steel subjected to a shear strain during which the strain is reversed at various strains. The stress-strain curves are shown in (a). For comparison reasons, the absolute stress versus the total strain is shown in (b). The relations between strain and stress with the magnetic induction of the steel are shown in (c) and (d), respectively. 
The austenitic stainless steel without a crystallographic texture, Steel 1, was subjected to a similar strain reversal experiment. These experiments are performed on the Arcan fixture, as described in Section 4.2. This steel shows a similar behavior as the textured steel, as can be observed from the experimental results displayed in Figure 6.4 .

\subsubsection{Non-Proportional Experiments}

In addition to the shear reversal experiments, a non-proportional experiment was performed as well. During this experiment a plane strain deformation was applied to the specimen. At a certain level of the strain, the stress was released and a shear strain was applied. The resulting equivalent stress-equivalent strain curves, together with a proportional shear and plane strain experiment, are shown in Figure 6.5. Similar to the shear strain reversal experiments, the stress after the strain path change lies above the expected stress values from the proportional experiments, see Figure 6.5(a).

The transformation curves presented in Figure 6.5(c) show that the driving force at which the magnetic induction increases after the strain path change is higher compared to the transformation curve from a proportional shear strain experiment. In the figure, the relation between stress and magnetic induction can be clearly observed in the part of the curve where the stress is released after the plane strain deformation. However, applying a shear strain on the specimen will cause no decrease in signal with increasing stress. This can indicate that either i) the martensite is less stressed during the shear strain deformation or ii) the signal increase due to a small amount of transformation counteracts the decrease of signal due to increasing stress. 


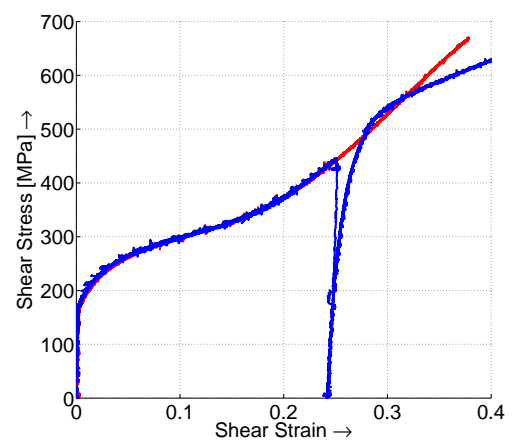

(a)

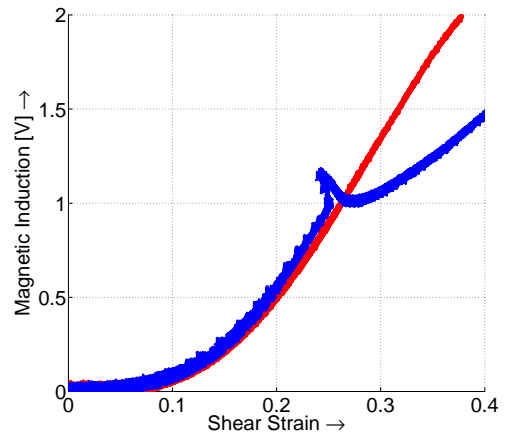

(b)

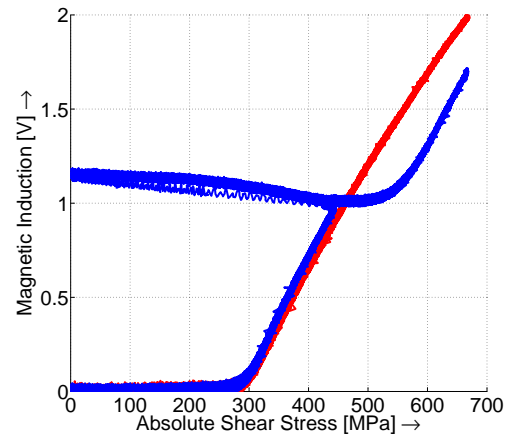

(c)

Figure 6.4: Material behavior of the untextured austenitic steel during a shear strain experiment and during a shear strain experiment during which the shear strain is reversed. The stress-strain curves are shown in (a), the relations between shear strain and shear stress with respect to the magnetic induction are shown in (b) and (c), respectively. 


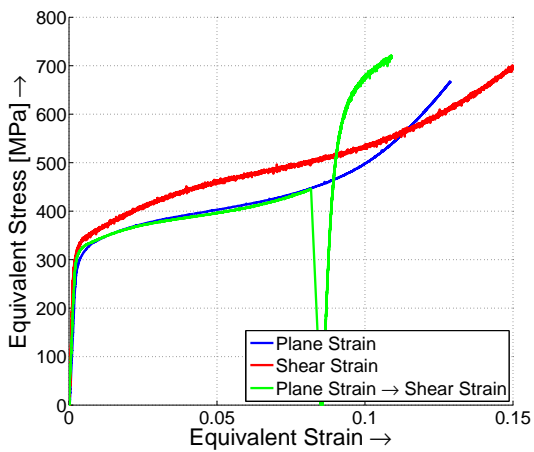

(a)

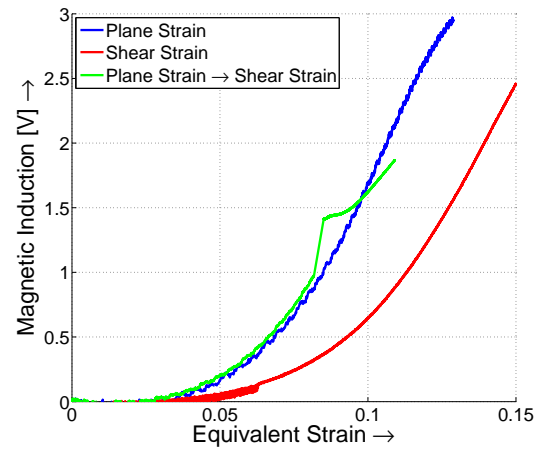

(b)

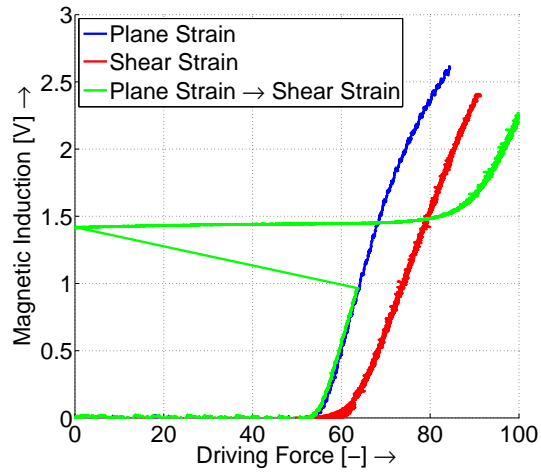

(c)

Figure 6.5: Material behavior of the textured austenitic steel during a shear strain and plane strain proportional experiment and during a non-proportional experiment during which the plane strain is followed by a shear strain. The stress-strain curves are shown in (a), the relations between equivalent strain and driving force with respect to the magnetic induction are shown in (b) and (c), respectively. 


\subsection{Strain Reversal Simulations}

In this thesis, two models were presented which show good results describing proportional experiments: the Texture Based Stress Induced Transformation (TBSIT) model from Section 4.4 and the more advanced model described in Chapter 5. A shear reversal experiment was modeled with both models and the results are presented in this section.

\subsubsection{TBSIT}

The TBSIT model is solely based on the texture and the average stress in the austenite phase of the steel. Therefore, the stress state before and after the strain path change is important. Both before and after the strain reversal a shear stress is present in the steel, although in a different direction. While the direction is different, the driving force distribution is the same when performing a shear deformation in either direction, which is shown in Figure 4.8(e). However, since the driving force based on a shear stress has a period of $180^{\circ}$ over $\phi_{2}$ in Euler space, there is a difference in distribution when a load reversal is applied. As a result, the TBSIT model predicts that the transformation starts at a lower stress after strain reversal, as shown in Figure 6.6. The results of a non-proportional experiment, simulated with the TBSIT model, is presented in Figure 6.6 as well. Here, it is predicted that transformation starts at a lower driving force after the strain path change as well.

\subsubsection{Advanced Model}

The advanced model described in Chapter 5 was adjusted to simulate shear strain experiments and experiments during which a strain reversal is applied. The results of a proportional shear strain experiment and a non-monotonic shear strain experiment during which a strain reversal occurred are presented in Figure 6.7. Comparing the simulation results with the experimental results presented in Section 6.2 shows that the mechanism causing the increased stress after the strain rate change is not included in the model. This indicates that the texture evolution occurring during the shear deformation in the first part of the experiment does not influence the transformation behavior to the extent observed during the experiments. Implementing the Bauschinger effect in the model might yield more accurate results. 


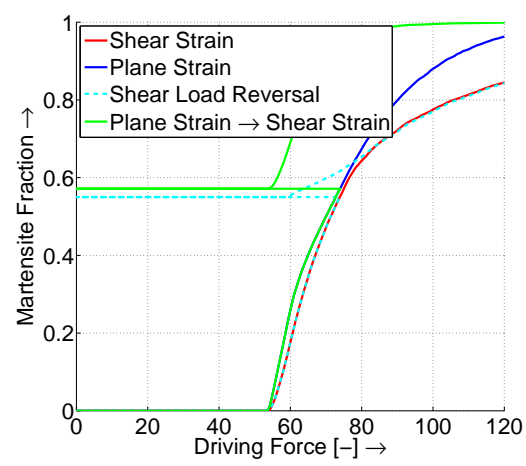

Figure 6.6: Simulated transformation curve of a shear strain reversal experiment and a non-proportional experiment as calculated with the TBSIT model.

\subsection{Discussion}

Applying a strain path containing a load reversal to a metastable austenitic stainless steel results in material behavior that, as such, has not been observed in other materials. Three phenomena can be deduced from the experiments:

1. At low strains and martensite fractions a strong Bauschinger effect is observed. At increasing strains and martensite fractions this effect is strongly reduced.

2. At high strains and martensite fractions, the absolute stress after the load reversal exceeds the stress found at the same equivalent strain during proportional experiments.

3. The measured stress and strain at which transformation occurs increase after applying a strain reversal.

Several possible causes as the origin of this observed material behavior were investigated. To eliminate the effect of the measurement setup on the results, several experiments were duplicated on the Arcan fixture. The same material behavior was observed as the experiments performed on the Twente Biaxial Tester. In addition, a reference steel sample, DP600, containing no metastable austenite -and hence without the ability to transform during mechanical loading- 


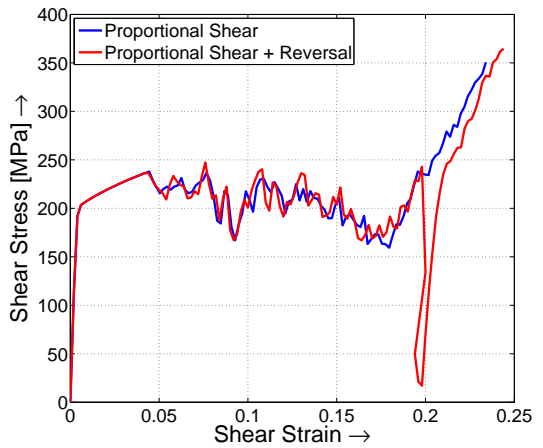

(a)

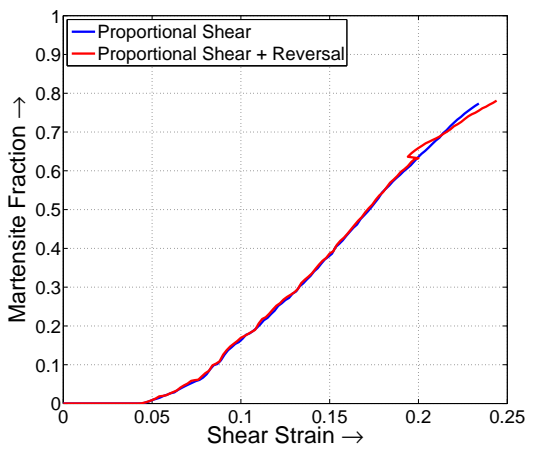

(b)

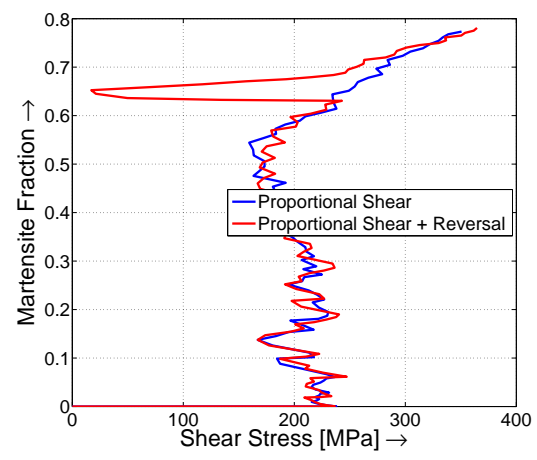

(c)

Figure 6.7: Simulation results of a shear strain experiment and of an experiment during which the shear strain is reversed. The stress-strain curves are shown in (a), the relations between shear strain and shear stress with respect to the magnetic induction are shown in (b) and (c), respectively. 
was tested using the same setups as well. It did not show the same overshoot in stress as observed using the metastable austenitic stainless steels employed here. This excludes the influence of the setups used on the experimental results obtained. Furthermore, the results strongly suggest that the occurrence of the phase transformation during the strain reversal experiments is important to the observed phenomena.

As discussed earlier, there are several factors that can have an influence on the austenite to martensite transformation behavior, such as the chemical composition, the temperature, the orientation distribution of the austenite grains (i.e. the austenitic texture) and the grain size. The chemical composition did not change during the experiment and also the temperature of the samples remained constant as the rate of deformation was kept low enough to prevent substantial heating of the samples. In addition, a proportional experiment where the stress was reduced at some points during the experiment (see Figure 6.2) did not show the observed phenomena, indicating that a pause in plastic deformation, potentially allowing the sample material to cool down, does not influence the results to any extent.

In this thesis it is shown that the austenitic texture can have a large influence on the transformation behavior during proportional loading. Since both the textured and the untextured steel showed the same behavior, the observed behavior is independent of the initial austenitic texture. Applying a shear strain on a steel might result in a texture which is not symmetric with respect to the $\mathrm{RD}$ and TD. As a result, the driving force distribution over all grains might change after the strain path change, resulting in a change in the transformation behavior. However, since the remaining austenite grains after a high amount of transformation have a low driving force, changing the strain direction generally only increases the driving force, allowing transformation at lower stresses, opposed to the observed higher stresses.

This is clear when considering the non-proportional experiment from Section 6.2.3. During the plane strain deformation a low amount of crystal rotations is expected, as is the case during uniaxial tensile tests in the Rolling Direction. During the plane strain phase and the shear strain phase, different orientations have a high driving force. Therefore, transformation should start at lower stresses after the strain path change. Since the same material behavior is observed in the non-proportional experiment as during the proportional strain reversal experiments, the initial texture and texture evolution, as well as the orientation of grains with respect to the applied stress do not cause the delayed transformation observed during the strain reversal experiments. In addition, the simulation results performed in Section 6.3, where the effect of texture is 
implemented, did not show the observed behavior. Therefore, it can be assumed that the mechanism causing the observed behavior has not yet been included in the simulation model.

One of the most important mechanisms missing in the simulations is the Bauschinger effect, the softening behavior after the load reversal as can be clearly seen during experiment R04 in Figure 6.3(a). In literature, two mechanisms are suggested which can cause the observed behaviour: a change in the forming of dislocation structures after the strain path change and textural softening. Hoc et al. [75] showed that considering only textural effects cannot explain the whole observation. A lot of experimental work is devoted on the microstructure after a strain path change $[76,77,78]$. It was demonstrated that the softening behaviour is caused by a changing arrangement of dislocations after a strain path change rather than the average dislocation density [79, 80].

Due to the decrease in flow stress in the austenite phase after the load reversal, more strain is needed to reach the stress in the austenite phase at which transformation can start. This can explain the relation between strain and transformation observed in Figure 6.3(c).

When the load reversal occurs at higher strains and martensite fractions, an increase in flow stress is observed. This can be caused by a different distribution of strains over the austenite and martensite phase: the austenite phase -with its lower flow stress after the strain path change-- will be strained more, while the martensite phase will be stressed more. This, in combination with the absence of the transformation and its accompanying transformation softening, results in an increase in overall flow stress when the load is reversed.

According to this theory, the stress increase is attributed to the martensite phase. Therefore, while the average overall stress at which transformation occurs increases, as shown in Figure 6.3(d), the austenite stress at which transformation starts after the load reversal might still be the same as before the load reversal and agrees with the stress-induced transformation theory. The apparent increase in transformation rate with respect to the average stress might also be contributed to the increased contribution of the martensite to the average stress. 


\subsection{Summary}

In this chapter, results of several non-monotonic experiments were presented. The main focus was on shear strain reversal experiments on a textured metastable austenitic stainless steel. By applying a strain reversal at low martensite fractions, a softening of the steel can be observed, commonly known as the Bauschinger effect. However, applying the strain reversal at higher martensite fractions, the steel showed a hardening after the strain path change. The same behavior was found when applying a non-proportional strain path and when using an untextured austenitic steel, indicating that this behavior is common when applying a non-monotonic strain path on a metastable austenitic steel. Simulations using the models developed in Section 4.4 and Chapter 5 could not reproduce the observed results. The origin of the observed behavior is thought to be the effect the Bauschinger effect has on the strain distribution between the austenite and martensite phases. 


\section{Chapter 7}

\section{Conclusions \& Recommendations}

During the development of models describing the material behavior of metastable austenitic stainless steels, the influence of the austenitic texture is often overlooked. The work presented in this thesis shows that the austenitic texture has a large influence on the transformation behavior and cannot be ignored when developing a material model for a textured metastable austenitic stainless steel which must describe 3D deformation processes accurately.

The stress-induced transformation theory was used to describe the criterion for the transformation of a grain. This criterion depends on the stress state and the stress magnitude on a grain as well as the orientation of the grain with respect to the stress. Experiments on both a textured and a non-textured austenitic steel show a strong dependency of the transformation behavior on the deformation direction in the textured steel, while this is not the case for the untextured steel. The austenitic textures after transformation can be explained by the stress-induced transformation theory and crystal rotation due to crystallographic slip, indicating that the transformation theory used is correct.

Several models were constructed to describe the influence of the austenitic texture. The Texture Based Stress Induced Transformation (TBSIT) model, based on the starting texture and applied global stress, is capable of qualitatively describing the transformation behavior of a metastable austenitic stainless steel. 
This simple model can be used to calculate the stress at which transformation occurs, which can be used as input for existing models describing transformation behavior independent of the texture. To some extent, the differences in transformation rates in different stress directions can be obtained from this model as well. The use of Generalized Spherical Harmonics, for both the description of the driving force for all orientations in Euler space as well as the texture will provide a quick evaluation of the model. Combining this quick evaluation of the driving force distribution with a model capable of quickly describing the texture evolution due to plastic deformation will yield a model usable in Finite Element Analysis (FEA).

A more elaborate model has been developed for further understanding of the influence of textures on the transformation behavior. The same transformation criterion as in the TBSIT model is used in the elaborate model, but several additional mechanisms are implemented as well, such as stepwise transformation, plasticity and texture evolution due to deformation. While still a relatively simple model, it is capable of quantitatively describing the transformation behavior as a function of the strain direction during monotomic straining. However, several improvements can still be made on the model. Due to the Taylor-Voigt constraint implemented in the model the transformation in a grain has a limited influence on the behavior in the surrounding grains. Incorporating fixed locations of grains and the strain field around a transforming grain might yield a more realistic description of the interaction between the grains when transformation occurs. The Taylor-Voigt constraint prescribes the same strain on all grains. This results in two problems. The first comes from the strain distribution between grains with a high martensite content and grains with a low martensite content. Since the martensite is hard compared to the austenite, the austenitic grains will yield more if a stress is applied. This is already implemented inside a grain, and the implementation of a homogenization scheme between grains is recommended. Prescribing the same strain also results in the poor performance of the model while calculating the average stress, since relaxation of grains with respect to its environment is prohibited. Again, an improved interaction scheme between grains can improve this.

In the last chapter of this thesis, the influence of texture on a non-monotonic strain paths was discussed. While most steels show a softening behavior after a strain path change, called the Bauschinger effect, experiments on metastable austenitic stainless steels showed that the softening effect competed with a hardening effect: at low martensite fractions a softening behavior still occurred, but 
with increasing martensite fractions a hardening behavior can be observed. The stress at which transformation occurs after the strain path change is also higher than expected from the stress-induced transformation theory. A theory based on the Bauschinger effect causing the observed effects was postulated, but no proof of any such kind can be presented at this moment. Therefore, more research into this topic is required. Several experiments can be performed to gain a better understanding of the mechanisms behind the observed behavior. A few examples are listed below.

1. From the experiments it is already known that the Bauschinger effect occurs when the strain path change is applied when no martensite is formed yet. Performing a strain path change on a specimen with a high martensite fraction will show whether the martensite phase also shows the Bauschinger effect and the increase in flow stress after the load reversal. This will lead to an improvement of the material model for the martensite phase.

2. It was postulated that the flow stress after the strain path change is the flow stress of the austenite and martensite mixture in the absence of transformation. This can be investigated by a two-part experiment: the first part consists of deformation at room temperature, during which martensite is formed. In the second part of the experiment, the temperature is first increased such that no transformation occurs by subsequent deformation. While the flow stress itself is also temperature dependent, continuing the deformation in the same direction as in part one or changing the strain path will give some insight into the effect of a strain path change without the transformation.

3. The change in strain distribution between the austenite and martensite phase is another possible cause of the observed behavior during nonmonotonic experiments. It is possible to measure the lattice strains during deformation of a specimen by X-Ray diffraction techniques. The same techniques can be applied during a strain reversal experiment to measure the stress/strain distribution in the martensite and austenite phases before and after the strain path change.

4. According to the theory, the variants formed before a strain path change have different orientations than the variants formed after the strain path change. Electron Backscatter Diffraction (EBSD) measurements on the surface of a metastable austenitic stainless steel both before and after a strain path change can help to show whether this is indeed the case. 
Besides additional experiments the model developed in Chapter 5 can be improved as well to describe the non-monotonic experiments better. First, the implementation of the Bauschinger effect will result in a more realistic result with respect to the deformation of the phases. Next, gained knowledge from the experiments described above can be used to improve the model.

The non-proportional experiment shown in Figure 6.5 showed a similar behavior as the strain reversal experiments, but also a magnetic induction apparently unaffected by the increasing shear stress after the strain path change. Whether this is caused by an increased martensite fraction during deformation or because the martensite phase is not stressed during the first stage of the shear strain deformation can be investigated by additional experiments where the stress is released during various strain stages, and the martensite fraction is measured by methods independent of the stress in the martensite phase. 
Appendix 



\section{Appendix A}

\section{Crystallography of martensitic transformations}

In this Appendix, the mathematical derivation of the formation of $\mathrm{BCC}$ martensite in the FCC austenitic parent phase based on the work presented in [32] is discussed.

Figure A.1 shows the FCC structure of the austenite, together with a BCT structure which is already present in the FCC structure. In fact, due to the symmetry of the FCC lattice, there are in total 3 possible BCT structures in the FCC lattice. Each of these three structures has the long axis along a different lattice vector of the FCC lattice. To obtain the required BCC structure, one of the possible BCT structures is contracted along its long axis, while extended along the other two axes. The accompanying deformation, the so-called Bain strain [81], can be described with the lattice parameters of the austenite $\left(a_{0}\right)$ and martensite $(a)$. Since there are three BCT structures present, there can be three strains to obtain the BCC structure:

$\left[\mathbf{B}_{1}\right]=\left[\begin{array}{ccc}\eta_{2} & 0 & 0 \\ 0 & \eta_{1} & 0 \\ 0 & 0 & \eta_{1}\end{array}\right],\left[\mathbf{B}_{2}\right]=\left[\begin{array}{ccc}\eta_{1} & 0 & 0 \\ 0 & \eta_{2} & 0 \\ 0 & 0 & \eta_{1}\end{array}\right]$ and $\left[\mathbf{B}_{3}\right]=\left[\begin{array}{ccc}\eta_{1} & 0 & 0 \\ 0 & \eta_{1} & 0 \\ 0 & 0 & \eta_{2}\end{array}\right]$,

with

$$
\eta_{1}=\frac{\sqrt{2} a}{a_{0}}, \eta_{2}=\frac{a}{a_{0}} .
$$

By deforming the FCC structure according to the Bain strain, the correct 

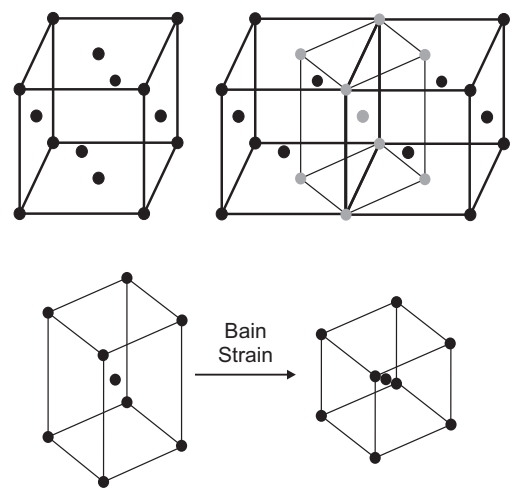

Figure A.1: The FCC unit cell (top left) and one of the three possible BCT lattices in the FCC lattice (top right). The Bain strain converts the BCT lattice into the observed BCC martensite lattice.

BCC structure is obtained. However, the Bain strain alone is not sufficient to describe the observed orientation of a martensite grain with respect to the parent austenite grain. Observations show that the interface between the austenite and martensite, the so-called habit plane, is both undistorted and unrotated [29, 30], which reduces the strain energy and allows the interface to move easily. This is required to reach the observed transformation speed. For this coherent plane to exist, the transformation strain needs to be an Invariant Plane Strain (IPS) [31]. This invariant plane cannot be achieved by the Bain strain alone: the Bain strain, in combination with a specific rigid body rotation, results in an Invariant Line Strain (ILS). To obtain an invariant plane strain, an additional deformation is needed. Since the required crystal structure is already obtained by the Bain strain, it cannot be deformed further. Instead, the lattice invariant deformation is obtained by either slip or twinning of the martensite. Both these deformations result in mathematically equivalent results. The martensite formed during the deformation experiments performed in this thesis all show twinning, and only the mathematical method in case of twinning is presented here. An extensive mathematical treatment of the subject can be found in the work of Bhadeshia [33] and, for both the twinning and the slip case, in the work of Wechsler et al. [32].

When the IPS is obtained by twinning, each area of the twin is deformed by a different Bain strain. In total there are three possible combinations of Bain 
strains. The deformation tensor $\mathbf{F}^{\prime}$, when the twins are deformed by $\mathbf{B}_{1}$ and $\mathbf{B}_{2}$, becomes

$$
\mathbf{F}^{\prime}=\left[x \mathbf{B}_{1}+(1-x) \mathbf{R}_{T} \cdot \mathbf{B}_{2}\right],
$$

where $x$ is the relative fraction of the first twin compared to the second twin. One of the twins is rotated by $\mathbf{R}_{T}$ such that the invariant line of the first twin agrees with the one of the second. This way, a coherent interface between the twins is created. This can be achieved by rotating twin 2 by $\phi$ or $-\phi$ around the common axis of tension of the Bain strains of the twins, as is demonstrated in Figure A.2. Choosing either $\phi$ or $-\phi$ results, as shown in figure A.2 as well, in a different orientation of the habit plane. The sine and cosine components of the rotation matrix $\mathbf{R}_{T}$ are

$$
\begin{aligned}
\cos \phi & =\frac{2 \eta_{1} \eta_{2}}{\eta_{1}^{2}+\eta_{2}^{2}} \\
\sin \phi & =\frac{\eta_{1}^{2}-\eta_{2}^{2}}{\eta_{1}^{2}+\eta_{2}^{2}} .
\end{aligned}
$$

To obtain an IPS and a coherent interface between the martensite and the austenite, another rotation is needed, Figure A.2. The total deformation tensor of the invariant plane strain due to deformation now becomes

$$
\mathbf{F}=\mathbf{R} \cdot \mathbf{F}^{\prime}
$$

For the calculation of $x$, a property of an invariant plane is used. A vector in such plane is still in the same plane after the transformation, which is only achieved when one of the principal strains is equal to zero. As a result, the determinant of an IPS is equal to zero as well:

$$
\operatorname{det}(\mathbf{E})=0
$$

with $\mathbf{E}$ the Green-Lagrange tensor

$$
\mathbf{E}=\frac{1}{2}\left(\mathbf{F}^{T} \cdot \mathbf{F}-\mathbf{I}\right)
$$

Using a property of rotation matrices, $\mathbf{R}^{T} \cdot \mathbf{R}=\mathbf{I}$, substituting Equation (A.6) in Equation (A.8) leads to

$$
\mathbf{E}=\frac{1}{2}\left(\mathbf{F}^{\prime T} \cdot \mathbf{F}^{\prime}-\mathbf{I}\right)
$$




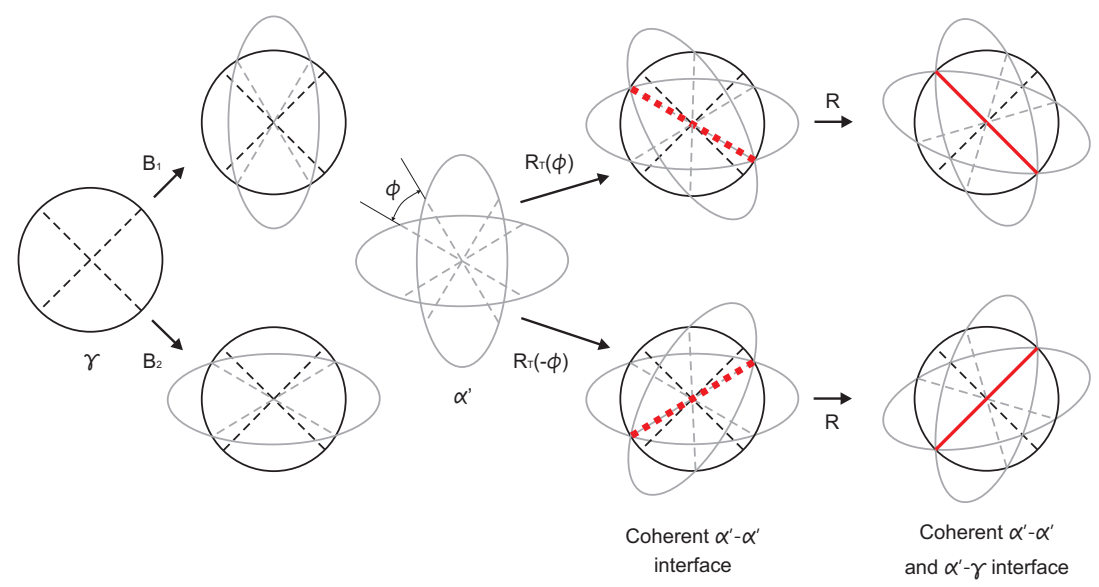

Figure A.2: Schematic two-dimensional representation of the deformation of the austenitic lattice by Bain strains $B_{1}$ and $B_{2}$, the rotation by either $\phi$ or $-\phi$ to bring both invariant lines (dashed lines) of the two twins in the same plane (dotted lines) and the final rotation by $\mathbf{R}$ to obtain a coherent plane between the FCC and BCC phases (Red).

In combination with the IPS property in Equation (A.7) the two possible values for the fraction $x$ can be calculated:

$$
x=\frac{1}{2} \pm \frac{1}{2} \frac{1-\eta_{1}^{2} \eta_{2}^{2}}{\eta_{1}^{2}-\eta_{2}^{2}} \sqrt{1-A_{x}^{2}}
$$

with

$$
A_{x}=\frac{\left(\eta_{1}^{2}-1\right)\left(1-\eta_{2}^{2}\right)}{1-\eta_{1}^{2} \eta_{2}^{2}}
$$

With this, all components of $\mathbf{F}^{\prime}$ are known, which only leaves the rotation R. For this, first the equation for the habit plane must be derived. A property of the IPS is such that, when $\mathbf{r}$ lies in the invariant plane, it will stay in the plane after transformation and the magnitude of the vector is preserved. This is described by

$$
|\mathbf{F} \cdot \mathbf{r}|^{2}=|\mathbf{r}|^{2}
$$


Since rotations have no influence on the length of a vector, tensor $\mathbf{F}$ can be replaced by $\mathbf{F}^{\prime}$. Furthermore, the deformation tensor $\mathbf{F}^{\prime}$ is non symmetrical and can be decomposed into a pure distortion part, $\mathbf{U}$, and a rotation part, $\mathbf{Q}$, such that

$$
\mathbf{F}^{\prime}=\mathbf{Q} \cdot \mathbf{U}
$$

The rotation part is omitted again, resulting in

$$
|\mathbf{U} \cdot \mathbf{r}|^{2}=|\mathbf{r}|^{2} .
$$

For simplicity, the tensor $\mathbf{U}$ is rotated by $\Phi$ such that $\mathbf{U}_{d}$ is created, representing $\mathbf{U}$ in the principal directions with the eigenvalues $\lambda_{1}, \lambda_{2}$ and $\lambda_{3}$ on the diagonal: $\mathbf{U}=\Phi \cdot \mathbf{U}_{d} \cdot \Phi^{T}$. Rotating the vector $\mathbf{r}$ into $\mathbf{r}_{d}$ as well and omitting the rotational parts once more, results in

$$
\left|\mathbf{U}_{d} \cdot \mathbf{r}_{d}\right|^{2}=\left|\mathbf{r}_{d}\right|^{2}
$$

or, written in component form,

$$
\lambda_{1}^{2} x_{d}^{2}+\lambda_{2}^{2} y_{d}^{2}+\lambda_{3}^{2} z_{d}^{2}=x_{d}^{2}+y_{d}^{2}+z_{d}^{2}
$$

with $\lambda_{i}$ the principal stretches and $x y z$ the components of $\mathbf{r}_{d}$. One of the stretches is equal to one: the vector $\mathbf{r}_{d}$ stays in the plane. Including this in Equation (A.16), the equation for the habit plane is obtained. When, for example, the eigenvalue $\lambda_{1}$ is equal to one, two possible equations for the habit plane are obtained:

$$
\begin{aligned}
\frac{z_{d}}{y_{d}} & =-K \\
K & = \pm \sqrt{\frac{1-\lambda_{3}^{2}}{\lambda_{2}^{2}-1}}= \pm \sqrt{\frac{1-\eta_{1}^{2} \eta_{2}^{2}}{\eta_{1}^{2}-1}} .
\end{aligned}
$$

To calculate the deformation due to the transformation, two properties of the invariant plane are considered:

1. the habit plane does not rotate

2. no line in the plane undergoes extension or contraction.

This means that the deformation $\mathbf{F}$ must consist of an extension along the normal of the habit plane and a simple shear on the habit plane. 
The normal to the habit plane can be obtained using the equation for the plane in Equation (A.17). Each vector which follows Equation (A.17) is in the habit plane. Two examples are

$$
\mathbf{v}_{1}=\left[\begin{array}{c}
0 \\
y_{1} \\
-K y_{1}
\end{array}\right] \text { and } \mathbf{v}_{2}=\left[\begin{array}{c}
x_{2} \\
y_{2} \\
-K y_{2}
\end{array}\right]
$$

The cross product of these vectors, $\mathbf{v}_{1} \times \mathbf{v}_{2}$, will give the normal on the habit plane, $\boldsymbol{n}_{d}$. Reducing this vector to unit size gives

$$
\begin{aligned}
\boldsymbol{n}_{d} & =\frac{1}{\sqrt{K^{2}+1}}\left[\begin{array}{c}
0 \\
K \\
1
\end{array}\right], \\
\boldsymbol{n} & =\Phi \cdot \boldsymbol{n}_{d}
\end{aligned}
$$

where $\boldsymbol{n}$ is the normal to the habit plane in the austenite axis system. Now the direction of the extension is known. Since a simple shear does not contribute to the volume change, the extension along $\boldsymbol{n}_{d}$ must be equal to the volume change due to transformation. Since rotations do not contribute to the volume change either, the volume change can be calculated by

$$
\delta V=\operatorname{det}\left(\mathbf{U}_{d}\right)-1=\lambda_{1} \lambda_{2} \lambda_{3}-1=\eta_{1}^{2} \eta_{2}-1
$$

The simple shear is on the habit plane, perpendicular to the normal of the plane. Since $\lambda_{1}=1$, it must also be perpendicular to the $x_{d}$ axis. Thus, the direction of the shear component becomes

$$
\boldsymbol{s}_{d}^{\prime}=\left[\begin{array}{l}
1 \\
0 \\
0
\end{array}\right] \times\left[\boldsymbol{n}_{d}\right]
$$

The increase in size of the normal $\boldsymbol{n}_{d}$ due to transformation $\mathbf{U}_{d}$ is caused by both the expansion and the shear, as shown in figure A.3:

$$
\begin{aligned}
\left|\mathbf{U}_{d} \cdot \boldsymbol{n}_{d}\right|^{2} & =\left(\operatorname{det}\left(\mathbf{U}_{d}\right)\right)^{2}+S^{2} \\
S & =\sqrt{\left(\eta_{1}^{2}-1\right)\left(1-\eta_{1}^{2} \eta_{2}^{2}\right)}
\end{aligned}
$$

with $S$ the magnitude of the shear. 


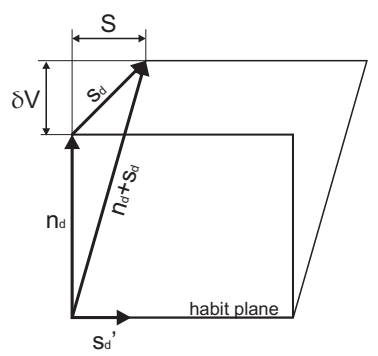

Figure A.3: Deformation consisting of an extension of $\delta V$ along the habit plane normal $\boldsymbol{n}_{d}$ and the simple shear $S \boldsymbol{s}_{d}^{\prime}$ on the habit plane.

The final deformation direction, from both shear and extension, is given by

$$
\begin{aligned}
\boldsymbol{s}_{d} & =S \boldsymbol{s}_{d}^{\prime}+\delta V \boldsymbol{n}_{d} \\
\boldsymbol{s} & =\Phi \cdot \boldsymbol{s}_{d} .
\end{aligned}
$$

with $s$ the deformation direction in the austenite axis system.

The total deformation of $\boldsymbol{n}$ by tensor $\mathbf{F}$ is now

$$
\mathbf{F} \cdot \boldsymbol{n}=\boldsymbol{n}+\boldsymbol{s}
$$

which results in

$$
\mathbf{F}=\mathbf{I}+\boldsymbol{s} \boldsymbol{n}^{T}=\mathbf{I}+\boldsymbol{s} \otimes \boldsymbol{n} .
$$

This leaves only the rotation matrix $\mathbf{R}$ unknown, which can be calculated by

$$
\mathbf{R}=\mathbf{F} \cdot \mathbf{F}^{\prime-1}
$$

\section{A.1 Multiplicity of solution}

At several points in the analysis a choice can be made, resulting in a different solution for $\mathbf{F}$. The first one is the Bains strain producing the twins: only two of the three Bain strains are needed in Equation (A.3), so there is a choice of three sets of Bain strains. Next, a choice for the habit plane is made by rotating one of the twins by $\phi$ or $-\phi$, Figure A.2. Thirdly, there are two possible values for the fraction $x$ obtained from Equation (A.10). Finally, the choice for $K$ or $-K$, Equation (A.18), results in another two possible solutions for the orientation of 
the habit plane. In total, there are $3 \cdot 2 \cdot 2 \cdot 2=24$ possible solutions for the deformation tensor, also called variants. Each of these variants has the same total strain, while the direction of the strain differs. 


\section{Bibliography}

[1] T. Angel, "Formation of martensite in austenitic stainless steels," Journal of the Iron and Steel Institute, vol. 1977, pp. 165-174, 1954.

[2] J. Venables, "The martensite transformation in stainless steel," Philosophical Magazine, vol. 7, no. 73, pp. 35-44, 1962.

[3] G. B. Olson and M. Cohen, "Kinetics of strain-induced martensitic nucleation," Metallurgical Transactions A, vol. 6, no. 3, pp. 791-795, 1975.

[4] R. G. Stringfellow, D. M. Parks, and G. B. Olson, "A constitutive model for transformation plasticity accompanying strain-induced martensitic transformations in metastable austenitic steels," Acta Metallurgica et Materialia, vol. 40, no. 7, pp. 1703-1716, 1992.

[5] I. Tamura, "Deformation-induced martensitic transformation and transformation-induced plasticity in steels," Metal science, vol. 16, no. 5, pp. 245-253, 1982.

[6] U. F. Kocks, C. N. Tomé, and H.-R. Wenk, Texture and anisotropy: preferred orientations in polycrystals and their effect on materials properties. Cambridge University Press, 1998.

[7] B. D. Cullity, Elements of X-ray diffraction. Addison-Wesley Pub. Co., 1956 .

[8] H. J. Bunge, Texture Analysis in Materials Science: Mathematical Methods. Butterworth-Heinemann, 1983.

[9] R. O. Williams, "Analytical methods for representing complex textures by biaxial pole figures," Journal of Applied Physics, vol. 39, no. 9, pp. 43294335, 1968. 
[10] S. Matthies and G. W. Vinel, "On the reproduction of the orientation distribution function of texturized samples from reduced pole figures using the conception of a conditional ghost correction," Physica Status Solidi B, vol. 112, no. 2, pp. K111-K114, 1982.

[11] K. Pawlik, "Determination of the orientation distribution function from pole figures in arbitrarily defined cells," Physica Status Solidi (B) Basic Research, vol. 134, no. 2, pp. 477-483, 1986.

[12] I. M. Gel'fand, R. Minlos, and Z. Y. Shapiro, Representations of the rotation and Lorentz groups and their applications. Pergamon Press, 1963.

[13] R. Hielscher and H. Schaeben, "A novel pole figure inversion method: specification of the MTEX algorithm," Journal of Applied Crystallography, vol. 41, no. 6, pp. 1024-1037, 2008.

[14] H. R. Wenk and U. F. Kocks, "Representation of orientation distributions," Metallurgical transactions A, Physical metallurgy and materials science, vol. 18 A, no. 6, pp. 1083-1092, 1987.

[15] L. S. Toth and P. van Houtte, "Discretization techniques for orientation distribution functions," Textures and Microstructures, vol. 19, pp. 229-244, 1992.

[16] M. A. Melchior and L. Delannay, "A texture discretization technique adapted to polycrystalline aggregates with non-uniform grain size," Computational Materials Science, vol. 37, no. 4, pp. 557-564, 2006.

[17] P. Eisenlohr and F. Roters, "Selecting a set of discrete orientations for accurate texture reconstruction," Computational Materials Science, vol. 42, no. 4, pp. 670-678, 2008.

[18] L. Kaufman and M. Cohen, "Thermodynamics and kinetics of martensitic transformations," Progress in Metal Physics, vol. 7, no. C, pp. 165-246, 1958.

[19] M. Izumiyama, M. Tsuchiya, and Y. Imai, "Effects of alloying element on supercooled a $\mathrm{a}_{3}$, J Jap Inst Metals, vol. 34, no. 3, pp. 291-295, 1970.

[20] C. Y. Kung and J. J. Rayment, "An examination of the validity of existing empirical formulae for the calculation of $\mathrm{m}_{s}$ temperature," Metallurgical Transactions A, vol. 13, no. 2, pp. 328-331, 1982. 
[21] R. H. Leal and J. R. C. Guimarães, "Microstructure evolution during mechanically induced martensitic transformation in $f e-33 \% n i-0.1 \% c$," Materials Science and Engineering, vol. 48, no. 2, pp. 249-254, 1981.

[22] S.-J. Lee and Y.-K. Lee, Effect of austenite grain size on martensitic transformation of a low alloy steel, vol. 475-479 of Materials Science Forum. 2005 .

[23] A. García-Junceda, C. Capdevila, F. G. Caballero, and C. G. de Andrés, "Dependence of martensite start temperature on fine austenite grain size," Scripta Materialia, vol. 58, no. 2, pp. 134-137, 2008.

[24] H. Yang and H. K. D. H. Bhadeshia, "Austenite grain size and the martensite-start temperature," Scripta Materialia, vol. 60, no. 7, pp. 493495, 2009.

[25] S. Turteltaub and A. S. J. Suiker, "Grain size effects in multiphase steels assisted by transformation-induced plasticity," International Journal of Solids and Structures, vol. 43, no. 24, pp. 7322-7336, 2006.

[26] G. B. Olsen, Martensite. ASM, 1992.

[27] R. F. Bunshah and R. F. Mehl Transactions, AIME, vol. 197, pp. 12511258, 1953.

[28] K. Mukherjee Trans. TMS-AIME, vol. 242, pp. 1495-1501, 1968.

[29] E. S. Machlin and M. Cohen, "Habit phenomenon in the martensitic transformation," Journal of metals, vol. 191, p. 1019, 1951.

[30] J. W. Christian, The theory of transformations in metals and alloys, Part 1, 2nd edition. Pergamon Press, 1975.

[31] J. W. Christian and K. M. Knowles, Solid-solid phase transformations. TMS-AIME, 1981.

[32] M. S. Wechsler, D. S. Lieberman, and T. A. Read, "On the formation of martensite," Trans. AIME, vol. 197, pp. 1503-1515, 1953.

[33] H. K. D. H. Bhadeshia, Worked examples in the Geometry of Crystals, 2nd edition. Institute of Metals, 1987. 
[34] J. R. Patel and M. Cohen, "Criterion for the action of applied stress in the martensitic transformation," Acta Metallurgica, vol. 1, no. 5, pp. 531-538, 1953.

[35] S. Kundu and H. K. D. H. Bhadeshia, "Transformation texture in deformed stainless steel," Scripta Materialia, vol. 55, no. 9, pp. 779-781, 2006.

[36] S. Kundu and H. K. D. H. Bhadeshia, "Crystallographic texture and intervening transformations," Scripta Materialia, vol. 57, no. 9, pp. 869-872, 2007.

[37] E. S. Perdahcioglu, H. J. M. Geijselaers, and M. Groen, "Influence of plastic strain on deformation-induced martensitic transformations," Scripta $M a$ terialia, vol. 58, no. 11, pp. 947-950, 2008.

[38] E. S. Perdahcioglu, H. J. M. Geijselaers, and J. Huétink, "Influence of plastic strain on mechanically induced martensitic transformations," in Proceedings of the International Conference on Martensitic Transformations, ICOMAT-08, pp. 615-620, 2009.

[39] E. S. Perdahcioglu and H. J. M. Geijselaers, "A macroscopic model to simulate the mechanically induced martensitic transformation in metastable austenitic stainless steels," Acta Materialia, vol. 60, no. 11, pp. 4409-4419, 2012.

[40] C. L. Magee, Transformation kinetics, microplasticity and aging of martensite in Fe-31 Ni. PhD thesis, Carnegie Institute of Technology, 1966.

[41] J. Post, H. Nolles, K. Datta, and H. J. M. Geijselaers, "Experimental determination of the constitutive behaviour of a metastable austenitic stainless steel," Materials Science and Engineering A, vol. 498, no. 1-2, pp. 179-190, 2008.

[42] A. Creuziger and T. Foecke, "Transformation potential predictions for the stress-induced austenite to martensite transformation in steel," Acta Materialia, vol. 58, no. 1, pp. 85-91, 2010.

[43] E. C. Oliver, P. J. Withers, M. R. Daymond, S. Ueta, and T. Mori, "Neutron-diffraction study of stress-induced martensitic transformation in TRIP steel," Applied Physics A: Materials Science and Processing, vol. 74, no. SUPPL.II, pp. S1143-S1145, 2002. 
[44] S. Kruijver, L. Zhao, J. Sietsma, E. Offerman, N. Van Dijk, L. Margulies, E. Lauridsen, S. Grigull, H. Poulsen, and S. Van Der Zwaag, "In situ observations on the austenite stability in TRIP-steel during tensile testing," Steel Research, vol. 73, no. 6-7, pp. 236-241, 2002.

[45] V. Mertinger, E. Nagy, F. Tranta, and J. Sólyom, "Strain-induced martensitic transformation in textured austenitic stainless steels," Materials Science and Engineering A, vol. 481-482, no. 1-2 C, pp. 718-722, 2008.

[46] M. Humbert, B. Petit, B. Bolle, and N. Gey, "Analysis of the $\gamma-\epsilon-\alpha$ ' variant selection induced by $10 \%$ plastic deformation in 304 stainless steel at $60^{\circ}$ C," Materials Science and Engineering A, vol. 454-455, pp. 508-517, 2007.

[47] H. F. G. De Abreu, M. J. G. Da Silva, L. F. G. Herculano, and H. Bhadeshia, "Texture analysis of deformation induced martensite in an AISI 301L stainless steel: Microtexture and macrotexture aspects," Materials Research, vol. 12, no. 3, pp. 291-297, 2009.

[48] P. J. Jacques, J. Ladrière, and F. Delannay, "On the influence of interactions between phases on the mechanical stability of retained austenite in transformation-induced plasticity multiphase steels," Metallurgical and Materials Transactions A: Physical Metallurgy and Materials Science, vol. 32, no. 11, pp. 2759-2768, 2001.

[49] E. Jimenez-Melero, N. H. van Dijk, L. Zhao, J. Sietsma, S. E. Offerman, J. P. Wright, and S. van der Zwaag, "Martensitic transformation of individual grains in low-alloyed TRIP steels," Scripta Materialia, vol. 56, no. 5, pp. 421-424, 2007.

[50] M. Arcan, Z. Hashin, and A. Voloshin, "A method to produce uniform plane-stress states with applications to fiber-reinforced materials - a specially designed specimen yields material properties under pure shear or uniform plane-stress conditions," Experimental Mechanics, vol. 18, no. 4, pp. 141-146, 1978.

[51] H. Nolles, J. Post, and J. Beyer, "Inductive measurements of the stress assisted and strain induced martensite transformations of Sandvik maraging steel 1RK91 before, during and after metal forming," in Journal De Physique. IV : JP, vol. 112 I, pp. 425-428, 2003. 
[52] S. Shang, G. Hu, and J. Shen, "Determination of volume fraction in textured titanium alloy sheet," Scripta Materialia, vol. 45, no. 3, pp. 287-292, 2001.

[53] L. Lutterotti, S. Matthies, H.-R. Wenk, A. S. Schultz, and J. W. Richardson Jr., "Combined texture and structure analysis of deformed limestone from time-of-flight neutron diffraction spectra," Journal of Applied Physics, vol. 81, no. 2, pp. 594-600, 1997.

[54] J. A. Jiménez and G. Frommeyer, "Analysis of the microstructure evolution during tensile testing at room temperature of high-manganese austenitic steel," Materials Characterization, vol. 61, no. 2, pp. 221-226, 2010.

[55] G. Lin and K. S. Havner, "On the evolution of texture and yield loci in axisymmetric deformation of f.c.c. polycrystals," International Journal of Plasticity, vol. 10, no. 5, pp. 471-498, 1994.

[56] G. Taylor, "Plastic strain in metals," J. Inst. Metals, vol. 62, pp. 307-324, 1938.

[57] S. Turteltaub and A. S. J. Suiker, "Transformation-induced plasticity in ferrous alloys," Journal of the Mechanics and Physics of Solids, vol. 53, no. 8, pp. 1747-1788, 2005.

[58] V. G. Kouznetsova and M. G. D. Geers, "A multi-scale model of martensitic transformation plasticity," Mechanics of Materials, vol. 40, no. 8, pp. 641$657,2008$.

[59] N. Gey, B. Petit, and M. Humbert, "Electron backscattered diffraction study of $\epsilon / \alpha^{\prime}$ martensitic variants induced by plastic deformation in 304 stainless steel," Metallurgical and Materials Transactions A: Physical Metallurgy and Materials Science, vol. 36, no. 12, pp. 3291-3299, 2005.

[60] H. K. D. H. Bhadeshia, "Problems in the calculation of transformation texture in steels," ISIJ International, vol. 50, no. 11, pp. 1517-1522, 2010.

[61] M. Chen, D. Terada, A. Shibata, and N. Tsuji, "Identical area observations of deformation-induced martensitic transformation in sus304 austenitic stainless steel," Materials Transactions, vol. 54, no. 3, pp. 308-313, 2013.

[62] J. Eshelby, "The determination of the elastic field of an ellipsoidal inclusion, and related problems," Proceedings of the Royal Society of London. Series $A$, vol. 241, no. 1226 , pp. 376-396, 1957. 
[63] J. Eshelby, "The elastic field outside an ellipsoidal inclusion," Proceedings of the Royal Society of London, vol. 252, no. 1271, pp. 561-569, 1959.

[64] E. S. Perdahcioglu and H. J. M. Geijselaers, "Constitutive modeling of two phase materials using the mean field method for homogenization," International Journal of Material Forming, vol. 4, no. 2, pp. 93-102, 2011.

[65] G. Lielens, P. Pirotte, A. Couniot, F. Dupret, and R. Keunings, "Prediction of thermo-mechanical properties for compression moulded composites," Composites Part A: Applied Science and Manufacturing, vol. 29, no. 1-2, pp. 63-70, 1998.

[66] J. Bishop and T. Hill, "A theory of the plastic distortion of a polycrystalline aggregate under combined stresses," Philosophical Magazine Series 7, vol. 42, no. 327, pp. 414-427, 1951.

[67] P. van Houtte, S. Li, M. Seefeldt, and L. Delannay, "Deformation texture prediction: from the taylor model to the advanced lamel model," International Journal of Plasticity, vol. 21, pp. 589-624, 2005.

[68] R. Lebensohn and C. Tomé, "A self-consistent anisotropic approach for the simulation of plastic deformation and texture development of polycrystals: application to zirconium alloys," Acta metallurgica et materialia, vol. 41, no. 9, pp. 2611-2624, 1993.

[69] M. Crumbach, G. Pomana, P. Wagner, and G. Gottstein, "A taylor type deformation texture model considering grain interaction and material properties. part i - fundamentals," Recrystallization and grain growth, vol. 2, pp. 1053-1060, 2001.

[70] H.-J. Bunge, "Some applications of the taylor theory of polycrystal plasticity," Kristall und Technik, vol. 5, pp. 145-175, 1970.

[71] D. Peirce, R. J. Asaro, and A. Needleman, "An analysis of nonuniform and localized deformation in ductile single crystals," Acta Metallurgica, vol. 30, no. 6, pp. 1087-1119, 1982.

[72] E. S. Perdahcioglu, Constitutive Modeling of Metastable Austenitic Stainless Steel. PhD thesis, University of Twente, 2008.

[73] J. Post, K. Datta, and J. Beyer, "A macroscopic constitutive model for a metastable austenitic stainless steel," Materials Science and Engineering A, vol. 485, no. 1-2, pp. 290-298, 2008. 
[74] H. Pijlman, Sheet material characterisation by multi-axial experiments. PhD thesis, University of Twente, 2001.

[75] T. Hoc, G. Dirras, and C. Rey, "Mesostructure of the localization in prestrained mild steel," Materials Science and Engineering: A, vol. 319-321, pp. 304-307, 2001.

[76] J. Fernandes and J. Schmitt, "Dislocation microstructures in steel during deep drawing," Philosophical Magazine A, vol. 48, no. 6, pp. 841-870, 1983.

[77] E. Rauch and J.-H. Schmitt, "Dislocation substructures in mild steel deformed in simple shear," Materials Science and Engineering A, vol. 113, pp. 441-448, 1989.

[78] E. Rauch and S. Thuillier, "Rheological behaviour of mild steel under monotonic loading conditions and cross loading," Materials Science and Engineering $A$, vol. 164, no. 1-2, pp. 255-259, 1993.

[79] A. Turner, "Cyclic deformation behavior of type 304 stainless steel at elevated temperature," Metallurgical and materials transactions A, vol. 10, no. 2, pp. 225-234, 1979.

[80] T. Hasegawa, T. Yakou, and S. Karashima, "Deformation behaviour and dislocation structures upon stress reversal in polycrystalline aluminium," Materials Science and Engineering, vol. 20, pp. 267-276, 1975.

[81] E. C. Bain, "Nature of martensite," Trans. AIME, vol. 70, p. 25, 1924. 